\title{
A Comparison of Regional Vulnerability Factors for Department of Defense (DoD) Installations
}

US Army Corps of Engineers $s_{\circledast}$ Engineer Research and Development Center

Elisabeth M. Jenicek, Natalie R.D. Myers, Brad Boesdorfer, and Donald F. Fournier 



\section{A Comparison of Regional Vulnerability Factors for Department of Defense (DOD) Installations}

Elisabeth Jenicek

Construction Engineering Research Laboratory

PO Box 9005

Champaign, IL 61826-9005

Natalie R.D. Myers and Brad Boesdorfer

The PERTAN Group, Champaign, IL

Donald F. Fournier

Building Research Council, University of Illinois at Urbana-Champaign

Final Report

Approved for public release; distribution is unlimited.

Prepared for U.S. Army Corps of Engineers

Washington, DC 20314-1000

Under

SERDP Project CS-1257 
ABSTRACT: A key concern for Department of Defense (DoD) installations is their ability to sustain, and sometimes change or expand, their mission activities. Optimal use of installations in the face of changing missions, closures, and realignments requires an understanding of each installation's capabilities. Regional competition for land, transportation, energy, water, and other resources may put an installation's ability to perform essential activities at risk. This research adapted the Sustainable Installation Regional Resource Assessment (SIRRA) methodology to consider primary military mission as a weighting factor in determining vulnerability to a set of sustainability issues, and to identify the most vulnerable installations within each DoD service, and to determine those installations that would benefit from further study and intervention.

DISCLAIMER: The contents of this report are not to be used for advertising, publication, or promotional purposes. Citation of trade names does not constitute an official endorsement or approval of the use of such commercial products. All product names and trademarks cited are the property of their respective owners. The findings of this report are not to be construed as an official Department of the Army position unless so designated by other authorized documents. 


\section{Contents}

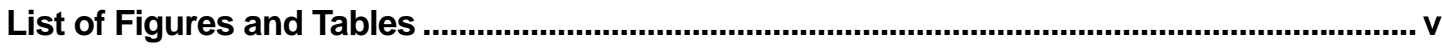

Conversion Factors ......................................................................................................... vii

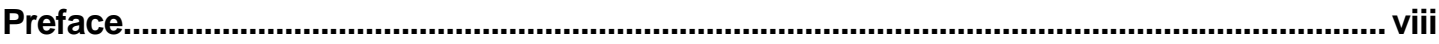

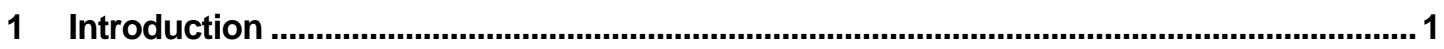

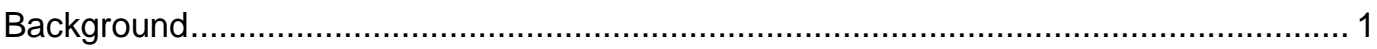

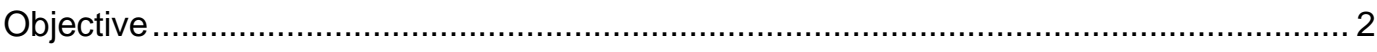

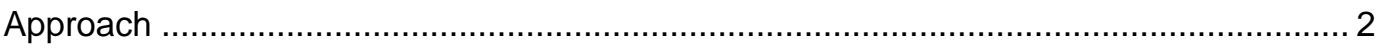

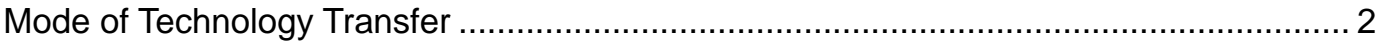

2 Sustainable Installations Regional Resource Assessment ......................................... 3

Regional Resource Assessment Framework and Metrics ................................. 4

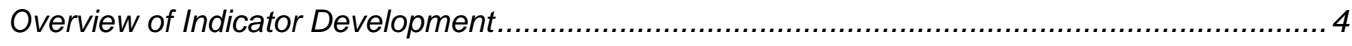

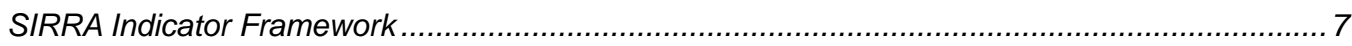

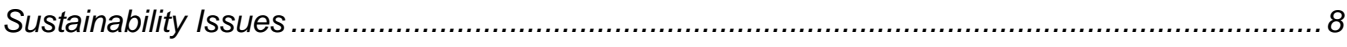

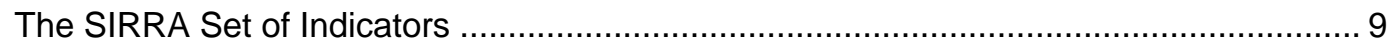

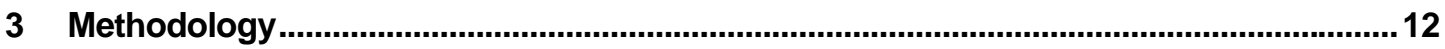

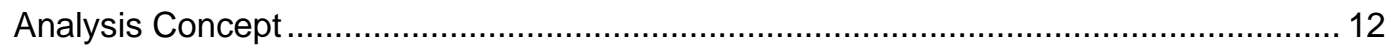

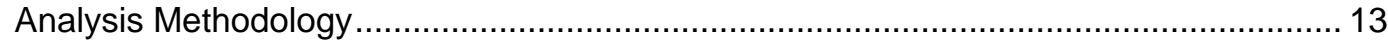

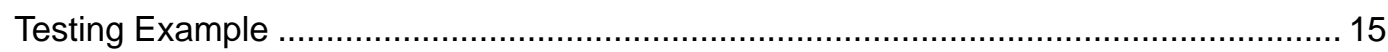

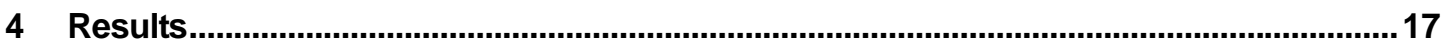

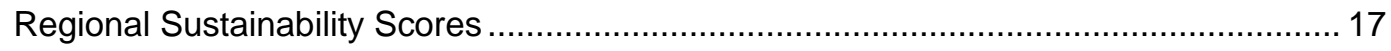

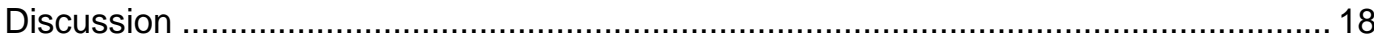

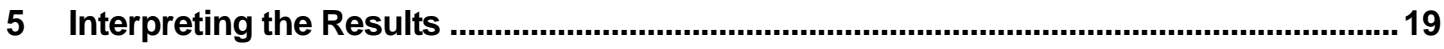

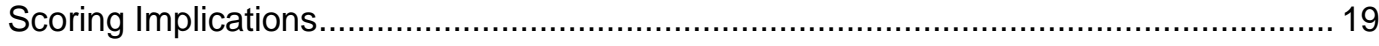

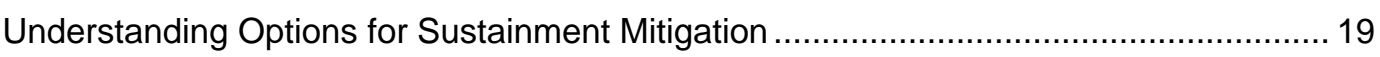

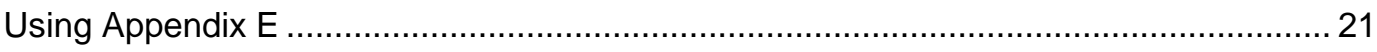

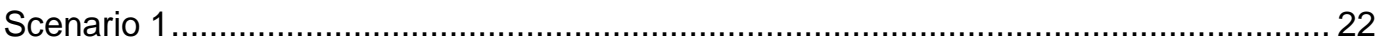

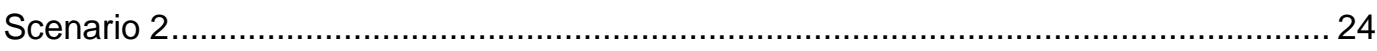

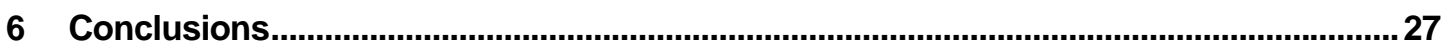




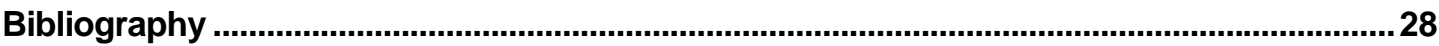

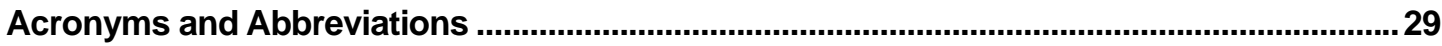

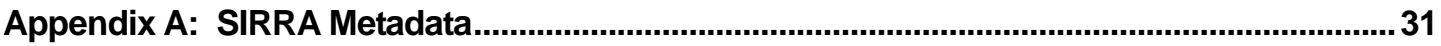

Appendix B: Indicator Weighting Matrix by Mission/Function ..........................................143

Appendix C: Installation Region Vulnerability Scores by Service........................................146

Appendix D: Installation Region Vulnerability Scores by Mission .....................................152

Appendix E: Interactive Installation Region Vulnerability Scores Spreadsheet ................158

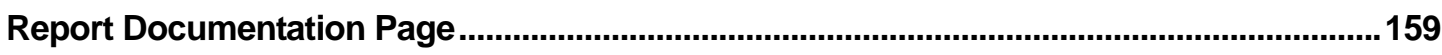




\section{List of Figures and Tables}

\section{Figures}

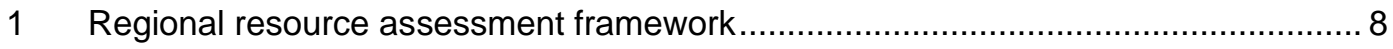

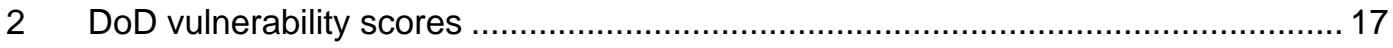

3 Screen capture of Appendix E resulting from Step 1 of Scenario 1. Army installations located in the southeast have been highlighted .................................. 23

4 Screen capture of Appendix E resulting from Step 1 of Scenario 2. Cannon

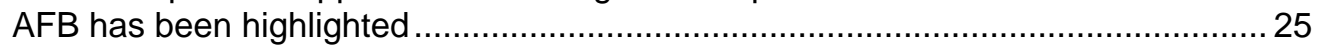

5 Screen Capture of Appendix E resulting from Step 4 of Scenario 2. Cannon AFB has been highlighted and water indicators are displayed.

\section{Tables}

1 Matrix of SIRRA indicators broken out by issue area ........................................... 10

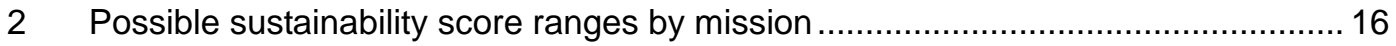

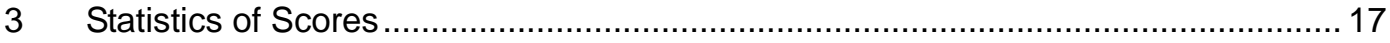

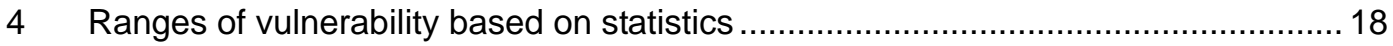

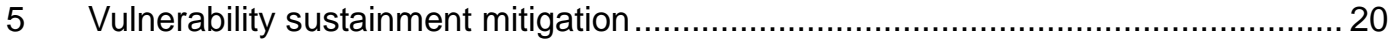

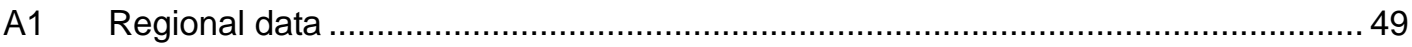

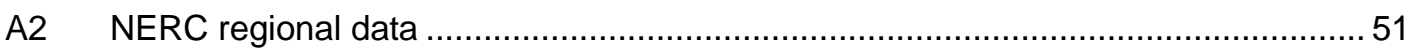

A3 List of Railroad Crossings in the State of Hawaii (USDoT. FRA 2003) ................... 134

A4 Annual Freeway Vehicle-Miles Traveled, by State (USDoT. FHA 2002) ................. 138

A5 Annual Rural Principal Arterial Vehicle-Miles Traveled, by State (USDoT. FHA

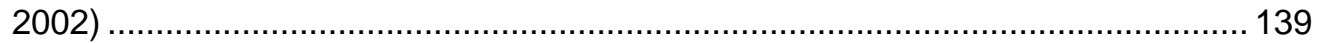

A6 Annual Urban Principal Arterial Vehicle-Miles Traveled, by State (USDoT. FHA

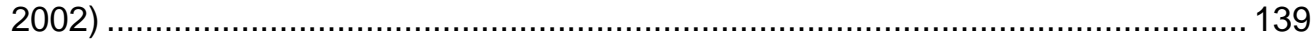

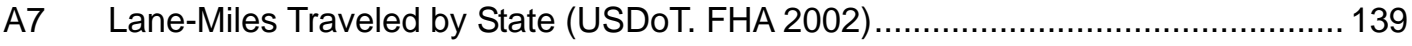

C1 Installation region vulnerability scores, in rank order (Air Force) ......................... 146

C2 Installation region vulnerability scores, in rank order (Army) ............................... 147

C3 Installation region vulnerability scores, in rank order (Defense Logistics

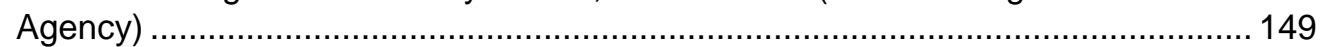

C4 Installation region vulnerability scores, in rank order (Marine Corps) ..................... 149

C5 Installation region vulnerability scores, in rank order (Navy) ............................... 150

D1 Installation region vulnerability scores, by mission (Air Force) ............................. 152 
D2 Installation region vulnerability scores, by mission (Army) ….............................. 153

D3 Installation region vulnerability scores, by mission (Defense Logistics Agency) .... 155

D4 Installation region vulnerability scores, by mission (Marine Corps) ....................... 155

D5 Installation region vulnerability scores, by mission (Navy) .................................. 156 


\section{Conversion Factors}

Non-SI* units of measurement used in this report can be converted to SI units as follows:

\begin{tabular}{|c|c|c|}
\hline Multiply & By & To Obtain \\
\hline acres & $4,046.873$ & square meters \\
\hline cubic feet & 0.02831685 & cubic meters \\
\hline cubic inches & 0.00001638706 & cubic meters \\
\hline degrees (angle) & 0.01745329 & radians \\
\hline degrees Fahrenheit & $(5 / 9) \times\left({ }^{\circ} \mathrm{F}-32\right)$ & degrees Celsius \\
\hline degrees Fahrenheit & $(5 / 9) \times\left({ }^{\circ} \mathrm{F}-32\right)+273.15$ & kelvins \\
\hline feet & 0.3048 & meters \\
\hline gallons (U.S. liquid) & 0.003785412 & cubic meters \\
\hline horsepower (550 ft-lb force per second) & 745.6999 & watts \\
\hline inches & 0.0254 & meters \\
\hline kips per square foot & 47.88026 & kilopascals \\
\hline kips per square inch & 6.894757 & megapascals \\
\hline miles (U.S. statute) & 1.609347 & kilometers \\
\hline pounds (force) & 4.448222 & newtons \\
\hline pounds (force) per square inch & 0.006894757 & megapascals \\
\hline pounds (mass) & 0.4535924 & kilograms \\
\hline square feet & 0.09290304 & square meters \\
\hline square miles & $2,589,998$ & square meters \\
\hline tons (force) & $8,896.443$ & newtons \\
\hline tons (2,000 pounds, mass) & 907.1847 & kilograms \\
\hline yards & 0.9144 & meters \\
\hline
\end{tabular}

\footnotetext{
*Système International d'Unités ("International System of Measurement"), commonly known as the "metric system."
} 


\section{Preface}

This study was conducted for the Office of the Chief of Engineers (OCE), Headquarters, U.S. Army Corps of Engineers (HQUSACE) under RDTE SERDP Project CS1257, and Project T233FF, "FF Training Range sustainability"; Work Unit L74711, "FF Environmental Stewardship." The SERDP technical reviewer was Dr. Robert Holst, SERDP Conservation Program Manager. The technical monitors were Dr. Michael Case, Program Manager, Office of Technical Directors, and William Goran, Director of Special Projects, Construction Engineering Research Laboratory (CERL).

The work was performed by the Energy Branch (CF-E) and the Business Processes Branch the CF-N of the Facilities Division (CF), CERL. The CERL Principal Investigator was Elisabeth M. Jenicek. Thomas J. Hartranft is Chief, CF-E, Donald K. Hicks is Chief, CF-N, and L. Michael Golish is Chief, CF. The associated Technical Directors are Michael Case and William Goran. Part of this work was done by Donald Fournier of the University of Illinois at Urbana-Champaign under contract number DACA88-99-D-002, Delivery Order 0031, and by Natalie Myer and Brad Boesdorfer of the PERTAN Group, contract number DACA42-01-D-0002, Delivery Order 11. The Acting Director of CERL is Dr. Ilker R. Adiguzel.

CERL is an element of the U.S. Army Engineer Research and Development Center (ERDC), U.S. Army Corps of Engineers. The Commander and Executive Director of ERDC is COL Richard B. Jenkins, and the Director of ERDC is Dr. James R. Houston. 


\section{Introduction}

\section{Background}

One of the key concerns for Department of Defense (DoD) installations is their ability to sustain, and sometimes change or expand, their mission activities. Optimal use of installations in the face of changing missions, closures, and realignments requires an understanding of each installation's capabilities. Regional competition for land, transportation, energy, water, and other resources may put an installation's ability to perform essential activities at risk. It is critical that we understand those factors that impact an installation's ability to maintain its mission.

Over the last several decades, the population and amount of developed land around most U.S. cities and military installations have grown significantly. Economic expansion driven by the presence of DoD installations spurs development of new suburban communities while services such as utilities and housing offered by cities attract installations toward urban areas. As a result, many installations are now at the fringe or in the midst of large urbanized or urbanizing areas.

Land transformations near military installations affect how military lands are managed. For example, loss of habitat "outside the fence-line" can increase the importance of threatened and endangered species habitat inside the installation boundary; an addition of soldiers on an installation can deplete critical water resources for both the installation and surrounding community; and growing residential neighborhoods adjacent to the "fence-line" can limit flight patterns and range usage for DoD training. These pressures may limit the military's use of land-, air-, and sea-space and are defined as "encroachment" issues. Encroachment issues stress an installations' sustainability and/or threaten its viability to complete mission assignments. Installations often find themselves not only in competition for scarce regional resources, such as land for growth, water supply, air space, and radio/communication frequency spectrum, but they are also affected by stricter regulations for air and water quality standards, erosion control requirements, and wetland impacts. As a result, installations and their sustainability face a number of uncertainties, up to and including closure.

Sustainability is the foundation of the DoD's strategy to address both present and future needs while strengthening community partnerships that improve an installa- 
tion's ability to organize, equip, train, and deploy as part of a joint force. The Strategic Environmental Research and Development Program (SERDP) is the DoD's corporate environmental science and technology program (SERDP Program Office 2004). SERPD specifically focuses on identifying and developing environmental technologies that relate directly to defense mission accomplishment and encroachment issues. This research adapts one such technology, the Sustainable Installation Regional Resource Assessment (SIRRA) methodology, by considering primary military mission as a weighting factor in determining vulnerability to a set of sustainability issues.

\section{Objective}

The objective of this work was to identify the most vulnerable installations within each DoD service and to determine those installations that would benefit from further study and intervention by characterizing resources and stresses in the region surrounding an installation. The specific objective of this study was to use environmental research and sustainment indices to define and describe a methodology to identify installations whose mission sustainment has potential problems. The method identifies the potential for encroachment issues at $308 \mathrm{DoD}$ installations by ranking the regions around installations for vulnerability to sustainability issues.

\section{Approach}

This research initiative is based on previous work at CERL in the area of encroachment and sustainability indicator development, under the Sustainability, Encroachment, and Room-to-Maneuver (SERM) research program, which is part of the Fort Future initiative. As such, this work is a natural outgrowth of the SERM initiative. It represents an application of analysis techniques-developed in the SERM initiative-to stationing and installation realignment.

\section{Mode of Technology Transfer}

This report will be made accessible through the World Wide Web (WWW) at URL: http://www.cecer.army.mil 


\section{Sustainable Installations Regional Resource Assessment}

Planners for DoD installations face increasingly complex challenges, due to rapid land use changes, stakeholder involvement in planning processes, and transforming Defense forces, technologies, and global circumstances. In response to these issues, the U.S. Army Engineer Research and Development Center, Construction Engineering Research Laboratory (ERDC-CERL), Champaign, IL initiated several projects that are included in the SERM project grouping. These research efforts are all designed to provide tools, data, expertise, and processes that help the DoD sustain and evolve mission operations, both military and civil works. The concept for SERM emerged from exploratory research initiated at CERL during the 1997-1998 timeframe. The purpose of SERM is to provide Defense planners with greater flexibility and ability to evaluate complex issues, and to access "the right information at the right time" to enhance their planning outcomes while addressing current and future planning problems. SIRRA is one of the projects developed under SERM.

Regional resource assessment provides the opportunity to incorporate the broader perspective of regional issues into the concept of installation sustainability and its implications to mission sustainment. SIRRA is a process of characterizing regions containing installations based on a set of indicators grouped into several issues (Jenicek, Fournier et al. 2004). SIRRA uses uniform assessments with a broad set of indicators covering the range of issues that may affect military installations and their locality. The determined indicator(s) may be used to express the relative ranking of installations based on single measures (or groups of measures) that define an issue. This standardized approach enables the use of national level data to evaluate the regional aspects of the installation setting. This provides a heightened awareness of long-term issues that could threaten mission sustainment.

This methodology was first developed and presented in the ERDC/CERL Technical Report TR-02-27, An Assessment of Encroachment Mitigation Techniques for Army Lands (Deal et al. October 2002) and further developed in the ERDC/CERL Special Report SR-02-12 Sustainable Installation Risk Assessment and Stationing Implications (Fournier et al. September 2002). SIRRA Version 1a was released in July 2004. Its capabilities are described in the ERDC/CERL TR-04-9 The Sustainable Installations Regional Resource Assessment (SIRRA) Capability (Jenicek et al., July 2004). 


\section{Regional Resource Assessment Framework and Metrics}

Assessing installation or watershed sustainability is complex and requires the evaluation of a combination of indicators that are related to both exogenous and endogenous factors. These factors may not really lend themselves to prioritization, but present an indication of issues that may need to be addressed in installation or watershed planning and management. The effects of demographic change, community growth and sprawl, and regional economic vitality present levels of exogenous resource issues that may be a threat to continued mission sustainment or watershed vitality. Issues associated with installation mission, management, and cultural and natural histories define endogenous risk. The framework developed here looks outside the installation and is based on exogenous indicators that could be determined with data sets available nation-wide. Some indicators were deemed so critical that they were retained despite the lack of a national data set. Assessing levels of regional resource and environmental stress or demands entails developing a set of indicators or indices that can provide reliable information about the level and type of a given resource. The resource can vary from availability of clean water to the amount of vehicular traffic congestion in the region, the latter being an indicator of potential air and water pollution and water from non-point sources and the ability of military members residing off-post to quickly mobilize.

\section{Overview of Indicator Development}

An "indicator" is a piece of information that reflects what is happening in a larger system. It allows observers to see the big picture by looking at a smaller part of it. Indicators are often quantitative measures such as physical or economic data. For example, traditional indicators such as inflation and unemployment rates are used for making economic decisions. Indicators are widely used as a tool for monitoring progress and to simplify, quantify, and communicate complex issues. Multiple indicators are sometimes aggregated into an index, usually for comparison across locations or to indicate change over time. Indicators are often used as the feedback mechanism to inform policy changes intended to improve the situation being measured. Their intent in the SERM analysis cycle is to provide the baseline information about the region in which the installation resides and illuminate key issues which may be a current or future threat to mission sustainment, mission realignments, or regional environmental health. These provide the starting point for regional planning and impact amelioration. Because the process of measuring focuses attention on the impact, it makes a great deal of difference what is measured and how it relates to what we wish to measure.

Developing indicators is a six-step process (Maclaren 1996):

1. Define and conceptualize the goals for which indicators are needed. 
2. Identify the target audience, the associated purpose for which indicators will be used, and the relative number of indicators needed.

3. Choose an appropriate indicator framework.

4. Define indicator selection criteria.

5. Identify a set of potential indicators and evaluate them against the selection criteria.

6. Choose a final set of indicators and test their effectiveness.

As noted above, the goal of the indicators is to define and highlight regional issues that may define current or future encroachment and resource issues or potential future impacts. The encroachment and mission sustainment issue areas that have been defined by the Senior Readiness Oversight Council are:

- endangered species and critical habitat

- unexploded ordinance and munitions

- frequency encroachment

- maritime sustainability

- airspace restrictions

- air quality

- airborne noise

- urban growth.

Many of these issues are associated with external aspects: what is located and what happens outside the fence line. Incompatible residential and commercial development of land close to military installations can affect the ability of an installation to carry out its mission. Such development also threatens public safety because accidents sometimes occur in areas surrounding an installation. The economic health of a community is affected if military operations and missions must relocate because of urban encroachment.

The target audience for the indicators and the regional resource assessment are decisionmakers and planners who need broadly based information to inform their processes of determining future stationing, base realignments, and installation sustainability actions. Regional and local planners must also be included if encroachment amelioration is to be successful.

A framework for developing a set of indicators is necessary for every indicator effort. The choice of framework must meet users' needs and priorities. A number of frameworks have been identified and used. These frameworks provide a starting point for any organization embarking on a sustainability effort.

Virginia MacLaren (Maclaren 1996) reviews four general frameworks for use in organizing sustainability indicators: domain-based, goal-based, sectoral, or causal 
frameworks. She adds a fifth type, known as issue-based, and a combination framework, which uses two or more of the other frameworks.

A domain-based framework is based on the three key dimensions of sustainability: environment, economy, and society. Indicators are identified for each dimension. This framework is effective at ensuring that the key dimensions of sustainability are covered. A weakness of this framework is that indicators are not linked to sustainability goals. An example of the domain-based framework is the Sustainable Seattle effort.

A goal-based framework is predicated on the development of organization sustainability goals. Indicators are then created for each goal. A benefit of this framework is that there are fewer indicators. A weakness is that it does not capture linkages among the dimensions of sustainability. Examples of goals are basic human needs, social well-being, economic prosperity, and carrying capacity. The United Kingdom's Local Government Management Board (LGMB) employed this kind of framework.

A sectoral framework may tie indicators to different sectors of a governing entity. This framework makes it easier to assign responsibilities for problems or results revealed by indicators. A drawback to using this framework is the resulting compartmentalization that often masks linkages between domains.

A causal framework is useful in explaining changes in indicators or whether policy interventions are effective. A drawback to this framework is that it implies simple linkages between stressors and conditions that may be very complex. This oversimplification can confuse the issues and lead to erroneous perceptions.

An issue-based framework may be popular because it addresses visible problems. A weakness of this framework is that it lacks explicit linkages to policy and presents a "shotgun" approach to developing indicators. Some examples of issues are urban sprawl, solid waste management, crime and safety, job creation, and industrial pollution.

The difficulty in selecting indicators is not a lack of measures but rather the overwhelming number of potentially useful indicators. The International Institute for Sustainable Development selected the following criteria based on indicator literature and practical experience with performance measurement (IISD 2000):

- Relevance. Can the indicator be associated with one or several issues around which key policies are formulated? The indicator must be linked to critical decisions and policies. 
- Simplicity. Can the information be presented in an easily understandable, appealing way to the target audience? Complex issues and calculations should yield clearly presentable and understandable information.

- Validity. Is the indicator a true reflection of the facts? Was the data collected using scientifically defensible measurement techniques? Is the indicator verifiable and reproducible? Methodological rigor is needed to make the data credible.

- Temporality. Is time-series data available, reflecting the trend of the indicator over time? Several data points are needed to visualize the direction the community or region may be going in the near future.

- Measurability. Is the data quantifiable - something that can be measured directly or can be counted? Data must be based on tangible information.

- Availability and Affordability of Data. Is good quality data available at a reasonable cost or is it feasible to initiate a monitoring process that will make it available in the future?

- Expansiveness. Is the indicator about a narrow or broad issue? Indicators that aggregate information on broader issues are preferred. For example, forest canopy temperature is a useful indicator of forest health and is preferable to measuring other indicators to come to the same conclusion.

- Sensitivity. Can the indicator detect a small change in the system? Determine whether small or large changes are relevant for monitoring.

- Reliability. Will you arrive at the same result if you make two or more measurements of the same indicator? Others should reach the same conclusions based on the indicator.

\section{SIRRA Indicator Framework}

The research team developed a SIRRA framework based on the process, framework, and criteria considerations described above. This framework is both issue-based and domain-based. It addresses many aspects of installation sustainability from a regional perspective. Using a combined framework offers the advantage of being able to draw on the strengths of the two frameworks while downplaying their weaknesses (Maclaren 1996). This framework enables a relatively easy assessment of the potential resource issues in a region and highlights the issues within that region that an installation or range may be experiencing. The indicators show where the issues lie and highlight potential long-term sustainability implications. 


\begin{tabular}{|c|c|c|}
\hline \multicolumn{3}{|l|}{ Issue } \\
\hline & Indicator & Data \\
\hline & Indicator & Data \\
\hline & Indicator & Data \\
\hline \multicolumn{3}{|c|}{ Threatened and Endangered Species } \\
\hline & \# of TES in state & Fish and Wildlife Service \\
\hline & Species at risk & $\begin{array}{l}\text { Journal of American Water } \\
\text { Resources Association }\end{array}$ \\
\hline & $\begin{array}{l}\text { Federally listed TES by } \\
\text { Ecoregion }\end{array}$ & NatureServe \\
\hline & TES of Concern & NatureServe \\
\hline
\end{tabular}

Figure 1. Regional resource assessment framework.

Figure 1 shows the regional resource assessment framework of issues and indicators, including an example of the issue-indicator relationship. Each indicator measures a different dimension of potential risk or stress. Comparison across installations of values for an individual indicator can give a measure of relative stress along one dimension. Each issue has several indicators and sometimes a combination of several indicators, or indices. Organizing the indicators by sustainability issue area allows the user to determine the issues that are relevant for their particular analysis and to consider only those.

The research team has developed a set of regional resource assessment indicators based on the process, framework, and criteria considerations described above. To help determine installation sustainability, our indicators are a combination of issuebased and domain-based. Using a combination framework has the advantage of being able to draw on the strength of the two frameworks while downplaying their weaknesses (Maclaren 1996). This framework enables a relatively easy assessment of the potential resource issues in a region and highlights the issues within that region an installation may be experiencing. The indicators show the status of the issues and highlight potential long-term sustainability implications.

\section{Sustainability Issues}

The selected sustainability issues are based on regional resource issues outside the installation boundaries. The associated indicators were developed based on criteria discussed in the next section. Community growth increases the contiguity between outside development and the installation or range. This contiguity increases the likelihood of incompatibility of land use between military missions and nearby urban development resulting in conflicts. The issues have been generated to apply to 
military installations, but a subset of these issues and indicators would also apply to watersheds, political boundaries, energy grids, etc. Water and energy resources are impacted by regional growth and related consumption and contamination. Regional types of energy use and their sources affect energy security and availability. Based on the criteria, the research team developed a set of 10 sustainability issue areas with a total of 54 indicators. The sustainability issue areas are: Air Quality, Airspace, Energy, Urban Development, TES, Locational, Water, Economic, Quality of Life, and Transportation.

\section{The SIRRA Set of Indicators}

Indicators with the potential for assessing these regional resources within the 10 issue areas were selected based on these requirements:

- the availability at a uniform scale nation-wide to ensure uniformity in comparisons

- records for multiple time periods to enable the evaluation of change

- preparation by a reputable source, such as a government agency or professional data vendor, and accompanied by metadata for quality assurance

- provision in a digital format, to accelerate data gathering and preparation for analysis

- the ability to be converted to geographic information system (GIS) format.

The 10 sustainability issue areas, with their corresponding indicators, represent a broad spectrum of topics related to resource availability and development. The 54 indicators provide a wide variety of information about population, economics, land development and usage, water availability and watershed health, natural disasters, infrastructure, air pollution, airspace availability, regional energy, and regional quality of life. Indicator data is from a variety of sources such as the U.S. Geological Survey (USGS) for seismicity information, the U.S. Environmental Protection Agency (USEPA) for air quality data and water supply characterization, the U.S. Fish and Wildlife Service (USFWS) and NatureServe for endangered species data, the U.S. Census Bureau for population statistics, and the U.S. Department of Energy for energy related data.

Appendix A includes the metadata documentation for each indicator, and provides the logic for indicator selection along with data sources, method of calculation, and assessment criteria. Since most of these are national data sets and were chosen due to their availability at the national level, incorporating them into GIS format for mapping provided a ready pictorial view of the sustainability issues. Table 1 lists the SIRRA indicators broken out by sustainability issue area, and also shows the data source and the data resolution level. All 54 indicators were used in this study. 
Table 1. Matrix of SIRRA indicators broken out by issue area.

\begin{tabular}{|c|c|c|c|}
\hline Issue & Indicator & Data Source & Data Level \\
\hline \multicolumn{4}{|c|}{ Air Quality Sustainability } \\
\hline AQ1 & Criteria Pollutant Non-Attainment & EPA/EIA & County \\
\hline AQ2 & Noise Sensitivity & US Census Bureau & Installation \\
\hline \multicolumn{4}{|c|}{ Airspace Sustainability } \\
\hline AS1 & SUA, Fighter Range & FAA & Installation \\
\hline AS2 & SUA, Bomber Range & FAA & Installation \\
\hline AS3 & Terminal Airspace & FAA & Installation \\
\hline AS4 & MTR, Fighter Range & FAA & Installation \\
\hline AS5 & MTR, Bomber Range & FAA & Installation \\
\hline \multicolumn{4}{|c|}{ Energy Sustainability } \\
\hline EN1 & Electrical Grid Congestion & NERC & NERCSub \\
\hline EN2 & Electrical Reserve Margin & NERC & NERCReg \\
\hline EN3 & Renewable Energy - Wind & NREL & Solargridunit \\
\hline EN4 & Renewable Energy - Solar & NREL & Windgridunit \\
\hline EN5 & Renewable Energy - Biomass & NREL & State \\
\hline EN6 & Electrical Price Structure (Dereg) & EIA & State \\
\hline EN7 & Net metering & Green Power network & State \\
\hline \multicolumn{4}{|c|}{ Urban Development Sustainability } \\
\hline UD1 & Regional population density & US Census Bureau & County \\
\hline UD2 & Incr. Regional Growth Rate & US Census Bureau & County \\
\hline UD3 & Regional population growth & US Census Bureau & County \\
\hline UD4 & Regional Land Urbanization & NLCD & Installation \\
\hline UD5 & State smart growth plans & APA web site & State \\
\hline UD6 & Joint Land Use Study (JLUS) & JLUS Office & Installation \\
\hline UD7 & Proximity to MSA & US Census Bureau & Installation \\
\hline \multicolumn{4}{|c|}{ TES Sustainability } \\
\hline TE1 & \# TES in state & FWS & State \\
\hline TE2 & Species at Risk & JAWRA & watershed \\
\hline TE3 & Federally Listed TES by Ecoregion & NatureServe & Ecoregion \\
\hline TE4 & TES of Concern & NatureServe & Ecoregion \\
\hline \multicolumn{4}{|c|}{ Locational Sustainability } \\
\hline LO1 & Federally declared floods & FEMA database & County \\
\hline LO2 & Seismic Zones & USGS maps & Zone \\
\hline LO3 & Weather-related damage & NWS/NOAA & State \\
\hline LO4 & Federally declared disasters & FEMA database & County \\
\hline LO5 & Tornadoes & NOAA & County \\
\hline
\end{tabular}




\begin{tabular}{|c|c|c|c|}
\hline Issue & Indicator & Data Source & Data Level \\
\hline \multicolumn{4}{|c|}{ Water Sustainability } \\
\hline WA1 & Level of Development & JAWRA & Watershed \\
\hline WA2 & Ground Water Depletion & JAWRA & Watershed \\
\hline WA3 & Flood Risk & JAWRA & Watershed \\
\hline WA4 & Low Flow Sensitivity & JAWRA & Watershed \\
\hline WA5 & Water Quality & JAWRA & Watershed \\
\hline \multicolumn{4}{|c|}{ Economic Sustainability } \\
\hline EC1 & DoD Local Employment & www.bea.gov (REIS) & County \\
\hline EC2 & Job Availability/unemployment & Bureau Labor Statistics & County \\
\hline EC3 & Housing Affordability & US Census Bureau & County \\
\hline EC4 & Poverty & US Census Bureau & County \\
\hline EC5 & Avg Hsg Value of New Construction & US Census Bureau & County \\
\hline EC6 & Housing Permits Issued & US Census Bureau & County \\
\hline \multicolumn{4}{|c|}{ QOL Sustainability } \\
\hline QL1 & Crime Rate & NACJD & County \\
\hline QL2 & Housing Availability & US Census Bureau & County \\
\hline QL3 & Rental Availability & US Census Bureau & County \\
\hline QL4 & Healthcare Availability & $\mathrm{HHS}$ & County \\
\hline QL5 & Educational Attainment & US Census Bureau & County \\
\hline QL6 & Commute Times & US Census Bureau & County \\
\hline \multicolumn{4}{|c|}{ Transportation Sustainability } \\
\hline TR1 & Capacity of Comml Airports & TAF System & Installation \\
\hline TR2 & Airport Suitability-C5 & FAA & Installation \\
\hline TR3 & Airport Suitability-C141 & FAA & Installation \\
\hline TR4 & Railroad Capacity & FRA & County \\
\hline TR5 & Proximity to Interstate & IRRIS & Installation \\
\hline TR6 & Roadway Congestion & 2002 Urban Mobility \& FHWA & State \\
\hline TR7 & Traffic Volume & TTI \& FHWA & State \\
\hline
\end{tabular}




\section{Methodology}

\section{Analysis Concept}

SIRRA has proven to be a useful and successful sustainability screening tool and has been used in the past to assess installations in a decision support function (Fournier, Deal et al. 2002). SIRRA version 1a was released in July 2004 using National data sets organized in a web-based analysis tool. The SIRRA methodology was reviewed by the individual DoD services before release. SIRRA data is derived from validated national sources, compiled in a consistent format, and covers a wide array of sustainability topics. SIRRA quantifies the state or condition of sustainability indicators and provides sustainability ratings for single indicators. However, it does not currently provide sustainability ratings based on an index, that is, a group of indicators. To meet the objective to rank the general sustainability of all DoD installations, this report generates a set of sustainability ratings based on multiple indicators with the capability to illustrate minor differences between DoD installations and regions of the country.

The SIRRA sustainment ratings contained in version 1a categorize indicator measures in three ratings as follows: sustainable, moderately sustainable, or unsustainable. The current SIRRA sustainment ratings were adjusted to have a finer resolution to highlight differences between a large number of installations within various regional settings. These ratings are not yet available on the SIRRA web site. This study characterizes indicator measures in five sustainment ratings:

1. Very low vulnerability

2. Low vulnerability

3. Moderate vulnerability

4. Vulnerable

5. High vulnerability.

Note that these ratings are not absolute in all cases as some are relative to a norm or mean. Also, note that not all indicators are broken out into five categories and some remain with three as the data did not lend itself to the finer scale. 


\section{Analysis Methodology}

The analysis methodology consists of initially characterizing and weighting sustainment issues at DoD installations using the SIRRA system. The full set of the original 48 indicators from SIRRA 1a, plus an additional six indicators, were used for this evaluation. The set of indicators is listed in Table 1 and also contained in Appendix A with metadata documentation.

The indicator weighting scheme relates the regional issues to specific missions or functions of an installation. For example, a storage depot facility is affected less by housing availability issues and affected more by inter-state transportation availability for the movement of its goods; while an expeditionary facility is affected greatly by housing availability for its soldiers and affected minimally by inter-state transportation availability. Both housing and transportation availability are considered sustainment issues that contribute to regional encroachment, but the weight given to each type of installation for those indicators is different. The regional sustainability ranking approach provides a weighted summary of assessment indicators that determine an overall mission sustainment or vulnerability rating for that region hosting the given installation. These weighted assessments can then be used as a screening tool to assess installations where additional studies, planning, and actions are recommended to ensure continued mission accomplishment.

The following steps were followed to accomplish this:

1. Compile data for 54 SIRRA indicators in the regions surrounding $308 \mathrm{DoD}$ installations.

Appendix A of this report includes the SIRRA metadata. Indicator data values were extracted from the revised SIRRA database, updated from the version 1a contained on the web-based analysis tool that is available online at URL:

https://ff.cecer.army.mil/ff/sirramx.do

The query results in several "not-available" data values-specifically for water sustainment indicators in Alaska and Hawaii where the data source does not report conditions in these areas. To assure these "not-available" data values neither hurt or help installations, these values were entered as "moderately sustainable" or the rating was interpolated from the surrounding nearby regions. The table in Appendix B reports all data values for the SIRRA indicators in regions surrounding the installations used in the analysis. Appendix B also provides the installation mission classifications. 
2. Assign numbers to 54 SIRRA indicator sustainability ratings into five categories of sustainability - where 1 represents very low vulnerability and 5 represents high vulnerability.

The metadata in Appendix A includes the sustainment rating thresholds for the SIRRA indicators. Once sustainment ratings are determined, they were assigned numbers. This allowed an indicator to be weighted and scored based on its criticality to mission.

- very low vulnerability $=1$

- low vulnerability $=2$

- moderate vulnerability $=3$

- vulnerable $=4$

- high vulnerability $=5$

3. Assign weights to 54 SIRRA indicators based on four DoD missions. A weight of 1 is applied to a low importance indicator, 2 to indicators of average importance, and 3 to indicators of major importance.

For each mission/installation type a different set of indicators are important. If an indicator is of major significance to a specific mission, its value is multiplied by 3. If an indicator is of average significance to a specific mission, its sustainment rating is multiplied by 2 . If an indicator is of lesser significance to a specific mission, its sustainment rating is multiplied by 1 . Appendix $\mathrm{C}$ contains the matrix characterizing indicators by missions used in this report.

4. Assign the primary mission/function to each installation.

Each installation is assigned a primary function or mission-expeditionary, training and ranges, industrial, and administrative support. Definitions of these missions follow:

- Expeditionary: Includes all installations (land, air, sea) that train and project forces-airbases with active runways, maneuver installations, naval air facilities, and selected training installations.

- Training and Ranges: These include non-expeditionary training installations, remote ranges, and reserve component training sites.

- Industrial: These include storage installations, arsenals, depots, industrial facilities, ammo plants, shipyards, and ocean terminals.

- Administrative Support: These include command, control, and administrative support installations; medical treatment facilities; nonmaneuver type training; professional development installations; and RDT\&E oriented locations.

Characterizations of these missions were determined based on judgment of overall activities present on the installation. Installations often perform more than one task and characterizing the function in a single term is often difficult. Installations' official missions often compose a unique paragraph description. Gener- 
alizations of missions are used within this analysis. Appendix B includes a complete list of assigned installation missions.

5. Sum the sustainability ratings to arrive at an overall sustainability score or index that characterizes a level of encroachment potential or sustainment jeopardy. To arrive at a final sustainment/vulnerability score for the region around an installation, multiply indicator ratings by respective weights identified by mission criteria. These weighted indicator ratings are then summed to arrive at a total installation sustainability vulnerability score. The higher the score, the more vulnerable the installation is considered or the more stress experienced due to encroachment issues. The lower the score, the less vulnerable the installation is to encroachment and key issue stresses. Appendixes C, D, and E provide the final Vulnerability Score for each installation region.

Using this method, lower scores represent more sustainable or less vulnerable installations. In other words, low scores represent few regional risks for that particular mission. Understanding the mathematics, if an indicator is of lesser importance, the weights rank it positively (x 1). If an indicator is a key determinant, the weights will rank it relatively positively if it is a good rating ( $1 \times 3)$ and highly negatively if it is a poor weighting $(5 \times 3)$. Indicators of average importance act similarly to key indicators only not as significantly (x 2 vs. $\mathrm{x} 3$ ).

\section{Testing Example}

Is an urban area most suitable for an expeditionary or administrative support mission? expeditionary $=5 \times 3=15$ administrative support $=5 \times 1=5$

Warning! Users must be careful in comparing sustainability scores of installations/ regions with differing mission. Because of the set-up of the weights, majority of expeditionary mission indicators are multiplied by 3 , where majority of administrative support mission indicators are multiplied by 1 . Therefore, expeditionary mission installations will naturally have a higher vulnerability score compared to administrative support mission installations. Users should note the range of possible sustainability scores for each mission and compare where an installation falls within that scale to compare two or more installations of differing missions. The different mission weightings highlight the fact that expeditionary installations tend to be larger, produce more impacts, and be subjected to more environmental issues. Table 2 lists the range of possible scores by mission type. 
Table 2. Possible sustainability score ranges by mission.

\begin{tabular}{|l|c|}
\hline \multicolumn{1}{|c|}{ Mission } & Score Ranges \\
\hline Expeditionary Forces Facilities & $135-675^{*}$ \\
\hline Training Facilities and Ranges & $84-420$ \\
\hline Industrial Facilities & $92-460$ \\
\hline Administrative Support Facilities & $87-435$ \\
\hline * Range determined by taking the sum of all weights (for a given \\
mission) multiplied by 1 and then by 5. \\
\hline
\end{tabular}




\section{Results}

\section{Regional Sustainability Scores}

Figure 2 shows the resulting rankings of all 308 DoD installations' mission Vulnerability Scores for the regions, which ranged from 169 to 454 .

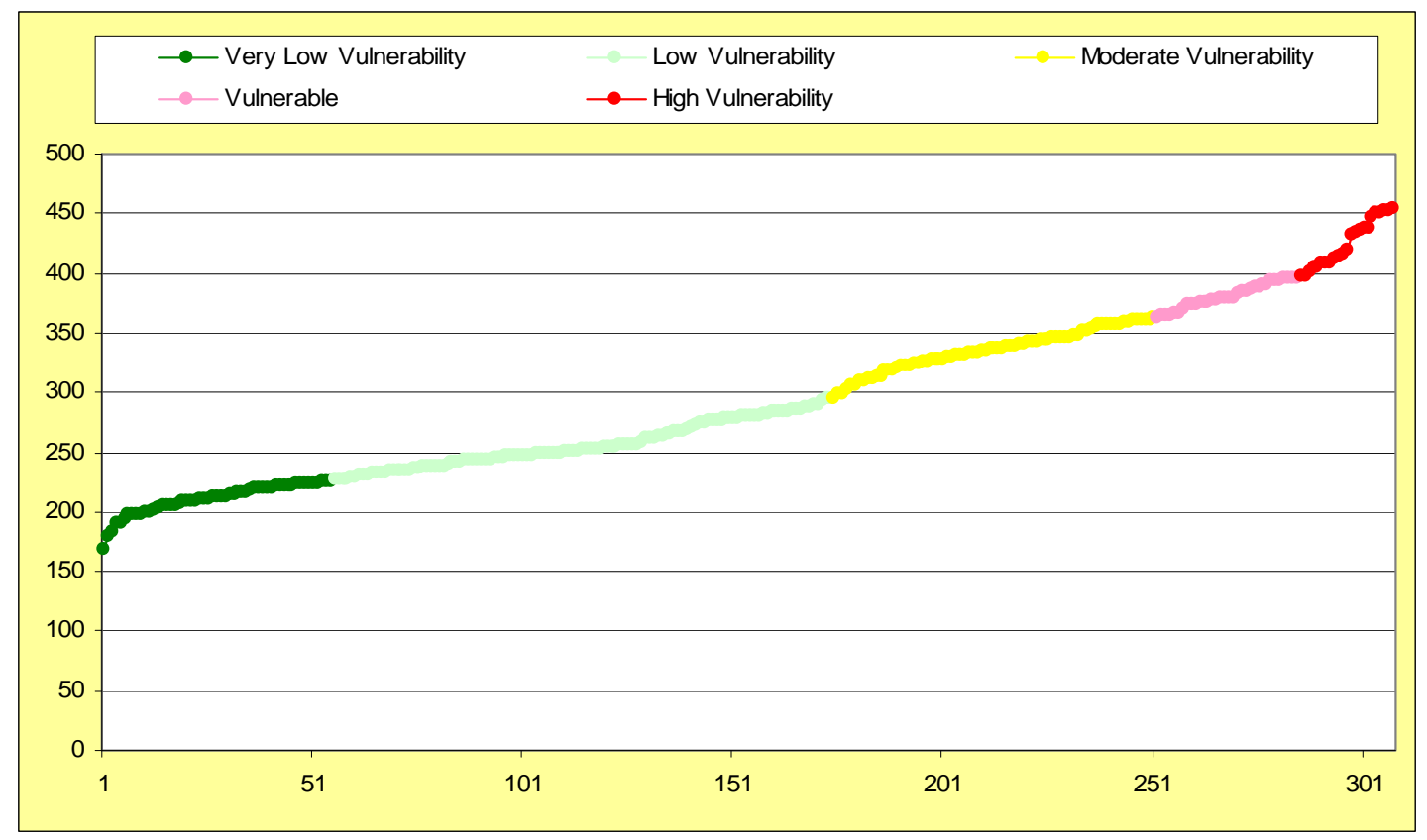

Figure 2. DoD vulnerability scores.

Possible overall sustainability scores range from 84 to 675 , where 84 represents lowest vulnerability and 675 represents the maximum vulnerability. Table 3 , below, lists the range of scores and their statistics. Table 4 lists the ranges for the various vulnerability classifications.

Table 3. Statistics of Scores.

\begin{tabular}{|l|c|}
\hline Statistical Analysis & Score \\
\hline Median & 280 \\
\hline Average & 294.2 \\
\hline Standard Deviation & 68.1 \\
\hline Lowest Score & 169 \\
\hline Highest Score & 454 \\
\hline
\end{tabular}


Table 4. Ranges of vulnerability based on statistics.

\begin{tabular}{|l|l|}
\hline Vulnerability Range & Definition \\
\hline Very Low Vulnerability & Less that 1 Std Dev below Mean $(<226.1)$ \\
\hline Low Vulnerability & Between 1 Std Dev below Mean and Mean (226.1 - 294.2) \\
\hline Moderate Vulnerability & Between 1 Std Dev above Mean and Mean (294.2-362.3) \\
\hline Vulnerable & $\begin{array}{l}\text { Between } 1 \text { Std Dev above Mean and 1.5 Std Dev above Mean (362.3 - } \\
\text { 396.3) }\end{array}$ \\
\hline High Vulnerability & Above 1.5 Std Dev above Mean $(>396.3)$ \\
\hline
\end{tabular}

\section{Discussion}

Installations with the highest vulnerability tended to be expeditionary installations located in or near large metropolitan areas or in either California or Hawaii. Installations in areas rated the least vulnerable tended to be non-expeditionary training or administrative facilities located in rural areas or settings in the lesser populated areas. Also, administrative and industrial facilities were not negatively impacted by being located in or near metropolitan areas.

All locations have some issues of sustainability creating vulnerabilities as shown by the fact that the lowest rating score was still significantly higher than the lowest possible score. Also, the highest scored region was a good deal less than the maximum possible score indicating that installation settings do vary and that not all of the indicators are high for any given location.

The range of scores was fairly linear across the range except for either extreme. The regions with the highest vulnerability have a fairly steep rise in scores, indicating that vulnerabilities were worsening en masse. The same is true for regions rated least vulnerable, the indicators tended to get much better as a whole. 


\section{Interpreting the Results}

\section{Scoring Implications}

The vulnerability scores presented here represent a generic evaluation of the potential for encroachment issues and general sustainability of any given setting for a DoD installation. The ranking methodology is meant to be a screening tool. It is not a final, definitive evaluation of the sustainability of any given installation's location and region. Further detailed studies specific to an installation and its region are required. In other words, this study screened for certain issues and identified installations in regions where the set of indicators and mission weightings were considered to have potential problems.

For example, an installation may show poor water quality within its region and thus be rated high in terms of vulnerability. However, in practice the installation may use its own potable water system with its own sources-making its actual vulnerability rating to this issue of sustainability "low" instead of "high." The methodology of this report is exogenous to an installation and does not factor in site specific conditions. As a national level screening tool, the information represents entire counties, watersheds, and ecoregions and this data will not always agree with local data sources for specific towns or managed units within a county, watershed, or ecoregion.

There are trade-offs between using this standardized approach, which allows the use of national-level data to evaluate regional aspects of the installation setting, and one that uses installation specific data. The best recommendation is to examine the indicators that are most important and to seek additional information to better understand the rating. Any decision relevant to a specific installation or location should always be informed by more than SIRRA. This report (and appendixes) is a helpful screening tool that organizes these numerous exogenous sustainability data and provides relative characterizations of installations based on that information.

\section{Understanding Options for Sustainment Mitigation}

The characterization process results in a list of installations that may soon be experiencing or are already experiencing impacts on mission and readiness due to ex- 
ogenous forces in the region. Any decision on how to proceed should be based on the characterization and any known sustainability issues endogenous to the installation. An installation facing sustainability encroachment issues has essentially five courses of action. Table 5 lists general guidelines for determining mitigation strategies for a given installation. Each progressive step of action includes the previous step, so, if step 5 is recommended, so are the actions in steps 2-4. The best sustainment mitigation strategy is often a combination of options.

Very Low Vulnerability: There are limited concerns, however, continuous monitoring is the recommended action for those installations rated as having a very low vulnerability. Indicators illustrate that the region and the installation mission are currently in fairly good harmony. This action includes a need to continue monitoring the installation and updating the sustainment assessment as new information is made available. Temporal changes in indicators will provide a measure of how the situation is evolving and, eventually, identify when "no action" is no longer viable.

Low Vulnerability: Installations that are experiencing select pressures and need immediate action in a selected sustainment issue may require mitigation in that particular issue. Examples of select pressures are U.S. Endangered Species Act (USESA) compliance, local community concerns, or a private landowner lawsuit.

Moderate Vulnerability: Installations characterized with moderate vulnerability may be struggling with some sustainability issues. They may require long-term efforts in regional planning that rely on external jurisdictions for enabling real change within the region. This action is valuable for building connections with neighbors, exposing positive installation efforts to the public, establishing zoning to ensure military compatible land uses, and awakening local area responsibility for ecosystem sustainability. Programs that support this action include Joint Land Use Studies (JLUS), USDA programs that keep farm land actively farming, and regional transportation studies and plans. In other words, moderately vulnerable installations should collaborate with local governments to ensure a future for both the installation and local communities.

Table 5. Vulnerability sustainment mitigation.

\begin{tabular}{|c|l|l|}
\hline Vulnerability Score & \multicolumn{1}{|c|}{ Vulnerability Range } & \multicolumn{1}{c|}{ Interpretation of Scores } \\
\hline $169-226$ & Very Low Vulnerability & Limited concerns; continue to monitor \\
\hline $226-294$ & Low Vulnerability & Concerns may require mitigation \\
\hline $294-362$ & Moderate Vulnerability & $\begin{array}{l}\text { Concerns likely to require mitigation and proactive } \\
\text { coordination with regional stakeholders }\end{array}$ \\
\hline $362-396$ & Vulnerable & Significant concern(s) to address and resolve \\
\hline $396-454$ & High Vulnerability & Many significant concerns to address and resolve \\
\hline
\end{tabular}


Vulnerable: Installations considered vulnerable should initiate an assessment of on-site activities for how they reach beyond the fence line, maximizing effective use of existing lands, and ensuring long-term sustainability. These are accomplished by characterizing the installation assets, understanding how those assets meet the current mission, and predicting what might be needed in the future. This action should generally be implemented at all installations, yet is recommended for those installations considered Vulnerable.

High Vulnerability: Installations classified as highly vulnerable should actively work with local governments to develop sustainable solutions for their region. This refers to controlling land use actions outside the fence through mechanisms such as conservation easements and land purchase. Other mitigations may include technology infusion, codes and standards, and market approaches. It assumes the potential for short-term, concrete action to mitigate severe on-post issues while the longer-term efforts are being negotiated. It should not be assumed that pursuing this option will de facto be beneficial. Success depends on sufficient understanding of the issues and the availability of appropriate off-post partners. It also depends on the ability to develop and implement mitigation strategies, the ability to identify suitable land for easement acquisition or other land control options, and that fact that these options must be affordable.

\section{Using Appendix E}

Appendix E is attached as a Microsoft Excel workspace (AppendixE.xls). The workspace provides the 54 individual, weighted indicator vulnerability scores, a total weighted issue area vulnerability score for the 10 issues, and the final weighted vulnerability scores for all 308 installations. As previously stated, the higher the score the more vulnerable the installation is considered or the more stress it incurs due to development and encroachment issues. The lower the score, the less vulnerable the installation is to environmental and key issue stresses. When opening Appendix E workspace, be certain that all macros remain enabled. Once open, the workspace contains two worksheets-MAIN Page and SIRRA Indicators. These are identifiable by tabs located in the bottom, left corner of the workspace.

The MAIN Page holds all weighted vulnerability scores. SIRRA Indicators is a reference worksheet. Users may refer to this worksheet for a quick reference of indicator identifiers, source, and data level (i.e., users may recollect that $\mathrm{AQ} 1$ represents Criteria Pollutant Non-Attainment data from the USEPA at the county level).

Appendix E provides users the ability to analytically identify potential sustainability problems for any given installation as well as view vulnerability ratings in rela- 
tion to other installations. Data columns include installation name, state, service branch, MACOM, and mission; total weighted vulnerability score; and, individual issue area weighted vulnerability score. Check boxes located above the issue area column headings may be checked to reveal or unchecked to hide a break-down of individual indicator vulnerability scores. For example, checking the "AQ" box reveals $\mathrm{AQ} 1$ and $\mathrm{AQ} 2$ rating columns. Removing the checkmark collapses these columns. Users may sort the MAIN Page columns using the Microsoft Excel sort function for several analyses including a ranking of all installations by vulnerability score and a ranking of installations by state, branch, MACOM, mission, issue area, or indicator.

The "Vulnerability Scores" are the sum of all 54 indicator vulnerability scores weighted by mission. Individual issue area vulnerability scores are the sum of all indicators within that issue weighted by mission. Overall, these sustainability assessments are intended to be used as a screening tool to identify installations for which additional studies, planning, and actions may be recommended to ensure continued viability and sustainability. To go beyond this initial screening, users are advised to review the indicators that led to a high or low sustainability score and judge the score based on local knowledge. Example applications of the data follow.

\section{Scenario 1}

As an Army Forces Command planner, you are curious as to the viability of adding a training range to an existing installation located within the Southeast region of the United States (the Southeast region is defined by Alabama, Georgia, Florida, North Carolina, and South Carolina). You wish to identify Army installations in the Southeast capable of supporting an additional training range.

Step 1: Using the Microsoft Excel sorting function, sort the "MAIN Page" data by Service Branch (column C), then by State (column B), and then by Vulnerability Score (column G), in ascending order. (Figure 3)

These steps produce a grouping of Army installations by state and ranked by Vulnerability Scores. In other words, it becomes clear which Army installations have the lowest vulnerability ratings in each respective state. 


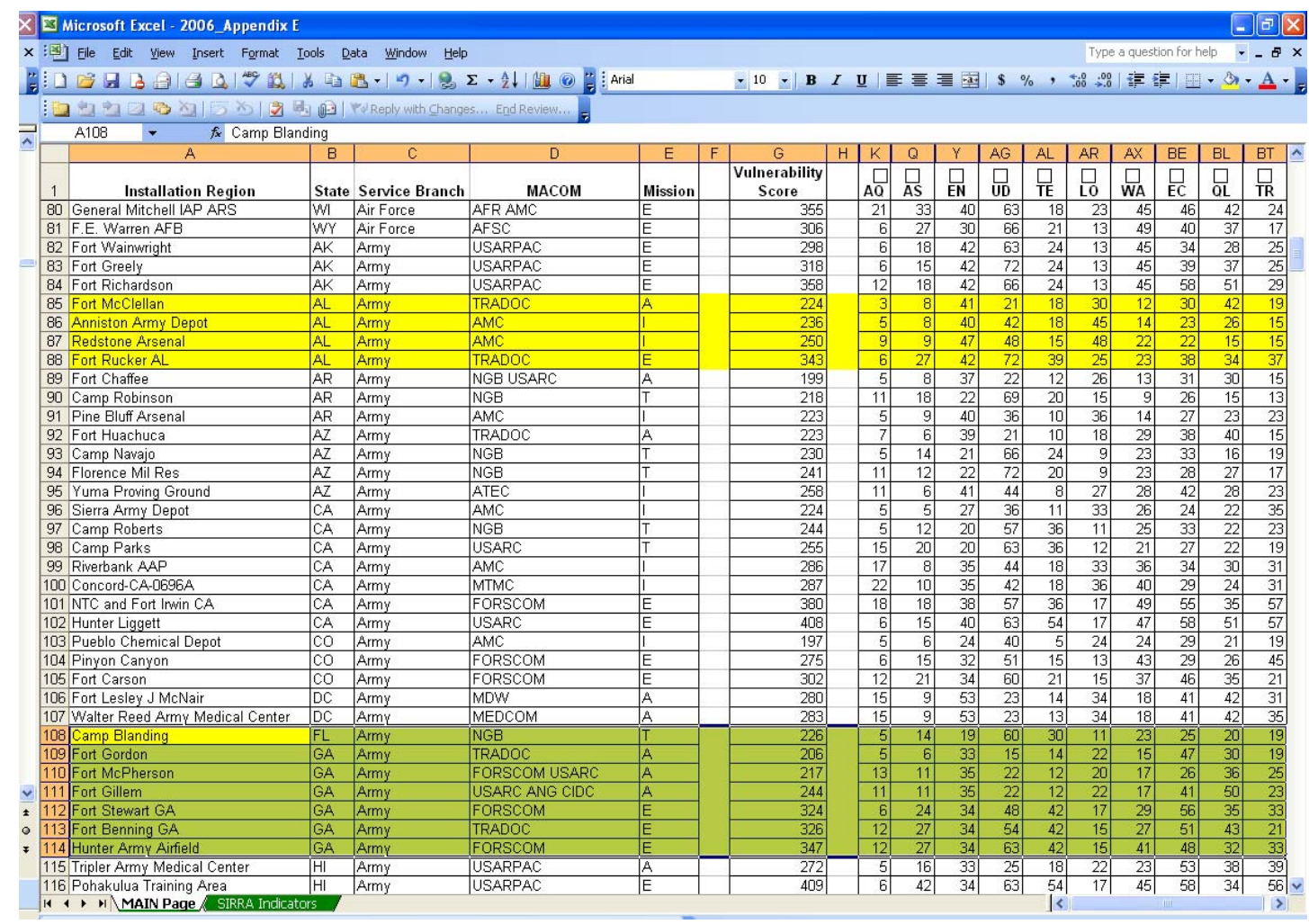

Figure 3. Screen capture of Appendix E resulting from Step 1 of Scenario 1. Army installations located in the southeast have been highlighted.

Step 2: Identify sustainability issue areas critical to a training mission.

The vulnerability rating is based on 10 issue areas weighted by current missions, yet, the relevance of an issue changes depending on the specific missions or functions of an installation. For example, a storage depot facility is impacted less by soldier quality of life issues and impacted more by transportation availability for the movement of its goods. A radar bomb scoring range is impacted greatly by air space and noise indicators and less by energy and water availability. Thus, it is necessary to acknowledge how critical issue areas were weighted according to the installation's current mission. For this example one should assume for the type of training being added, critical issue areas include AQ and QL (air quality and quality of life, respectively).

Step 3: Highlight installations within the Southeast region-Alabama, Georgia, Florida, North Carolina, and South Carolina - having a moderate vulnerability rating or better in all critical issue areas (e.g., 1, 2, or 3). Obtain vulnerability ratings by dividing indicator vulnerability scores by its respective weight. (e.g., divide AQ1 vulnerability scores by 3 for all expeditionary forces facilities, by 2 for all training facilities, etc.) 
These installations include: Redstone Arsenal, AL.

Step 4: Review the indicators that led to a high or low sustainability score and interpret the score based on local knowledge.

The results of Step 3 identified one viable installation for the addition of a training range in the Southeast United States. Users are advised to review this result and interpret scores based on local knowledge. For example, Fort Benning, GA was eliminated primarily due to a poor threatened and endangered species (TE) rating. However, local knowledge reveals that Fort Benning is currently proactively addressing threatened and endangered species issues through participation in the SERDP Ecosystem Management Program (SEMP). In this instance the high TE vulnerability rating would be of less concern and the installation could be considered viable.

\section{Scenario 2}

A realignment proposal has been made at Cannon AFB, NM, to relocate the $1^{\text {st }} \mathrm{Ar}$ mored Division, Artillery Brigade, Maneuver Battalion, Support Battalion, and Aviation Unit to Cannon AFB. You wish to ensure that the Cannon AFB region has sufficient infrastructure to support this proposal. You want to know if Cannon AFB can sustain the additional missions and if not, what actions need to be taken to ensure sustainability.

Step 1: Using Microsoft Excel sorting function, sort the MAIN Page data by Installation (column A) ascending alphabetically (Figure 4).

Cannon AFB should appear in row 54 and show a final vulnerability score of 365 . A vulnerability score of 365 indicates that Cannon AFB is currently vulnerable to encroachment issues.

Step 2: Identify sustainability issues critical to the 1st Armored Division, Artillery Brigade, Maneuver Battalion, Support Battalion, and Aviation Unit missions.

Overall, Cannon AFB is vulnerable to encroachment issues. However, its most vulnerable issues may not be relevant to the proposed missions. It is necessary to assess whether "vulnerable" is the proper designation for Cannon AFB given its functions. The user should assume for the missions being added that critical issue areas include AS, EN, TE, WA, and TR (airspace, energy, threatened and endangered species, water, and transportation respectively). 


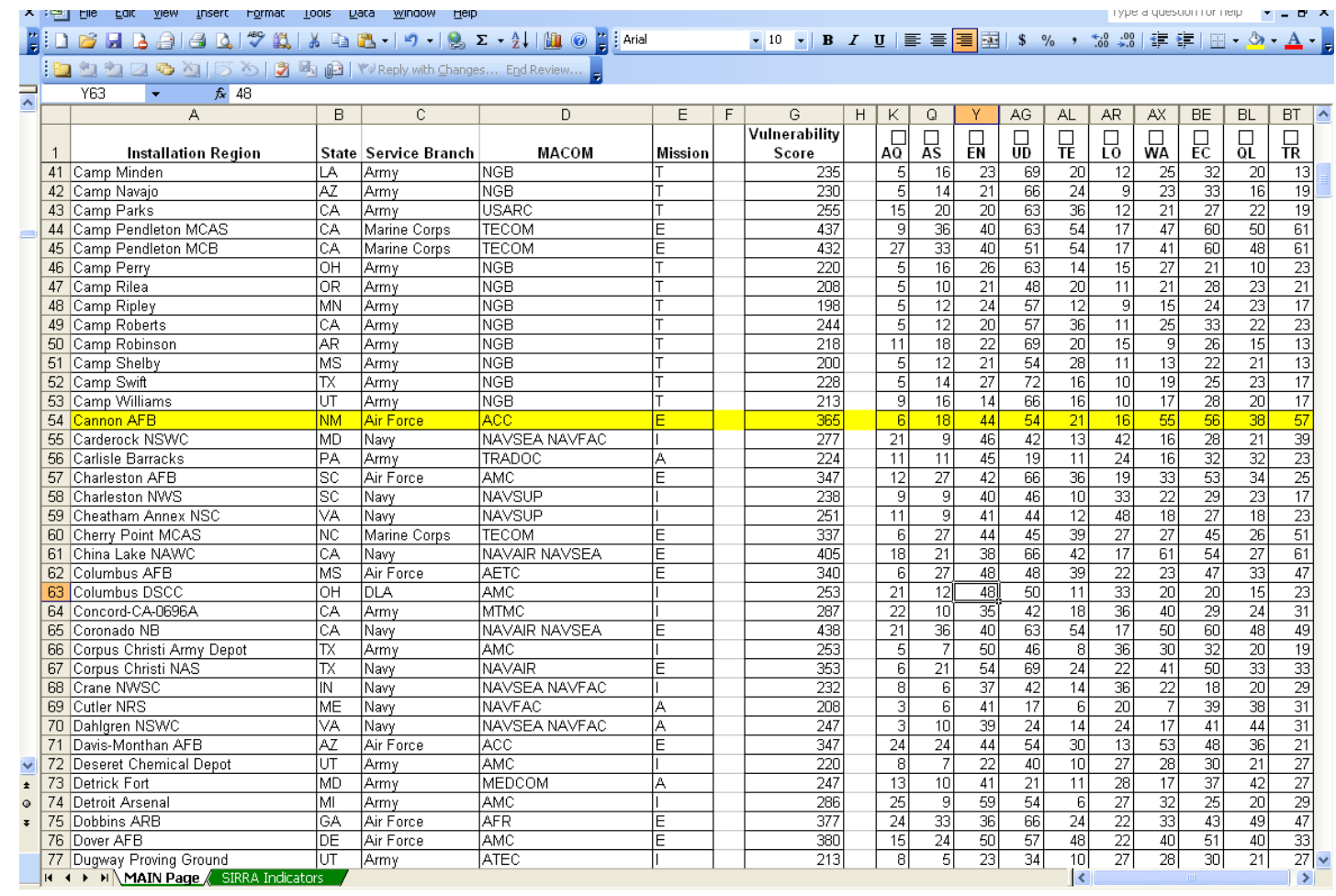

Figure 4. Screen capture of Appendix E resulting from Step 1 of Scenario 2. Cannon AFB has been highlighted.

Step 3: Highlight the critical issues having a high (4) or very high (5) vulnerability rating (e.g., highlight if AS rates above 60, EN rates above 48, TE rates above 48, WA rates above 52 , or TR rates above 68 ).

High vulnerability issue areas include water (WA).

Step 4: Check the column heading of WA issues. This opens individual indicator ratings for water issues. Next, highlight indicators having a high (4) or very high (5) vulnerability rating (e.g., highlight if WA1 rates above 12 , WA2 rates above 8, WA3 rates above 8, WA4 rates above 12, or WA5 rates above 12) See Figure 5.

High vulnerability indicators include WA1 and WA2, and WA4 (level of development, groundwater depletion, and low flow sensitivity respectively).

Step 5: Review the indicators that led to a high or low sustainability score and interpret the score based on local knowledge.

The results of Step 4 identified water availability problems in the region that may conflict with the proposed additional missions and accompanying personnel. 


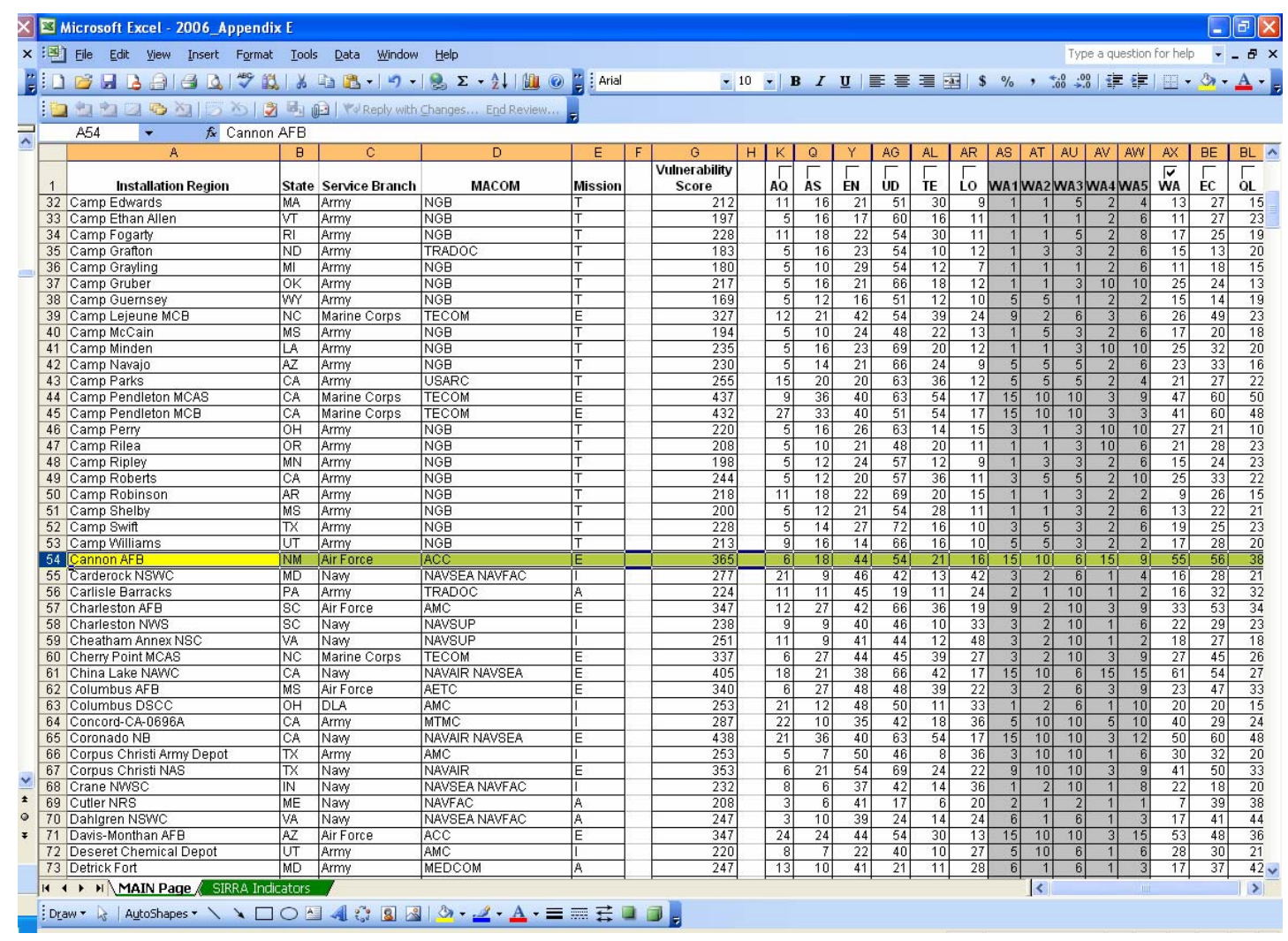

Figure 5. Screen Capture of Appendix E resulting from Step 4 of Scenario 2. Cannon AFB has been highlighted and water indicators are displayed.

To ensure sustainability, actions addressing water availability need to be taken. Further analysis will be required to determine the extent of vulnerability that these indicators pose to Cannon AFB sustainability under the proposed realignment. This analysis results in identifying possible conflicts. It does not provide installation-specific assessments. For example, the scenario identifies ground water sources within the watershed as insufficient. However, it does not know if Cannon AFB uses its own water source; that would decrease the relevance of this rating. Use of local knowledge and understanding of indicator measures (found in indicator metadata) are critical to the application of this analysis. 


\section{Conclusions}

The outcome of using the SIRRA methodology to rank DoD installation regions has provided a prioritized list of installations that require further analysis and evaluation. Of the 308 installations included in the analysis, the results indicate that 57 (about 19 percent) of the installations are located in regions that are Vulnerable or have High Vulnerability. Another 77 of the installations were located in regions rated as Moderately Vulnerable. The remaining 174 (56 percent) of the installations were located in regions rated as having Low or Very Low Vulnerability.

This use of the SIRRA tool demonstrates how a Web-based decision support framework can be applied to regions surrounding military installations. This approach used the SIRRA information, databases, and index models coupled with GIS capabilities for system-wide assessments. This specialized application of SIRRA added an indicator weighting scheme, based on the installation mission, to the methodology extant on the SIRRA web-based analysis tool. This report represents the first tier of a multi-tiered approach that allows use of various levels of models and tools based on scientific needs, user ability, and available resources. The framework supports decisionmaking flexibly, allowing individual applications of the information.

The SIRRA methodology allows USACE Division and District planners and project managers, regulators, and operation and maintenance managers involved with system-wide studies such as installation studies, ecosystem restoration, and resource reallocation studies to obtain a first-cut evaluation of an installation using national data sets. SIRRA provides an assessment tool for the U.S. Army Corps of Engineers that contains a significant new capability to apply national data sets in an installation context that addresses sustainability support to the military mission on a regional scale. It provides data and analysis to support efforts toward sustainable management of national resources. The SIRRA-based installation analysis capability provides an information link that increases the effectiveness of partnering with other agencies and private stakeholders. The installation-based screening tool may also reduce costs associated with determining installations that need further study. 


\section{Bibliography}

Deal, Brian M., Donald F. Fournier, Diane M. Timlin, and Elisabeth M. Jenicek, ERDC/CERL Technical Report TR-02-27, An Assessment of Encroachment Mitigation Techniques for Army Lands (Engineer Research and Development Center, Construction Engineering Research Laboratory (ERDC-CERL), Champaign, IL, October 2002).

Fournier, D., B. Deal, et al. Sustainable Installation Risk Assessment and Stationing Implications (ERDC-CERL, 2002), p 44.

Fournier, Donald F., Brian M. Deal, Elisabeth M. Jenicek, and Adam J. Sagert, ERDC/CERL Special Report SR-02-12 Sustainable Installation Risk Assessment and Stationing Implications (ERDC-CERL, September 2002).

IISD (2000), Measurement and Indicators for SD (International Institute for Sustainable Development, 2002).

Jenicek, Elisabeth M., Donald F. Fournier, William D. Goran, Natalie R. Downs, and Adam J. Sagert, ERDC/CERL TR-04-9, The Sustainable Installations Regional Resource Assessment (SIRRA) Capability (ERDC-CERL, July 2004).

Maclaren, V.W., Developing Indicators of Sustainability: A Focus on the Canadian Experience (Intergovernmental Committee on Urban and Regional Research Press, Toronto, Canada, 1996).

Maclaren, V.W., “Urban Sustainability Reporting,” APA Journal (Spring 1996), pp 184-202.

SERDP Program Office, Annual Report to Congress_Fiscal Year 2003 (Department of Defense, Arlington, VA, 2004), p 324.

Tomich, K., and B. Deal, Environmental Factors to Consider Prior to Restationing Forces (Center for Army Analysis, Alexandria, VA, 2002).

U.S. Army Environmental Center (USAEC), Environmental Regulatory Climate Model (USAEC, 2002). 


\section{Acronyms and Abbreviations}

\begin{tabular}{|c|c|}
\hline Term & Spellout \\
\hline AADT & Annual Average Daily Traffic per Lane \\
\hline AEC & U.S. Army Environmental Center \\
\hline AFB & Air Force Base \\
\hline ANSI & American National Standards Institute \\
\hline APA & American Planning Association \\
\hline AVMT & annual vehicle miles traveled \\
\hline CERL & Construction Engineering Research Laboratory \\
\hline $\mathrm{CO}$ & carbon monoxide \\
\hline DA & Department of the Army \\
\hline DC & direct current \\
\hline DO & Dissolved Oxygen \\
\hline DoD & Department of Defense \\
\hline DOI & Department of Interior \\
\hline EIA & Energy Information Administration \\
\hline EO & Executive Order \\
\hline EPA & Environmental Protection Agency \\
\hline ERDC & Engineer Research and Development Center \\
\hline ES & Electrical System \\
\hline ESRI & Environmental Systems Research Institute, Inc. \\
\hline FAA & Federal Aviation Administration \\
\hline FEMA & Federal Emergency Management Agency \\
\hline FHA & Federal Housing Authority \\
\hline FHWA & Federal Highway Administration \\
\hline FY & fiscal year \\
\hline GIS & geographic information system \\
\hline HQ & headquarters \\
\hline HQUSACE & Headquarters, U.S. Army Corps of Engineers \\
\hline HUC & hydrologic unit code \\
\hline ID & Identification \\
\hline IRRIS & Intelligent Road/Rail Information Server \\
\hline ITC & Installation Training Capacity \\
\hline JAWRA & Journal of American Water Resources Association \\
\hline JLUS & Joint Land Use Study \\
\hline MSA & Metropolitan Statistical Areas \\
\hline NAAQS & National Attainment Air Quality Standards \\
\hline NACJD & National Archive of Criminal Justice Data \\
\hline NAVFAC & Naval Facilities Engineering Command \\
\hline NEMIS & National Emergency Management Information System \\
\hline NERC & North American Electricity Reliability Council \\
\hline NLCD & National Land Use Data \\
\hline
\end{tabular}


Term

NOAA

NREL

NWS

OCE

$\mathrm{OMB}$

ORD

PDF

PM

$\mathrm{PO}$

QOL

$\mathrm{RCl}$

RDTE

REIS

SAR

SERM

SI

SIRRA

SR

SWWRP

TAF

TES

TNC

TR

TTI

URL

USACE

USAEC

USC

USCB

USDOA

USDOC

USDOE

USDOI

USDOJ

USDOL

USDOT

USEPA

USESA

USFWS

USGS

WWW
Spellout

National Oceanic and Atmospheric Administration

National Renewable Energy Laboratory

National Weather Service

Office of the Chief of Engineers

Office of Management and Budget

Operational Requirements Document

Portable Document Format

particulate matter

purchase order

Quality of Life

Roadway Congestion Index

Research, Development, Test, and Evaluation

U.S. Department of Commerce, Bureau of Economic

Analysis

Search and Rescue

Sustainability, Environment, and Room to Maneuver

Systeme Internationale

Sustainable Installations Regional Resource Assessment

Special Report

System-Wide Water Resources Program

Terminal Aerodrome Forecasts

threatened and endangered species

The Nature Conservancy

Technical Report

Travel Time Index

Universal Resource Locator

U.S. Army Corps of Engineers

U.S. Army Environmental Center

United States Code

U.S. Census Bureau

U.S. Department of Agriculture

U.S. Department of Commerce

U.S. Department of Energy

U.S. Department of the Interior

U.S. Department of Justice

U.S. Department of Labor

U.S. Department of Transportation

U.S. Environmental Protection Agency

U.S. Endangered Species Act

U.S. Fish and Wildlife Service

U.S. Geological Survey

World Wide Web 


\section{Appendix A: SIRRA Metadata}

\section{Contents}

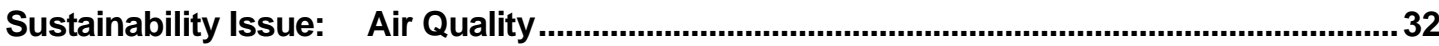

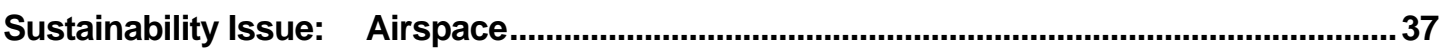

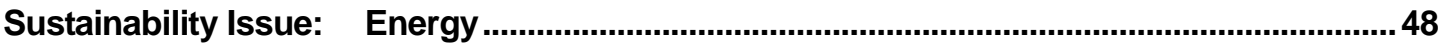

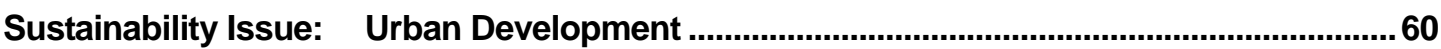

Sustainability Issue: Threatened and Endangered Species (TES) …....................................73

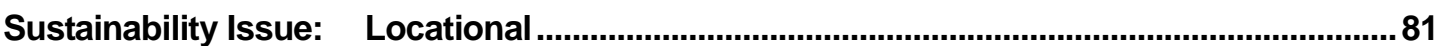

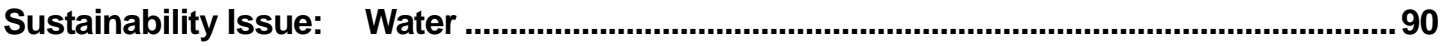

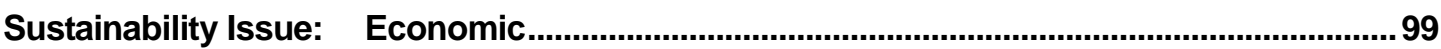

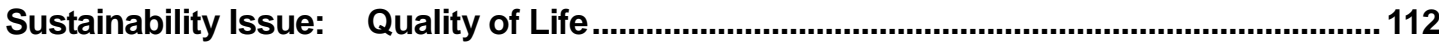

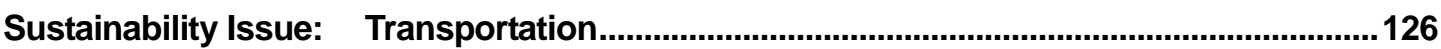




\title{
Sustainability Issue: Air Quality
}

\author{
Indicator: Criteria Pollutant Non-Attainment (AQ1) \\ Variables: Six Principal Air Pollutants (also referred to as criteria pollut- \\ ants): Nitrogen Dioxide $\left(\mathrm{NO}_{2}\right)$, Ozone $\left(\mathrm{O}_{3}\right)$, Sulfur Dioxide $\left(\mathrm{SO}_{2}\right)$, \\ Particulate Matter (PM), Carbon Monoxide (CO), and Lead (Pb) \\ Scale: $\quad$ County \\ Year: $\quad 2004$ \\ Data Sources:
}

USEPA. (2005). Green Book Nonattainment Areas for Criteria Pollutants. Office of Air and Radiation/Office of Air Quality Planning and Standards. Washington, DC. (Nonattainment Status for Each County by Year), available through URL: http://www.epa.gov/oar/oaqps/greenbk/anay.html

USEPA. (2004). The Particle Pollution Report: Current Understanding of Air Quality and Emissions through 2003. Office of Air Quality Planning and Standards, Emissions, Monitoring, and Analysis Division. Washington, DC, available through URL: http://www.epa.gov/airtrends/

Logic: The Clean Air Act provides the principal framework for national, state, tribal, and local efforts to protect air quality. Under the Clean Air Act, EPA establishes air quality standards to protect public health by setting National Attainment Air Quality Standards (NAAQS) for the six principal pollutants that are considered harmful to public health and the environment and ensuring that these air quality standards are met (in cooperation with the state, tribal, and local governments) through national standards and strategies to control air pollutant emissions from vehicles, factories, and other sources (USEPA 2004). EPA has set national air quality standards for six principal air pollutants (also referred to as criteria pollutants): nitrogen dioxide $\left(\mathrm{NO}_{2}\right)$, ozone $\left(\mathrm{O}_{3}\right)$, sulfur dioxide $\left(\mathrm{SO}_{2}\right)$, particulate matter $(\mathrm{PM})$, carbon monoxide $(\mathrm{CO})$, and lead $(\mathrm{Pb})$. Four of these pollutants $\left(\mathrm{CO}, \mathrm{Pb}, \mathrm{NO}_{2}\right.$, and $\mathrm{SO}_{2}$ ) result primarily from direct emissions from a variety of sources. PM results from direct emissions, but is also commonly formed when emissions of nitrogen oxides (NOx), sulfur oxides (SOx), ammonia, organic compounds, and other gases react in the atmosphere. Ozone is not directly emitted but is formed when NOx and volatile organic compounds (VOCs) react in the presence of sunlight (USEPA 2004).

EPA tracks trends in air quality based on actual measurements of pollutant concentrations in the ambient (outside) air at monitoring sites across the country. State, tribal, and local government agencies as well as some Federal agencies, including the EPA, operate monitoring stations. 
Air quality is important to military operations in non-attainment areas of EPA ambient air quality. The standards for the six criterion pollutants will have added restrictions on emissions from military operations. Gaining compliance for these regulations may cause financial strain on the DoD. Being located in a nonattainment zone is a strong indicator that the military may face restrictions on the amounts of certain emissions they can release (including mobility emissions) as part of the region's plan for coming into attainment. Information concerning what affects each criterion is available from the EPA at http://www.epa.gov. In summary, each criterion is vulnerable to change. Thus, the data should be updated regularly and the age of the data should be carefully noted in any analysis.

Additionally, the data reflects county level data where different values are reported for the same county in the same year in some cases. Thus, knowledge of the local area and its efforts need to be considered especially in large acreage counties.

Replicable: Each year EPA examines changes in levels of these ambient pollutants and their precursor emissions over time and summarizes the current air pollution status (USEPA 2005). The updates are available for download at: http://www.epa.gov/air/oaqps/greenbk/anay.html.

Directions: Download NonAttainment Status for Each County by Year for all U.S. counties from the EPA Green Book at http://www.epa.gov/air/oaqps/greenbk/anay.html (EPA 2005). Import the Classification data into a GIS program and join it with county boundary files to create a GIS air quality attainment status indicator layer.

Indicator Measure: Emission status indicates whether or not a U.S. County is in attainment of EPA air quality emission standards for the six criteria pollutants. The EPA designates a classification rating for each criteria depending on the nonattainment status - extreme, severe, serious, moderate, marginal, primary, subpart 1, and section 185A (USEPA 2005). Different values may be reported for the same county in the same year in some cases. In this case, the worst value is indicated (USEPA 2004).

The emission ratings were grouped into the following classifications.

Very Low Vulnerability

Low Vulnerability

Moderate Vulnerability

Vulnerable

High Vulnerability
(1): Attainment

(2): Primary, Section 185A, Subpart 1, Incomplete Data, Not Classified, and Other Violations

(3): Marginal and Moderate Violations

(4): Serious and Severe Violations

(5): Non-attainment and Extreme Violations 
Rules: Installations are often in two or more counties. Therefore, the region around an installation is classified by a weighted average. The weighted average calculation determines what percentage of the installation is in each county and multiplies that percentage for each county by that county's classification value. The values for each county are then totaled to arrive at a value for the region around the installation. This value is subjected to the same metric that determined the classification for the individual counties.

Example:

Indicator Value for the Region Around Installation = (Percentage of Installation in County $A^{*}$ Indicator Value for County A) + (Percentage of Installation in County $B^{*}$ Indicator Value for County B)...etc.

\section{Indicator: Noise Sensitivity (AQ2) \\ Variables: Environmental Noise Sensitivity \\ Scale: Installation \\ Year: $\quad 2000$ \\ Data Sources:}

U.S. Bureau of the Census, Department of Commerce. (2000). Incorporated Places /Census Designated Places. Compiled and edited by Geography Division. Washington, DC, available through URL: http://www.census.gov/geo/www/cob/pl2000.html

U.S. Department of the Army (DA). (2002). FY03 Army Well-Being Action Plan. Deputy Chief of Staff for Personnel. Washington, DC, available through URL: http://www.odcsper.army.mil/Directorates/wb/FY03 WBAP Vol 1.pdf

Logic: Lower noise levels will result in improved quality of life for both military personnel and the residents of the region surrounding military installations. Fewer noise problems helps to ensure that military personnel are well-trained, will remain in the military, and will be able to carry out missions with greater effectiveness and reduced losses. The training and testing capability impacts include loss of training hours, rescheduling training and testing, modifying training procedures, and the consequences of inadequate training. An effective and proactive noise management program greatly improves effective military operations as well as relations with the surrounding community (USDA 2002).

The U.S. military has articulated goals of: (1) protecting the ability of personnel to train as they fight by working to limit civilian encroachment into areas exposed to high levels of military noise; (2) protecting people who live near military training areas from unhealthy levels of noise from military operations; and (3) protecting military families. 
Every installation has its own style of keeping noise complaint logs, and there is no central repository-making it difficult to track noise complaints by installation. Noise researchers often generate noise contours surrounding a noise source to spatially represent noise levels (Westervelt 2004). A method similar to this is used to characterize noise sensitivity. Yet, this method may not easily be used to explore circumstance patterns. Missing from this data is the situational patterns that affect noise. For instance, topography, climate, community activity, and community value all impact noise-large mountains or buildings absorb sounds, high humidity slows the travel of sound, additional noises tend to go unnoticed or are "blocked-out" in high sound areas, social contexts react differently to differing sound types, etc. Therefore small noises may generate a big impact and large noises may generate no complaints depending on the surrounding environment. Because of these concerns, it is important to use local knowledge and applicable supplemental analysis in interpreting the noise sensitivity classifications for a particular environment.

Replicable: It is recognized that noise complaints have a direct relationship with population concentrations. Theoretically, noise complaints have a greater chance of occurring near civilian development. Any section of an installation located within or near a civilian population is considered sensitive or vulnerable to noise complaints. Therefore, this indicator may be updated every 10 years as the U.S. Census updates the Incorporated Places / Census Designated Places GIS compatible maps available online at http://www.census.gov/geo/www/cob/pl2000.html

Directions: Download Incorporated Places/Census Designated Places GIS compatible shapefile for all of the United States from the U.S. Census Bureau at http://www.census.gov/geo/www/cob/pl2000.html. Note, the U.S. Census makes no population requirements for incorporated or designated places-all populations are indicated within the shapefile. Make sure the average population per square mile is attached in the attribute table of each place. Import the data into a GIS program and create 3-mile buffers around all places. Join the place and buffer shapefiles with installation boundary files to create a GIS noise sensitivity indicator layer.

Indicator Measure: Because military installations are often of a significant size, what goes on within one area of the installation may not affect what goes on within another area. Thus, only the area of the installation located in or within 3 miles of an incorporated or designated place is classified as noise sensitive. As noted earlier, the size of the population affected also makes a difference. Therefore, the installation area in or within 3 miles of an incorporated or designated place is multiplied by the population per square mile of the specified place. The result is an estimated population affected by possible installation generated noise. The following vulnerability thresholds were defined under expert guidance from Army Corps of Engineers, Construction Engineering Research Laboratory (CERL). 
Very Low Vulnerability

Low Vulnerability

Moderate Vulnerability

Vulnerable

High Vulnerability
(1): $<=50,000$ affected persons

(2): $\quad>50,000-<=100,000$ affected persons

(3): $>100,000-<=150,000$ affected persons

(4): $\quad>150,000-<=200,000$ affected persons

(5): $>200,000$ affected persons

Rules: Installations are possibly located within 3 miles of two or more incorporated or designated places. Therefore, the estimated population sensitive to noise is calculated on each place and summed to establish a total estimated population sensitive to noise. The total estimated population sensitive to noise is then subject to the same metric noted above. 


\title{
Sustainability Issue: Airspace
}

\author{
Indicator: Proximity to Special Use Airspace, Fighter Range (AS1) \\ Variables: Warning Area, Military Operations Area, Restricted Area, and \\ Controlled Firing Area Special Use Airspace (SUA) \\ Scale: $\quad$ Installation \\ Year: $\quad 2005$ \\ Data Sources:
}

U.S. Air Force. (2005). Air Force Link. Factsheets: Aircraft. Washington, DC http://www.af.mil/factsheets/

Aircraft Owners and Pilots Association (AOPA) Air Safety Foundation. (2002). Safety Advisor, Regulation No. 1. Frederick, MD http://www.aopa.org/asf/publications/sa02.pdf

Digital Aeronautical Flight Information File (DAFIF), National Imagery and Mapping Agency. (2005). DAFIF Edition 6. Bethesda, MD

https://164.214.2.62/products/digitalaero/index.cfm

Logic: Airspace structure is complex. The Federal Aviation Administration regulates aircraft based on altitudes as well as through the development of special use airspace (SUA). SUAs were developed to advise pilots of an activity or surface area that dictates special rules or notices and may possibly be hazardous. There are five main types of SUAs (prohibited areas, restricted areas, warning areas, military operations areas, and alert areas) and several secondary types (national security areas, military training routes, air defense identification zones, controlled firing areas, local airport advisory areas, and parachute jump areas). Descriptions of commonly referred to SUAs follow (AOPA 2002).

Prohibited areas are established for security reasons or for national welfare. They are permanently "off limits." An example of a prohibited area is the White House, or Camp David.

Restricted areas, though not entirely prohibited to flight activity, are areas in which unauthorized penetration is not only illegal, but also extremely dangerous. Restricted areas generally contain operations that do not mix well with aircraft such as artillery firing, guided missiles, or aerial gunnery.

Warning areas are airspace over domestic or international water that extend beyond shore. Warning areas are advisory in nature and alert pilots that they may be entering areas of hazardous activity. 
Military operations areas (MOA) separate high-speed military traffic from other traffic. Although no one is prohibited from entering MOAs, they are cautioned to keep a watchful eye out for military operations such as aerial refueling, air combat training, and formation flying.

Alert areas are airspace in which an unusual type of aerial activity or dense pilot training takes place. They advise pilots of possible aerial conflicts, but have no special rules.

National security areas are established over areas that require increase security.

Military training routes are one-way high-speed routes for military traffic.

Controlled firing areas allow military activity such as artillery fire that is suspended when radar detects approaching aircraft.

SUAs primarily used by the military include warning areas, MOAs, restricted areas, and controlled firing areas. This indicator provides a measurement of special use airspace available to fighter aircraft. Availability is measured by the aircrafts unrefueling range as defined by the U.S. Air Force (Air Force 2005). Having available airspace is typically a necessity for military training. If access is inadequate, then it is a strong indicator of pressures on the future use and vulnerability of airspace, leading to greater demands and limitations on military development and missions. This would then place the military installation in a vulnerable state, affecting the type and intensity of training that could take place on the installation.

It is important to note that although this indicator describes availability of fighter aircraft training airspace, not all installations make use of training airspace. Ideally, installations are prepared for transformations to any mission. However, it may not be realistic. It is important to use local knowledge of an installation's current and future mission requirements when interpreting this indicator.

Replicable: This indicator could be replicated annually based on information updated in the DAFIF System (DAFIF 2005).

Directions: Download the SUA file from the DAFIF System at https://164.214.2.62/products/digitalaero/index.cfm (DAFIF 2005). This file includes boundary files for six SUA designations - warning (W), military operation (M), alert $(\mathrm{A})$, restricted $(\mathrm{R})$, prohibited $(\mathrm{P})$, controlled firing area, and national security $(\mathrm{T})$. Delete prohibited, alert, and national security SUAs for the purposes of this indicator. Import the remaining SUA boundary files into a GIS program to create a Proximity to Special Use Airspace, Fighter Range indicator layer. Create buffers at 35, 
70,105 , and 140 mile intervals around the SUAs to form vulnerability-rating classifications.

Indicator Measure: This indicator provides insight into an installation's fighter aircraft SUA access. Classifications were defined based on fighter aircraft capabilities as recommended by Air Force Headquarters (Air Force 2005).

Very Low Vulnerability

Low Vulnerability

Moderate Vulnerability

Vulnerable

High Vulnerability
(1): Within a designated SUA or Within 35 miles of a SUA

(2): Greater than 35 miles but Less than 70 miles of a SUA

(3): Greater than 70 miles but Less than 105 miles of a SUA

(4): Greater than 105 miles but Less than 140 miles of a SUA

(5): Greater than 140 miles of a SUA

Rules: Installations typically have only one SUA located within 35 to 140 miles. However, several installations do have two or more SUAs located within 35 to 140 miles. In this instance, the region around an installation takes on the SUA classification of the lowest vulnerability. For instance, if an installation has an SUA located within 35 miles and another SUA located within 105 miles, the region would be classified as very low vulnerability.

\section{Indicator: Proximity to Special Use Airspace, Bomber Range (AS2) \\ Variables: Warning Areas, Military Operations Areas, Restricted Areas, and Controlled Firing Area Special Use Airspace (SUA) \\ Scale: Installation \\ Year: $\quad 2005$ \\ Data Sources:}

U.S. Air Force. (2005). Air Force Link. Factsheets: Aircraft. Washington, DC, available through URL: http://www.af.mil/factsheets/

Aircraft Owners and Pilots Association (AOPA) Air Safety Foundation. (2002). Safety Advisor, Regulation No. 1. Frederick, MD, available through URL: http://www.aopa.org/asf/publications/sa02.pdf

Digital Aeronautical Flight Information File (DAFIF), National Imagery and Mapping Agency. (2005). DAFIF Edition 6. Bethesda, MD, available through URL: https://164.214.2.62/products/digitalaero/index.cfm.

Logic: Airspace structure is complex. The Federal Aviation Administration regulates aircraft based on altitudes as well as through the development of special use airspace (SUA). SUAs were developed to advise pilots of an activity or surface area that dictates special rules or notices and may possibly be hazardous. There are five 
main types of SUAs (prohibited areas, restricted areas, warning areas, military operations areas, and alert areas) and several secondary types (national security areas, military training routes, air defense identification zones, controlled firing areas, local airport advisory areas, and parachute jump areas). Descriptions of commonly referred to SUAs follow (AOPA 2002).

Prohibited areas are established for security reasons or for national welfare. They are permanently "off limits." An example of a prohibited area is the White House, or Camp David.

Restricted areas, though not entirely prohibited to flight activity, are areas in which unauthorized penetration is not only illegal, but also extremely dangerous. Restricted areas generally contain operations that do not mix well with aircraft such as artillery firing, guided missiles, or aerial gunnery.

Warning areas are airspace over domestic or international water that extend beyond shore. Warning areas are advisory in nature and alert pilots that they may be entering areas of hazardous activity.

Military operations areas (MOA) separate high-speed military traffic from other traffic. Although no one is prohibited from entering MOAs, they are cautioned to keep a watchful eye out for military operations such as aerial refueling, air combat training, and formation flying.

Alert areas are airspace in which an unusual type of aerial activity or dense pilot training takes place. They advise pilots of possible aerial conflicts, but have no special rules.

National security areas are established over areas that require increase security.

Military training routes are one-way high-speed routes for military traffic.

Controlled firing areas allow military activity such as artillery fire that is suspended when radar detects approaching aircraft.

SUAs primarily used by the military include warning areas, MOAs, restricted areas, and controlled firing areas. This indicator provides a measurement of special use airspace available to bomber aircraft. Availability is measured by the aircrafts unrefueling range as defined by the U.S. Air Force (Air Force 2005). Having available airspace is typically a necessity for military training. If access is inadequate, then it is a strong indicator of pressures on the future use and vulnerability of airspace, leading to greater demands and limitations on military development and missions. 
This would then place the military installation in a vulnerable state, affecting the type and intensity of training that could take place on the installation.

It is important to note that although this indicator describes availability of bomber aircraft training airspace, not all installations make use of training airspace. Ideally, installations are prepared for transformations to any mission. However, it may not be realistic. It is important to use local knowledge of an installation's current and future mission requirements when interpreting this indicator.

Replicable: This indicator could be replicated annually based on information updated in the DAFIF System (DAFIF 2005).

Directions: Download the SUA file from the DAFIF System (DAFIF 2005)at https://164.214.2.62/products/digitalaero/index.cfm. This file includes boundary files for six SUA designations - warning (W), military operation (M), alert (A), restricted $(\mathrm{R})$, prohibited $(\mathrm{P})$, controlled firing area, and national security $(\mathrm{T})$. Delete prohibited, alert, and national security SUAs for the purposes of this indicator. Import the remaining SUA boundary files into a GIS program to create a Proximity to Special Use Airspace, Bomber Range indicator layer. Create buffers at 70, 140, 210, and 280 mile intervals around the SUAs to form vulnerability-rating classifications.

Indicator Measure: This indicator provides insight into an installation's bomber aircraft SUA access. Classifications were defined based on bomber aircraft capabilities as recommended by Air Force Headquarters (Air Force 2005).

Very Low Vulnerability (1): Within a designated SUA or Within 70 miles of a SUA

Low Vulnerability (2): Greater than 70 miles but Less than 140 miles of a SUA

Moderate Vulnerability (3): Greater than 140 miles but Less than 210 miles of a SUA

Vulnerable

(4): Greater than 210 miles but Less than 280 miles of a SUA

High Vulnerability $\quad$ (5): Greater than 280 miles of a SUA

Rules: Installations typically have only one SUA located within 70 to 280 miles. However, several installations do have two or more SUAs located within 70 to 280 miles. In this instance, the region around an installation takes on the SUA classification of the lowest vulnerability. For instance, if an installation has an SUA located within 70 miles and another SUA located within 210 miles, the region would be classified as very low vulnerability. 


\section{Indicator: Terminal Airspace (AS3) \\ Variables: Terminal Airspace \\ Scale: Installation \\ Year: $\quad 2005$ \\ Data Source:}

Digital Aeronautical Flight Information File (DAFIF), National Imagery and Mapping Agency. (2005). DAFIF Edition 6. Bethesda, MD, available through URL: https://164.214.2.62/products/digitalaero/index.cfm

Logic: This indicator provides a measurement of the quantity of terminal airspace within 20 miles of a military installation. Terminal airspace is airspace in which approach-control service or airport traffic control service regulates all traffic. In addition to the burden of coordinating traffic routes with one or more traffic controller, terminal airspaces are increasingly experiencing congestion problems due to increased traffic demands induced, for example, by the deregulation of the air transport industry. Congestion problems may arise from arrival/departure overloads, frequency of en route aircraft, or simply inadequate coordination.

Having available airspace is typically a necessity for military shipments, mobilization, and training. Inadequate access places the installation in a vulnerable state, affecting mobilization or, possibly, the type and intensity of training that could take place. Therefore, terminal airspace is considered an important encroachment indicator.

Although travel through any terminal airspace requires approval, not all terminal airspaces will impose restrictions on an installations desired traffic route. Depending on the time and altitude of military aircraft as well as the time and altitude of airport operations, the two may rarely conflict. Thus, it is important to use local knowledge when interpreting the impact of terminal airspace.

Replicable: This indicator could be replicated annually based on information updated in the DAFIF System (DAFIF 2005).

Directions: Download the Airspace Boundary file from the DAFIF System at https://164.214.2.62/products/digitalaero/index.cfm (DAFIF 2005). This file includes boundary files for airspace designations. Import the terminal airspace boundary files into a GIS program. In the same GIS workspace, create 20-mile buffers around each installation. Intersect the terminal airspace boundaries with the installation buffers. Calculate the percentage of terminal airspace located within 20 miles of each installation. Use this percentage to form vulnerability-rating classifications. 
Indicator Measure: This indicator provides insight into an installation's airspace accessibility. It is assumed that an installation's proximity to terminal airspace may restrict military shipments, mobilization, and training. Classifications were defined based on statistical analysis of the standard deviation (23.06) around the national average (15.34 percent). 135 of the 402 installations analyzed had no terminal airspace within 20 miles of the installation.

Very Low Vulnerability

Low Vulnerability

Moderate Vulnerability

Vulnerable

High Vulnerability
(1): 0 percent Terminal Airspace within 20 miles of the installation boundary

(2): $>0-<=15.34$ percent TerminalAirspace within 20 miles of the installation boundary

(3): $>15.34-<=38.4$ percent Terminal Airspace within 20 miles of the installation boundary

(4): $>38.4-<=61.46$ percent Terminal Airspace within 20 miles of the installation boundary

(5): >61.46 percent Terminal Airspace within 20 miles of the installation boundary

Rules: Since this data is collected by installation, there is no calculation to determine installation risk ratings.

Indicator: Proximity to Military Training Routes, Fighter Range (AS4) Variables: Military Training Routes (MTR) Primary and Alternate Entry and Exit points

Scale: Installation

Year: $\quad 2005$

Data Sources:

U.S. Air Force. (2005). Air Force Link. Factsheets: Aircraft. Washington, DC, available through URL: http://www.af.mil/factsheets/

U.S. Air Force. (2005). Air Force Link. Factsheets: Low-Altitude Flying Training. Washington, DC, available through URL: http://www.af.mil/factsheets/factsheet.asp?fsID=183

Digital Aeronautical Flight Information File (DAFIF), National Imagery and Mapping Agency. (2005). DAFIF Edition 6. Bethesda, MD, available through URL: https://164.214.2.62/products/digitalaero/index.cfm

Logic: National security depends largely on the deterrent effect of our airborne military forces. To be proficient, the military services must train in a wide range of airborne tactics. One phase of this training involves "low level" combat tactics. The required maneuvers and high speeds are such that they may occasionally make the avoid aspect of flight more difficult without increased vigilance in areas containing such operations. In an effort to ensure the greatest practical level of safety for all flight operations, the Military Training Route (MTR) was conceived. 
The MTR program is a joint venture by the Federal Aviation Administration and the Department of Defense. MTRs are mutually developed for use by the military for the purpose of conducting low-altitude, high-speed training. Generally, MTRs are established below 10,000 ft (mean sea level) for operations at speeds in excess of 250 knots (Air Force 2005). However, route segments may be defined at higher altitudes for purposes of route continuity. For example, route segments may be defined for descent, climb-out, and mountainous terrain.

This indicator provides a measurement of MTR airspace available to fighter aircraft. Availability is measured by the aircrafts un-refueling range as defined by the U.S. Air Force (Air Force 2005). Having available airspace is typically a necessity for military training. Inadequate access is a strong indicator of limitations on military development and missions. This would then place the military installation in a vulnerable state, affecting the type and intensity of training that could take place on the installation.

It is important to note that although this indicator describes availability of fighter aircraft MTRs, not all installations make use of training airspace. Ideally, installations are prepared for transformations to any mission. However, it may not be realistic. It is important to use local knowledge of an installation's current and future mission requirements when interpreting this indicator.

Replicable: This indicator could be replicated annually based on information updated in the DAFIF System (DAFIF 2005).

Directions: Download the MTR: Routes, Polylines, Entry/Exit Points, and Points file from the DAFIF System at https://164.214.2.62/products/digitalaero/index.cfm (DAFIF 2005). Import all points designated as "A" Alternate Entry Point, "B" Alternate Exit Point, "C" Alternate Entry/Exit Point, "S" Primary Entry Point, and "X" Primary Exit Point for all kinds of flying routes ("VR" Visual Route, "IR" Instrument Route, and "SR" Slow Route) into a GIS program to create a Proximity to Military Training Routes, Fighter Range indicator layer. Create buffers at 35, 70, 105, and 140 mile intervals around all points to form vulnerability-rating classifications.

Indicator Measure: This indicator provides insight into an installation's fighter aircraft MTR access. Classifications were defined based on fighter aircraft capabilities as recommended by Air Force Headquarters (Air Force 2005).

Very Low Vulnerability (1): Within a designated MTR or Within 35 miles of a MTR

Low Vulnerability

(2): Greater than 35 miles but Less than 70 miles of a MTR 
Moderate Vulnerability

Vulnerable

High Vulnerability
(3): Greater than 70 miles but Less than 105 miles of a MTR

(4): Greater than 105 miles but Less than 140 miles of a MTR

(5): Greater than 140 miles of a MTR

Rules: Installations typically have only one MTR located within 35 to 140 miles. However, several installations do have two or more MTRs located within 35 to 140 miles. In this instance, the region around an installation takes on the MTR classification of the lowest vulnerability. For instance, if an installation has an MTR located within 35 miles and another MTR located within 105 miles, the region would be classified as very low vulnerability.

\section{Indicator: Proximity to Military Training Routes, Bomber Range (AS5) \\ Variables: Military Training Routes (MTR) Primary and Alternate Entry and Exit points \\ Scale: Installation \\ Year: 2005 \\ Data Sources:}

U.S. Air Force. (2005). Air Force Link. Factsheets: Aircraft. Washington, DC, available through URL: http://www.af.mil/factsheets/

U.S. Air Force. (2005). Air Force Link. Factsheets: Low-Altitude Flying Training. Washington, DC, available through URL: http://www.af.mil/factsheets/factsheet.asp?fsID=183

Digital Aeronautical Flight Information File (DAFIF), National Imagery and Mapping Agency. (2005). DAFIF Edition 6. Bethesda, MD, available through URL:

https://164.214.2.62/products/digitalaero/index.cfm

Logic: National security depends largely on the deterrent effect of our airborne military forces. To be proficient, the military services must train in a wide range of airborne tactics. One phase of this training involves "low level" combat tactics. The required maneuvers and high speeds are such that they may occasionally make the avoid aspect of flight more difficult without increased vigilance in areas containing such operations. In an effort to ensure the greatest practical level of safety for all flight operations, the Military Training Route (MTR) was conceived.

The MTR program is a joint venture by the Federal Aviation Administration and the Department of Defense. MTRs are mutually developed for use by the military for the purpose of conducting low-altitude, high-speed training. Generally, MTRs are established below 10,000 ft (mean sea level) for operations at speeds in excess of 250 knots (Air Force 2005). However, route segments may be defined at higher altitudes for purposes of route continuity. For example, route segments may be defined for descent, climb-out, and mountainous terrain. 
This indicator provides a measurement of MTR airspace available to bomber aircraft. Availability is measured by the aircrafts un-refueling range as defined by the U.S. Air Force (Air Force 2005). Having available airspace is typically a necessity for military training. Inadequate access is a strong indicator of greater demands and limitations on military development and missions. This would then place the military installation in a vulnerable state, affecting the type and intensity of training that could take place on the installation.

It is important to note that although this indicator describes availability of bomber aircraft MTRs, not all installations make use of training airspace. Ideally, installations are prepared for transformations to any mission. However, it may not be realistic. It is important to use local knowledge of installation's current and future mission requirements when interpreting this indicator.

Replicable: This indicator could be replicated annually based on information updated in the DAFIF System (DAFIF 2005).

Directions: Download the MTR: Routes, Polylines, entry/Exit Points, and Points file from the DAFIF System at https://164.214.2.62/products/digitalaero/index.cfm (DAFIF 2005). Import all "A" Alternate Entry Point, "B" Alternate Exit Point, "C" Alternate Entry/Exit Point, "S" Primary Entry Point, and "X" Primary Exit Point for all kinds of flying routes ("VR" Visual Route, "IR" Instrument Route, and "SR" Slow Route) into a GIS program to create a Proximity to Military Training Routes, Bomber Range indicator layer. Create buffers at 70, 140, 210, and 280 mile intervals around all points to form vulnerability-rating classifications.

Indicator Measure: This indicator provides insight into an installation's bomber aircraft MTR access. Classifications were defined based on bomber aircraft capabilities as recommended by Air Force Headquarters (Air Force 2005).

Very Low Vulnerability (1): Within a designated MTR or Within 70 miles of a MTR

Low Vulnerability

(2): Greater than 70 miles but Less than 140 miles of a MTR

Moderate Vulnerability

(3): Greater than 140 miles but Less than 210 miles of a MTR

Vulnerable

(4): Greater than 210 miles but Less than 280 miles of a MTR

High Vulnerability $\quad$ (5): Greater than 280 miles of a MTR

Rules: Installations typically have only one MTR located within 70 to 280 miles. However, several installations do have two or more MTRs located within 70 to 280 
miles. In this instance, the region around an installation takes on the MTR classification of the lowest vulnerability. For instance, if an installation has an MTR located within 70 miles and another MTR located within 210 miles, the region would be classified as very low vulnerability. 


\title{
Sustainability Issue: Energy
}

\author{
Indicator: Electrical Grid Congestion (EN1) \\ Variables: Number of Transmission Loading Relief (TLR) Procedures and Re- \\ gional Self-Assessments \\ Scale: $\quad$ NERC Regional Reliability Councils and Sub-Regions \\ Year: $\quad 2004$ \\ Data Sources:
}

North American Electric Reliability Council (NERC) (2004). Long-Term Reliability Assessment: The Reliability of Bulk Electric Systems in North America. Princeton, New Jersey, North American Electric Reliability Council: 88.

NERC TLR Trend Logs (2004) http://www.nerc.com/ filez/Logs/index.html

Logic: Portions of the transmission systems are reaching their limits as customer demand increases and the systems are subjected to new loading patterns resulting from increased power transfers caused by market conditions and weather patterns. Operating procedures, market-based congestion management procedures, and transmission loading relief procedures (TLRs) are used to control the flow on the system within operating reliability limits.

Some well-known transmission constraints are recurring and new constraints are appearing as electricity flow patterns change with installation generation capacity. The transmission system is being subjected to flows in magnitudes and directions that were not contemplated when it was designed or for which there is minimal operating experience. These new flow patterns result in an increasing number of facilities being identified as limits to transfers, and market-based congestion management procedures and TLR procedures are required in areas not previously subject to overloads to maintain the transmission facilities within operating limits.

In some areas, market operators employ locational marginal pricing (LMP) to effect a generation redispatch through economic incentives. In other areas of the Eastern Interconnection, reliability coordinators invoke NERC TLRs to maintain reliability by managing transactions within transmission operating reliability constraints. In effect, TLRs cause generation redispatch by restricting or curtailing scheduled transfers. As such, the number of TLRs is an indication of the grid reaching its capacity in a certain region. Since several other methods in addition to TLRs are used to control grid traffic and some regions do not report, NERC regional selfassessments also provide insight into the grid capacity and operation in the given regions and sub-regions. 
The current operating paradigm for almost all defense installations is to obtain their electrical power from the grid. Therefore, grid congestion is an indicator of potential shortfalls in power availability and price volatility in a given region.

Replicable: This indicator could be replicated every year based on information updated in annual NERC reliability assessments. TLR data is continuously reported and updated.

Directions: The TLR data for the last 2 years is averaged to provide a preliminary assessment. This assessment is further tempered and adjusted based on the regional self-assessments in the annual long-term report. Data is from trend analysis of TLR logs on the NERC web-site (http://www.nerc.com/ filez/Logs/index.html). There is no TLR data for the Western Electricity Coordinating Council, Alaska, or Hawaii. Simply import the final data into a GIS program with NERC boundary files to create an Electrical Grid Congestion indicator layer.

Indicator Measure: Electrical Grid Congestion ranges were defined as follows based on natural breaks and implications in the data. Where TLR data was not available or incomplete, regional self-assessment data was used to generate or amplify the rating.
Very Low Vulnerability
(1): $\quad<=50$ TLRs
Low Vulnerability
(2): Not Applicable
Moderate Vulnerability
(3): $>50-<=500$ TLRs
Vulnerable
(4): Not Applicable
High Vulnerability
(5): $\quad>500$ TLRs

Rules: Every installation is located primarily in one reliability region, although several installations may cross regional boundaries. An area around an installation takes on the classification of the region in which the installation is primarily located.

Table A1. Regional data.

\begin{tabular}{|l|l|l|}
\hline $\begin{array}{l}\text { Reliability Region/Sub } \\
\text { Region }\end{array}$ & TLRs & Encroachment Vulnerability Classification \\
\hline ECAR & 82.5 & Moderate (Michigan \& WV) \\
\hline ERCOT & Market & Moderate (Dallas, Houston, West Texas) \\
\hline FRCC & 0 & Low \\
\hline MAAC & 188 & Moderate \\
\hline MAIN & 47.5 & Moderate (Wisconsin and delayed upgrades) \\
\hline MAPP & 1000 & High (Twin Cities area and interties) \\
\hline NPCC/New England & 0 & Low \\
\hline NPCC/New York & 0 & Moderate (NYC and Long Island) \\
\hline
\end{tabular}




\begin{tabular}{|l|l|l|}
\hline $\begin{array}{l}\text { Reliability Region/Sub } \\
\text { Region }\end{array}$ & TLRs & Encroachment Vulnerability Classification \\
\hline SERC/Entergy & 65 & Moderate \\
\hline SERC/TVA & 51 & Moderate \\
\hline SERC/SoCo & 1 & Low \\
\hline SERC/VACAR & 4 & Low \\
\hline SPP & 193 & Moderate \\
\hline WECC/AZMNSV & & Moderate \\
\hline WECC/CA & & Moderate \\
\hline WECC/NWPP & & Low \\
\hline WECC/RMPA & & Low \\
\hline
\end{tabular}

Indicator: Electrical Grid Reserve Capacity in 2010 (EN2)

Variables: Capacity Margins (\% of Capacity Resources) Summer 2010

Scale:

Year: $\quad 2010$

\section{Data Source:}

North American Electric Reliability Council (NERC) (2005). Long-Term Reliability Assessment: The Reliability of Bulk Electric Systems in North America. Princeton, New Jersey, North American Electric Reliability Council: 88.

Logic: The Electrical Grid Reserve Capacity indicator shows the percentage of capacity margin for the NERC regions for the summer of 2010 . This indicator is important because it shows how well the region is planning to meet electrical demand growth in the future. Reduced capacity margins indicate the possibility of future electric shortages in a region in times of high electrical demand.

Replicable: This indicator could be replicated every year based on the annual updates in NERC reliability assessments.

Directions: There are no calculations for this indicator. Data is from tables in the periodic reliability report. There is no data for Alaska or Hawaii, only the continental United States Simply import the final data into a GIS program with NERC boundary files to create an Electrical Grid Reserve Capacity indicator layer.

Indicator Measure: Electrical Grid Reserve Capacity ranges were defined as follows based on natural breaks in the data.

Very Low Vulnerability

Low Vulnerability

Moderate Vulnerability

Vulnerable

High Vulnerability
(1): $>20-<=30$ percent margin

(2): $>17.5-<=20$ percent margin

(3): $>15-<=17.5$ percent margin

(4): $>12.5-<=15$ percent margin

(5): $\quad<=12.5$ percent margin 
Rules: Every installation is located primarily in one reliability region, although several installations may cross regional boundaries. The area around an installation takes on the rating of the NERC region where the installation is primarily located (area basis).

Table A2. NERC regional data.

\begin{tabular}{|l|c|l|}
\hline Reliability Region & Reserve Margin (\%) & Rating \\
\hline ECAR & 12.6 & Vulnerability \\
\hline ERCOT & 11.9 & High Vulnerability \\
\hline FRCC & 16.3 & Moderate Vulnerability \\
\hline MAAC & 13.0 & Vulnerable \\
\hline MAIN & 12.9 & Vulnerable \\
\hline MRO & 12.8 & Vulnerable \\
\hline NPCC & 11.9 & High Vulnerability \\
\hline SERC & 7.8 & High Vulnerability \\
\hline SPP & 13.0 & Vulnerable \\
\hline WECC & 20.7 & Very Low Vulnerability \\
\hline
\end{tabular}

\section{Indicator: Wind Resources (EN3)}

Variables: Wind Power Density

Scale: $\quad 1 / 4$ degree of latitude by $1 / 3$ degree of longitude Grid Cells

Year: $\quad 1986$

\section{Data Source:}

Pacific Northwest Laboratory (2003). Wind Energy Resource Atlas of the United States. U.S. Department of Energy, Washington, DC. Available online at: http://rredc.nrel.gov/wind/

Logic: The Wind Resource indicator provides wind power class classifications ranging from 1 to 6 , with 6 being the windiest. The assigned wind power class is representative of the range of wind power densities likely to occur at exposed sites within the grid cell. This indicator is important because it shows how well equipped the region is to provide renewable energy sources to meet future energy requirements once fossil fuel becomes unavailable or too expensive.

The wind resource assessment was based on surface wind data, coastal marine area data, and upper-air data, where applicable. In data-sparse areas, three qualitative indicators of wind speed or power were used when applicable: topographic/meteorological indicators (e.g., gorges, mountain summits, sheltered valleys); wind deformed vegetation; and eolian landforms (e.g., playas, sand dunes). The data was evaluated at a regional level to produce 12 regional wind resource assessments; the regional assessments were then incorporated into the national wind resource assessment. 
The conterminous United States was divided into grid cells 1/4 degree of latitude by 1/3 degree of longitude. Each grid cell was assigned a wind power class ranging from 1 to 6 . The wind power density limits for each wind power class is shown in the table below.

\begin{tabular}{|c|c|c|c|c|}
\hline \multirow{2}{*}{$\begin{array}{l}\text { Wind } \\
\text { Power } \\
\text { Class }^{*}\end{array}$} & \multicolumn{2}{|c|}{$10 \mathrm{~m}(33 \mathrm{ft})$} & \multicolumn{2}{|c|}{$50 \mathrm{~m}(164 \mathrm{ft})$} \\
\hline & $\begin{array}{c}\text { Wind Power Density } \\
\left(\mathrm{W} / \mathbf{m}^{2}\right)\end{array}$ & $\begin{array}{c}\text { Speed }^{(\mathbf{b})} \mathbf{m} / \mathbf{s} \\
(\mathrm{mph})\end{array}$ & $\begin{array}{c}\text { Wind Power Density } \\
\left(\mathrm{W} / \mathbf{m}^{2}\right)\end{array}$ & $\begin{array}{c}\text { Speed }^{(b)} \mathrm{m} / \mathrm{s} \\
(\mathrm{mph})\end{array}$ \\
\hline \multirow{2}{*}{1} & 0 & 0 & 0 & \\
\hline & 100 & $4.4(9.8)$ & 200 & $5.6(12.5)$ \\
\hline 2 & 150 & $5.1(11.5)$ & 300 & 6.4 (14.3) \\
\hline 3 & 200 & $5.6(12.5)$ & 400 & 7.0 (15.7) \\
\hline 4 & 250 & $6.0(13.4)$ & 500 & 7.5 (16.8) \\
\hline 5 & 300 & $6.4(14.3)$ & 600 & 8.0 (17.9) \\
\hline 6 & 400 & $7.0(15.7)$ & 800 & 8.8 (19.7) \\
\hline 7 & 1000 & $9.4(21.1)$ & 2000 & 11.9 (26.6) \\
\hline
\end{tabular}

Where possible, existing ground measurement stations are used to validate the model. The degree of certainty with which the wind power class can be specified depends on three factors: the abundance and quality of wind data; the complexity of the terrain; and the geographical variability of the resource. Hilltops, ridge crests, mountain summits, large clearings, and other locations free of local obstruction to the wind are expected to be well exposed to the wind. In contrast, locations in narrow valleys and canyons, downwind of hills or obstructions, or in forested or urban areas are likely to have poor wind exposure. A certainty rating was assigned to each grid cell based on these three factors, and is included in the Wind Energy Resource Atlas of the United States available online at: http://rredc.nrel.gov/wind/

Furthermore, it is also recognized that there are several additional alternative sources of energy such as solar and biomass. For regions that lack wind resources, these additional resources may be prevalent and ample to meet future energy requirements. Given these recognitions, local knowledge of the region and its additional resources needs to be taken in consideration.

Replicable: The Pacific Northwest Laboratory typically updates the data annually. However, it is dependent on changes in the data. It is recommended to contact the Laboratory to inquire about the latest available data.

Directions: There are no calculations for this indicator. Data is downloaded directly from the Pacific Northwest Laboratory website located at: http://rredc.nrel.gov/wind/. Simply import the data into a GIS program to create the 
Wind Resource indicator layer. Note, there is no data for Alaska or Hawaii-only the continental United States.

Indicator Measure: Areas designated class 4 or greater are suitable for most utility-scale wind turbine applications, whereas class 3 areas are marginal for utilityscale applications but may be suitable for rural applications. Class 2 and 1 areas are generally not suitable, although a few locations (e.g., exposed hilltops) with adequate wind resource for wind turbine applications may exist in some class 1 areas (Pacific Northwest Laboratory 2003). Therefore, it is important to use local knowledge to interpret wind power classifications. Wind Resource ranges were defined as follows based on Pacific Northwest Laboratory literature.

Very Low Vulnerability

Low Vulnerability

Moderate Vulnerability

Vulnerable

High Vulnerability
(1): Wind Power Class of 6

(2): Wind Power Class of 5

(3): Wind Power Class of 4

(4): Wind Power Class of 3

(5): Wind Power Class of 1 or 2

Rules: Every installation is located primarily in one grid cell, although several installations may cross cell boundaries. The area around an installation takes on the rating of the grid cell where the installation is primarily located (area basis).

\section{Indicator: Solar Resources (EN4) \\ Variables: Solar Resources for Flat Plate Collectors \\ Scale: $\quad 40 \mathrm{~km}$ by $40 \mathrm{~km}$ Grid Cells \\ Year: $\quad 1985-1992$ \\ Data Source:}

National Renewable Energy Laboratory (NREL) (2003). Climatologically Solar Radiation Model. U.S. Department of Energy, Washington, DC. Available online at: http://rredc.nrel.gov/solar/

Logic: The Solar Resource indicator is based on the monthly average daily total solar resource information on grid cells of approximately $40 \mathrm{~km}$ by $40 \mathrm{~km}$ in size. The insolation values represent the resource available to a flat plate collector, such as a photovoltaic panel, oriented due south at an angle from horizontal equal to the latitude of the collector location. This is typical practice for PV system installation, although other orientations are also used (NREL 2003). This indicator is important because it shows how well equipped the region is to provide renewable energy sources to meet increasing demand in the future. The availability of renewable energy in a region is an indicator of future sustainability once transition away from fossil fuels is required due to resource limitations and cost. 
Indicator data was developed from the Climatological Solar Radiation (CSR) Model. The CSR model was developed by the NREL for the U.S. Department of Energy. This model uses information on cloud cover, atmospheric water vapor and trace gases, and the amount of aerosols in the atmosphere, to calculate the monthly average daily total insolation (sun and sky) falling on a horizontal surface. The cloud cover data used as input to the CSR model are an 8-year histogram (1985 - 1992) of monthly average cloud fraction provided for grid cells of approximately $40 \mathrm{~km} \mathrm{x} 40$ $\mathrm{km}$ in size. Thus, the spatial resolution of the CSR model output is defined by this database. The data are obtained from the National Climatic Data Center in Asheville, North Carolina, and were developed from the U.S. Air Force Real Time Nephanalysis (RTNEPH) program. Atmospheric water vapor, trace gases, and aerosols are derived from a variety of sources, as summarized in the references.

Where possible, existing ground measurement stations are used to validate the model. Nevertheless, there is uncertainty associated with the meteorological input to the model, since some of the input parameters are not available at a $40 \mathrm{~km}$ resolution. As a result, it is believed that the modeled values are accurate to approximately 10 percent of a true measured value within the grid cell. Due to terrain effects and other microclimate influences, the local cloud cover can vary significantly even within a single grid cell. Furthermore, the uncertainty of the modeled estimates increases with distance from reliable measurement sources and with the complexity of the terrain.

It is also recognized that there are several additional alternative sources of energy such as wind and biomass. For regions that lack solar resources, these additional resources may be prevalent and available to meet future energy requirements. Therefore, local knowledge of the region and its additional resources needs to be taken in consideration.

Replicable: NREL typically updates the data annually. However, it is dependent on changes in the data. It is recommended to contact the Laboratory to inquire about the latest available data.

Directions: There are no calculations for this indicator. Data is downloaded directly from the NREL website located at http://rredc.nrel.gov/solar/. Simply import the data into a GIS program to create the Solar Resource indicator layer. Note, there is no data for Alaska or Hawaii, only the continental United States It is assumed that Hawaii is very low vulnerability and Alaska is high vulnerability.

Indicator Measure: Solar Resource ranges were defined by NREL (NREL 2003).

Very Low Vulnerability (1): >=7 insolation value 


$\begin{array}{ll}\text { Low Vulnerability } & (2):>=6-<7 \text { insolation value } \\ \text { Moderate Vulnerability } & (3):>=5-<6 \text { insolation value } \\ \text { Vulnerable } & (4):>=4-<5 \text { insolation value } \\ \text { High Vulnerability } & (5):<4 \text { insolation value }\end{array}$

Rules: Every installation is located primarily in one grid cell, although several installations may cross cell boundaries. The area around an installation takes on the rating of the grid cell where the installation is primarily located (area basis).

\section{Indicator: Biomass Resources (EN5) \\ Variables: Total Annual Biomass Available (in dry tons) at $\$ 30 /$ dry ton Scale: $\quad$ State \\ Year: $\quad 1999$ \\ Data Sources:}

Walsh, Mary (2000). Bioenergy Feedstock Development Program. Oak Ridge National Laboratory, U.S Department of Energy Washington, DC. Available online at: http://bioenergy.ornl.gov/resourcedata/index.html

The White House, Office of the Press Secretary (1999). Executive Order 13134, Developing and Promoting Biobased Products and Bioenergy. Washington, DC. Available online at http://ceq.eh.doe.gov/nepa/regs/eos/eo13134.html

Logic: Current biobased product and bioenergy technology has the potential to make renewable farm and forestry resources major sources of affordable electricity, fuel, chemicals, pharmaceuticals, and other materials. These technologies can create new markets for farm and forest waste products, new economic opportunities for underused land, and new value-added business opportunities. They also have the potential to reduce our Nation's dependence on foreign oil, improve air quality, water quality, and flood control, decrease erosion, and help minimize net production of greenhouse gases. Executive Order 13134 of 12 August 1999 set the goal to develop a comprehensive national strategy, including research, development, and private sector incentives, to stimulate the creation and early adoption of technologies needed to make biobased products and bioenergy cost-competitive in large national and international markets (USA 1999). This indicator is important in assuring an affordable supply of energy for today and the future to a military installation. Thus, available biomass resources serves as an energy sustainability indicator.

Since Executive Order 13134, interest in using biomass feedstocks to produce power, liquid fuels, and chemicals in the United States is increasing. Central to determining the potential for these industries to develop is an understanding of the location, quantities, and prices of biomass resources. This indicator contains estimates of biomass quantities potentially available in five categories: mill wastes, urban wastes, forest residues, agricultural residues, and energy crops, and at an an- 
ticipated delivered price of $\$ 30$ per dry ton. A presentation that explains how this information was used to support the goal of increasing biobased products and bioenergy three times by 2010 expressed in Executive Order 13134 is available at:

http://bioenergy.ornl.gov/resourcedata/index.html

Furthermore, it is also recognized that there are several additional alternative sources of energy such as solar and wind. For regions that lack biomass resources at an affordable rate, these additional resources may be highly prevalent and ample to meet increasing demand growth in the future. Given these recognitions, local knowledge of the region and its additional resources need to be taken in consideration.

Replicable: The Oak Ridge National Laboratory typically updates the data every 2 to 4 years. However, it is dependent on changes in the data. It is recommended to contact the Laboratory to inquire about the latest available data.

Directions: Download total dry tons delivered at or below $\$ 30$ per dry ton directly from the Oak Ridge National Laboratory website located at: http://bioenergy.ornl.gov/resourcedata/index.html

Simply import the data into a GIS program to create the Biomass Resource indicator layer. Note, there is no data for Alaska or Hawaii-only the continental United States.

Indicator Measure: Biomass resources are available at a delivered price ranging from $\$ 20$ to over $\$ 50$ per dry ton. Research conducted by the Oak Ridge National Laboratory reveals $\$ 30$ per dry ton or less is considered an affordable delivery price (Oak Ridge National Laboratory 2000). Therefore, total dry tons delivered at or below $\$ 30$ per dry ton were used to classify biomass resource availability.

The quantity of biomass resources delivered per state was divided by its respective state area (square miles) resulting in available biomass resources by state per square mile. This distributes the data by area. Distributing the data by area allows for an equal comparison between large and small-area states. In other words, it protects against a small-area state from a more vulnerable classification because it naturally has less resources compared to a large-area state. Biomass Resources per square mile were statistically classified based on the mean (50.6) and standard deviation (39.6) values. Using this logic, the following classifications were defined.

Very Low Vulnerability (1): $>60$ tons per square mile

Low Vulnerability $\quad(2): \quad>50-<=60$ tons per square mile

Moderate Vulnerability (3): $>40-<=50$ tons per square mile 
Vulnerable

High Vulnerability
(4): $>30-<=40$ tons per square mile

(5): $\quad<=30$ tons per square mile

Rules: Every installation is located primarily in one state, although several installations do cross state boundaries. A region takes on the rating of the state the nearby installation is primarily located within.

\section{Indicator: Electrical Price Structure (Deregulation) (EN6) \\ Variables: Electric Utility Deregulation Status \\ Scale: State \\ Year: $\quad 2003$ \\ Data Source:}

Energy Information Administration, U.S. Department of Energy. (2003). Status of State Electric Industry Restructuring Activity. Office of Electricity. Washington, DC. http://www.eia.doe.gov/cneaf/electricity/chg str/regmap.html

Logic: The price structure for electricity demand and delivery indicates whether the commodity has been deregulated and is thus more susceptible to market distortion such as price instability and availability fluctuations (EIA 2003). Deregulation of electrical markets in the United States is still very much a "work in progress," and the market has not normalized. This indicator will affect the availability and price of electricity to a military installation, and is thus highly sought after as an energy sustainability indicator. Also, utilities in states that have been deregulated have not made the needed investments into the grid because return on investment is ill defined and thus these are more susceptible to outages as seen in the August 2003 blackout. Virtually all areas affected by the blackout were in deregulated markets.

Replicable: This indicator could be replicated every year based on events that occur from states that are in the process of going to electric industry restructuring. February 2003 was the last update made by the EIA.

Directions: The EIA website for electric utility deregulation can be found at URL: http://www.eia.doe.gov/cneaf/electricity/chg str/regmap.html, which contains a map showing the states that: (1) have active deregulation, (2) have deregulation activity delayed/suspended, and (3) have no deregulation activity (EIA 2003). Details on the deregulation status of each state can be found by clicking on the desired state on the map located on the EIA website listed above. Download this data. Import it into a GIS program and join it with state boundary files to create an Electrical Price Structure indicator layer. 
Indicator Measure: Electrical Price Structure classifications were defined as follows based on the definitions of the EIA (EIA 2003).

$\begin{array}{ll}\text { Very Low Vulnerability } & (1) \text { N } \text { No Regulation } \\ \text { Low Vulnerability } & (2) \text { N } \text { Not Applicable } \\ \text { Moderate Vulnerability } & \text { (3): Delayed/suspended } \\ \text { Vulnerable } & \text { (4): Not Applicable } \\ \text { High Vulnerability } & \text { (5): Active }\end{array}$

Rules: Every installation is located primarily in one state, although several installations do cross state boundaries. The area surrounding an installation takes on the classification of the state the installation is primarily located within.

\section{Indicator: Net Metering (EN7) \\ Variables: Net Metering Actions \\ Scale: State \\ Year: $\quad 2003$ \\ Data Source:}

Database of State Incentives for Renewable Energy (DSIRE). (2004). Green Power Network. Interstate Renewable Energy Council, U.S. Department of Energy. North Carolina State University Solar Center. (Summary of State Net Metering Programs; Map of Net Metering Programs).

http://www.dsireusa.org/ http://www.eere.energy.gov/greenpower/pdfs/metering 0603.pdf http://www.eere.energy.gov/greenpower/resources/maps/netmetering map.shtml)

Logic: The availability of net metering indicates whether a state allows non-energy producers, such as consumers, to sell excess electrical energy produced onsite back to the grid at the local rate. The implications of this indicator are whether or not the state is progressive in its approach to integrated resource planning and management. A progressive approach ensures electricity availability and security in the future, while other approaches may not. The use of distributed generation adds to the robustness of the grid and its overall reliability (DSIRE 2004).

Replicable: This indicator could be replicated every year based on updated actions by states that do not currently have net metering regulations.

Directions: Determine if each state participates in net metering using the Green Power Network website:

http://www.eere.energy.gov/greenpower/pdfs/metering 0603.pdf

Determine if enactments for net metering regulations are either (a) complete, (b) underway, or (c) not considered for action. If enactments are complete, specify the 
year in which the state net metering rules are implemented (DSIRE 2004). Download the data into a GIS program and join it to state boundary files to create a Net Metering indicator layer.

Indicator Measure: Net Metering classifications were defined as follows based on information provided by the DSIRE (DSIRE 2004).

Very Low Vulnerability (1): “Complete” (State-Wide Net Metering)

Low Vulnerability $\quad$ (2): Not Applicable

Moderate Vulnerability (3): “Underway" (Only Selected Utilities)

Vulnerable

(4): Not Applicable

High Vulnerability

(5): "No Action" (No Net Metering)

Rules: Every installation is located primarily in one state, although several installations do cross state boundaries. The region around an installation takes on the classification of the state the installation is primarily located within. 


\title{
Sustainability Issue: Urban Development
}

\author{
Indicator: Regional Population Density (UD1) \\ Variables: Population, Land Area (square mile) \\ Scale: $\quad$ County \\ Year: $\quad 2004$ \\ Data Sources:
}

Bureau of the Census, U.S. Department of Commerce. (2004). County Population Estimates and Estimated Components of Change, April 1, 2000 to July 1, 2004. Population Estimates Program. Washington, DC. http://eire.census.gov/popest/estimates dataset.php

Bureau of the Census, U.S. Department of Commerce. (2000). Summary File 1: GCT-PH1-R Population, Housing Units, Area, and Density. American FactFinder. Washington, DC. http://factfinder.census.gov

Craig, John. (1984). “Averaging Population Density.” Demography, 21(3), pp.405-412. http://www.jstor.org/

Logic: This indicator provides a measure of the population density of all counties in the United States. A high population density in the region surrounding an installation is a strong indicator of potential encroachment issues. This can affect the type and intensity of training that can take place on an installation.

Population density is a commonly quoted statistic. Almost no general descriptive summary of the population of an area is complete without a density listing, table, or map. As each such density statistic is an average, it is worth considering what kind of average is being used (Craig 1984). Additionally, it is important to note that this data is on the county level, not community or installation. Hence, it may be skewed by local "hotspots." In other words, if a county has one community with relatively high regional population density, the entire county data is skewed by that density and may be classified as high regional population density regardless of the characteristics of the remaining majority of the county. Because of these concerns, it is important to use local knowledge in interpreting the regional population density classifications.

Replicable: This indicator could be replicated every year based on Census population estimates, or every decade based on actual, verifiable counts.

Directions: Download county population from the Bureau of the Census (2004) website, County Population Estimates and Estimated Components of Change, April 1, 2000 to July 1, 2004 at URL: http://eire.census.gov/popest/estimates dataset.php. 
Download land area from Summary File 1: GCT-PH1-R Population, Housing Units, Area, and Density of the 2000 U.S. Census at http://factfinder.census.gov (Bureau of the Census 2000). Divide the total population for each county in the United States by the land area (not total area, which includes water bodies) in that county to reach a population density figure.

Regional Population Density $=$ total population / land area

Import the resulting math into a GIS program and join it with county boundary files to create a GIS Regional Population Density indicator layer.

Indicator Measure: The average population density for the entire United States is 79.6 people per square mile according to the 2000 U.S. Census. The mean density for U.S. counties is 267 people per square mile. The results were then subjected to a normal statistical distribution (19\%/62\%/19\%) to determine vulnerability classifications.

Very Low Vulnerability $\quad(1): \quad<6$ people per square mile

Low Vulnerability $\quad(2): \quad>=6-<12$ people per square mile

Moderate Vulnerability (3): $\quad>=12-<247$ people per square mile

Vulnerable $\quad(4): \quad>=247-<2,000$ people per square mile

High Vulnerability $\quad(5): \quad>=2,000$ people per square mile

Rules: Installations are often in two or more counties. Therefore, the region around an installation is classified by a weighted average. The weighted average calculation determines what percentage of the installation is in each county and multiplies that percentage for each county by that county's classification value. The values for each county are then totaled to arrive at a value for the region around the installation. This value is subjected to the same metric that determined the classification for the individual counties.

Example:

Indicator Value for the Region Around Installation $=($ Percentage of Installation in County $A^{*}$ Indicator Value for County A) + (Percentage of Installation in County $B^{*}$ Indicator Value for County B)...etc.

\section{Indicator: Increasing Regional Growth Rate (UD2) \\ Variables: Total Population 1995, 2000, and 2004 \\ Scale: County \\ Year: $\quad 2004$}




\section{Data Sources:}

Bureau of the Census, U.S. Department of Commerce. (2004). Intercensal State and County Characteristics Population Estimates with 1990-Base Race Groups. Population Division. Washington, DC. http://eire.census.gov/popest/estimates dataset.php

Bureau of the Census, U.S. Department of Commerce. (2004). County Population Estimates and Estimated Components of Change, April 1, 2000 to July 1, 2004. Population Estimates Program. Washington, DC. http://eire.census.gov/popest/estimates dataset.php

Logic: An increasing regional growth rate is a strong indicator of increased population pressures in the future, leading to greater demands for services, access, resources, and land in competition with the military installation. This can affect the type and intensity of training that can take place on the installation.

Additionally, it is important to note this data is on the county level, not community or installation. Hence, it may be skewed by local "hotspots." In other words, if a county has one community with relatively high regional growth rates, the entire county is classified as high regional growth regardless of the characteristics of the remaining majority of the county. Because of this concern, it is important to use local knowledge in interpreting the increasing regional growth rate classifications.

Replicable: This indicator could be replicated every year based on Census population estimates, or every decade based on actual, verifiable counts.

Directions: Download population for all U.S. counties for 1995 and 2000 from the Intercensal State and County Characteristics Population Estimates with 1990-Base Race Groups database maintained by the U.S. Census Bureau (Bureau of the Census 2004). Sum total population per county. Download populations for all U.S. counties for 2004 from the County Population Estimates and Estimated Components of Change, April 1, 2000 to July 1, 2004 database maintained by the U.S. Census Bureau (Bureau of the Census 2004). Compare the population growth rate from 1995 to 2000 with the growth rate from 2000 to 2004 . The increasing regional growth rate calculation used is as follows.

Increasing Regional Growth Rate = (Population Growth Rate from 2000 to 2004) (Population Growth Rate from 1995 to 2000)

Population Growth Rate from 2000 to $2004=$ [(Population $2004-$ Population 2000)/ Population 2000] *100

Population Growth Rate from 1995 to $2000=$ [(Population $2000-$ Population 1995)/ Population 1995] *100 
Import the resulting math into a GIS program and join it with county boundary files to create a GIS Increasing Regional Growth Rate indicator layer.

Indicator Measure: Increasing Regional Growth Rate is a measure of how fast a county is growing in the past 5 years compared with data from the previous 5 years. The population growth rate from 2000 to 2004 is compared with the growth rate from 1995 to 2000 . This data is available from the U.S. Census at

\section{http://eire.census.gov/popest/estimates dataset.php}

(Bureau of the Census 2004). The data illustrates a county average increasing growth rate of 3.13 percent. Range classifications were based on natural breaks.

Very Low Vulnerability

Low Vulnerability

Moderate Vulnerability

Vulnerable

High Vulnerability
(1): $<=-10$ percent change in population growth rate

(2): $>-10-<=0$ percent change in population growth rate

(3): $>0-<=5$ percent change in population growth rate

(4): $>5-<=10$ percent change in population growth rate

(5): >10 percent change in population growth rate

In random instances, the U.S. Census Bureau does not report population estimates for select counties. These instances are rare but do occur. Additionally, county boundaries are subject to change. Again, occurrence is rare but does occur. Drastic changes in population could reflect a division or merge of 1 or more counties.

Rules: Installations are often in two or more counties. Therefore, installation classifications are determined by a weighted average. The weighted average calculation determines what percentage of the installation is in each county and multiplies that percentage for each county by that county's classification value. Those values for each county of the installation are then totaled to arrive at a value for the region around an installation. This value is subjected to the same ranking metric that determined the classifications for the individual counties.

Example:

Indicator Value for the Installation $=\left(\right.$ Percentage of Installation in County $A^{*}$ Indicator Value for County $A)+\left(\right.$ Percentage of Installation in County $B^{*}$ Indicator Value for County B)...etc.

\section{Indicator: Regional Population Growth (UD3) Variables: Total Population 1995 and 2004 Scale: $\quad$ County Year: 2004}




\section{Data Sources:}

Bureau of the Census, U.S. Department of Commerce. (2004). Intercensal State and County Characteristics Population Estimates with 1990-Base Race Groups. Population Division. Washington, DC. http://eire.census.gov/popest/estimates dataset.php

Bureau of the Census, U.S. Department of Commerce. (2004). County Population Estimates and Estimated Components of Change, April 1, 2000 to July 1, 2004. Population Estimates Program. Washington, DC. http://eire.census.gov/popest/estimates dataset.php

Logic: This indicator measures the population growth over the last decade of every county in the United States. Population growth is one of the leading causes of environmental degradation, because more people use more resources including water, energy, and waste disposal, and other problems. This indicator assumes that fast growing human populations are less sustainable.

The degree of regional population growth is a strong indicator of the demand for services, access, resources, and land in competition with the military installation. This can affect the type and intensity of training that can take place on the installation. This indicator was calculated based on population data from the U.S. Census Bureau.

Additionally, it is important to note this data is on the county level, not community or installation. Hence, it may be skewed by local "hotspots." In other words, if a county has one community with relatively high regional population growth, the entire county is classified as high regional population growth regardless of the characteristics of the remaining majority of the county. Because of this concern, it is important to use local knowledge in interpreting the regional population growth classifications.

Replicable: This indicator could be replicated every year based on Census population estimates, or every decade based on actual, verifiable counts.

Directions: Download population for all U.S. counties for 1995 from the Intercensal State and County Characteristics Population Estimates with 1990-Base Race Groups database maintained by the U.S. Census Bureau (Bureau of the Census 2004). Sum total population per county. Download populations for all U.S. counties for 2004 from the County Population Estimates and Estimated Components of Change, April 1, 2000 to July 1, 2004 database maintained by the U.S. Census Bureau (Bureau of the Census 2004). Given the total population for each county in the United States for 1995 and 2004, the population growth rate from 1995 to 2004 was calculated as follows. 
Regional Growth Rate $=[($ Population $2004-$ Population 1995)/Population 1995]*100

Import the resulting math into a GIS program and join it with county boundary files to create a GIS Regional Growth Rate indicator layer.

Indicator Measure: Regional Growth Rate is a measure of how fast a county has grown during the previous decade. The population growth rate is measured from 1995 to 2004. This data is available from the Bureau of the Census (2004) at URL: http://eire.census.gov/popest/estimates dataset.php

The data illustrates a county average growth rate of 8.5 percent. The results were statistically classified based on the mean (8.5) and standard deviation (56.3) values.

Very Low Vulnerability

Low Vulnerability

Moderate Vulnerability

Vulnerable

High Vulnerability
(1): $<=0$ percent Population Growth

(2): $>0-<=8.5$ percent Population Growth

(3): $>8.5-<=22.5$ percent Population Growth

(4): $>22.5-<=36.5$ percent Population Growth

(5): $>36.5$ percent Population Growth

In random instances, the U.S. Census Bureau does not report population estimates for select counties. These instances are rare but do occur. Additionally, county boundaries are subject to change. Again, occurrence is rare but does occur. Drastic changes in population could reflect a division or merge of 1 or more counties.

Rules: Installations are often in two or more counties. Therefore, installation classifications are determined by a weighted average. The weighted average calculation determines what percentage of the installation is in each county and multiplies that percentage for each county by that county's classification value. Those values for each county of the installation are then totaled to arrive at a value for the region around an installation. This value is subjected to the same ranking that determined the ratings for the individual counties.

Example:

Indicator Value for the Installation $=\left(\right.$ Percentage of Installation in County $A^{*}$ Indicator Value for County $A)+\left(\right.$ Percentage of Installation in County $B^{*}$ Indicator Value for County B)...etc.

\section{Indicator: Regional Land Urbanization (UD4) Variable: Urbanized Land Area, Total Land Area Scale: $\quad$ Installation (30 Meter Cells) Year: $\quad 1992$}




\section{Data Source:}

U.S. Geological Survey Bureau (USGS), U.S. Department of the Interior. (1992). Land Cover Characterization Program. Reston, VA. (National Land Cover/MRLC). http://landcover.usgs.gov

Logic: This indicator provides a measure (in percent) of land urbanization within a 20-mile boundary surrounding the installation. The indicator value is found by dividing the amount of urbanized land by the total land area surrounding a given installation.

The degree of regional development is a strong indicator of potential encroachment problems that can affect the type and intensity of training that can take place on the installation.

Replicable: This indicator calculation was performed with GIS using the National Land Cover Characterization data available from the USGS online at http://landcover.usgs.gov (USGS 1992). This website provides more about the data and the USGS's program for land characterization. Overall, the data set describes land use for the entire United States, for a 1992 timeframe, by 60 land use and vegetation types (USGS 1992). Currently only 1992 data is available, but the USGS is in the process of making 2000 Land Cover data available on the USGS website. It is recommended that this indicator be updated as new data is available.

Directions: Download land coverages for each state from the USGS Internet site through URL:

http://landcover.usgs.gov

or more directly from:

http://edcww.cr.usgs.gov/pub/data/landcover/states

in a geotiff format (USGS 1992). Convert these tiff image files to raster data.

Once the data is in a grid/raster format, the only information needed for the regional land urbanization analysis for risk assessment is developed land; all other land covers are irrelevant for this task. Thus to simplify processing, reduce storage requirements, and minimize display and processing times, reclassify the dataset to display urban or non-urban land. Classify cells originally labeled as attribute 21, 22 , or 23 as urban (reclassify values to 1 ) and all other land covers (any other attribute value) as non-urban (reclassify values to 0 ).

Next, using the ArcGIS buffer wizard, create 20 -mile buffers around each military installation. Finally, tabulate the percentage of urban and non-urban land areas 
within each 20-mile buffer. With the data simplified to two classifications ( $1=$ urban and $0=$ non-urban) and a polygon file with the appropriate buffers for each installation, the ratio of urbanized land surrounding each installation was determined as follows.

Urbanization Ratio = value-1 area/(value -1 area + value -0 area $)$.

Indicator Measure: Regional Land Urbanization classifications are defined by the percent of land urbanization within a 20 -mile boundary surrounding the installation. This value is found by dividing urbanized land by the total land area. The classifications were defined by natural breaks in the data as follows.

Very Low Vulnerability $\quad$ (1): <=29 percent Urbanized

Low Vulnerability

(2): Not Applicable

Moderate Vulnerability

(3): $>29-<=35$ percent Urbanized

Vulnerable

(4): Not Applicable

High Vulnerability

(5): >35 percent Urbanized

Rules: Since this data is collected by installation, there is no calculation to determine installation risk ratings.

\section{Indicator: State Smart Growth Plans (UD5) \\ Variables: Presence of State Smart Growth Plan \\ Scale: State \\ Year: $\quad 2002$ \\ Data Source:}

American Planning Association (APA). (2002). Planning for Smart Growth: 2002 State of the States. Smart Growth Network. Chicago, IL, available through URL:

http://www.planning.org/growingsmart/states2002.htm

Logic: This indicator shows the status of State Smart Growth Initiatives across the United States. Smart growth is the planning, design, development, and revitalization of cities, towns, suburbs, and rural areas to create and promote social equity, a sense of place and community, as well as to preserve natural and cultural resources. Smart growth enhances ecological integrity over both the short- and long-term, and improves quality of life for all by expanding - in a fiscally responsible manner-the range of transportation, employment, and housing choices available to a region (APA 2002).

The presence of a state smart growth plan is important because smart growth legislation can reduce sprawl and decrease the growth of urbanized land surrounding a military installation. The potential encroachment caused by sprawl and urban de- 
velopment can affect the type and intensity of training that can take place on the installation.

However, this indicator does not indicate whether or not the initiatives were successful. Typically, state smart growth initiatives have positive results, yet there is never a guarantee. Additionally, APA monitors smart growth initiatives at a state level. Local communities may have established local smart growth initiatives, yet here they are rated as high vulnerability because of the state's status. Therefore, it is critical to use local knowledge in interpreting smart growth initiatives classifications.

Replicable: This indicator could be replicated regularly as long as the APA continues to monitor Smart Growth (which is likely considering that one of the main tenants of the APA currently is to get smart growth passed in every state). It is recommended that this indicator be updated annually. 2002 was the last update made by the APA.

Directions: APA constructed a map to chart the progress of smart growth reform. That map is available through URL:

http://www.planning.org/growingsmart/states2002.htm

and was synthesized to create the map and scale used for this indicator (APA 2002). Download the map data, import it into a GIS program, and join it with state boundary files to create a GIS State Smart Growth Plans indicator layer.

Indicator Measure: Substantial Reforms means that smart growth legislation has been passed in the state. Moderate reforms or pursuing additional reforms means that some form of land use laws resembling smart growth have been passed or legislation has been proposed. No reforms mean that no legislation has been passed or proposed (APA 2002).

Very Low Vulnerability

(1): Substantial Reforms

Low Vulnerability

(2): Not Applicable

Moderate Vulnerability

(3): Moderate Reforms or Pursuing

Vulnerable

(4): Not Applicable

High Vulnerability

(5): No Reforms

Rules: Every installation is located primarily in one state, although several installations do cross state boundaries. The region around an installation takes on the rating of the state in which the installation is primarily located. 


\section{Indicator: Joint Land Use Study (JLUS) (UD6) \\ Variables: JLUS Program Participation \\ Scale: \\ Year: \\ Installation \\ 1985-2003 \\ Data Sources:}

Joint Land Use Study Assistance Grant, Title 10 U.S. C. Section 2391 (1985).

Office of Economic Adjustment (OEA), U.S. Department of Defense. (2003). Joint Land Use Study

Program. Washington, DC, available through URLs:

http://www.nga.org/cda/files/1002LANDUSESUMMARY.pdf

http://www.ngms.state.ms.us/cfmo/joint land.html

Logic: Military operations can be loud and present safety concerns for nearby civilian communities. For example, low flying, high performance, military aircraft, create both noise and accident potential during landings, take-off, and training exercises. Likewise, ground-training exercises (e.g., artillery firing ranges, maneuver areas, and aerial bombing ranges) generate impact noise that can adversely affect the surrounding community if the civilian population chooses to locate too close. Conversely, civilian activities located adjacent to active military bases can impair the operational effectiveness, training, and readiness of the installations' mission (OEA 2003). In other words, urban encroachment near a military base, if allowed to go unregulated, can compromise the utility and effectiveness of the installation and its mission. Thus, in the mid-1970s, the Department of Defense (DoD) established the Air Installation Compatible Use Zone (AICUZ) and the Environmental Noise Management Program (ENMP) in response to existing and potential threats of incompatible land development compromising the defense missions at military installation (OEA 2003). The programs include noise propagation studies of military activities to delineate on- and off-base areas most likely to be affected by unacceptable noise levels. The programs also identify aircraft landing and take-off accident potential zones that often extend off a base into the neighboring community (OEA 2003).

Since then, Congress authorized the DoD to make community planning assistance grants ("Joint Land Use Study Assistance Grant," 1985) to state and local governments to help better understand and incorporate the AICUZ/ENMP technical data into local planning programs (OEA 2003). This is done in the form of a Joint Land Use Study (JLUS). The OEA manages the JLUS program. A JLUS is a cooperative land use planning effort between affected local government and the military installation. The recommendations present a rationale and justification, and provide a policy framework to support adoption and implementation of compatible development measures designed to prevent urban encroachment; safeguard the military mission; and protect the public health, safety, and welfare (OEA 2003). 
The presence of a JLUS indicates an effort between the local community and the military installation to work together. Thus, any form of a JLUS is viewed as a positive. Whether the installation has completed a JLUS, begun a JLUS, or is simply receiving technical assistance, the installation is classified as "very low vulnerability." If no effort is shown toward completing a JLUS, the installation is classified as "high vulnerability." However, this puts some limitations on the data. First, the classifications do not indicate whether or not the JLUS was successful. The local community and military installation may never have agreed on a future course of action and the result was less compatibility than before the JLUS. Typically all JLUS have positive results, yet there is never a guarantee. Second, and more critical, installations not near urban development have no need to perform a JLUS, yet they are rated as "high vulnerability" because they have not completed or pursued a JLUS. Thus, it is critical to read this data along with an understanding of the installation's proximity to Metropolitan Statistical Areas and other Urban Development sustainability issues. Any user of this data must have local knowledge to interpret the JLUS classifications.

Replicable: This indicator could be replicated every year based on material printed by the DoD, OEA concerning the JLUS program. The same material is often published on the DoD, OEA website. (2003 was the last update made by the OEA.) Current data may be found through URL:

http://www.ngms.state.ms.us/cfmo/joint land.html

Directions: OEA JLUS constructs a map to chart the progress of JLUSs. That map is available from the OEA JLUS program and updated periodically (OEA 2003). The data from the map was synthesized to create the map and scale used for this indicator. Download the map data, import it into a GIS program, and join it with the installation boundary files to create a GIS JLUS indicator layer.

Indicator Measure: The JLUS program identifies military installations where JLUS have been "completed," "underway," and where "technical assistance" has been given. Any installation with one of these characterizations was classified as very low vulnerability. All other installations were classified as high vulnerability. It is assumed that if a JLUS has been completed, is underway, or is expected to occur on a military installation, then the installation is concerned about land use compatibility and therefore received a "higher" rating. However, there are concerns in this logic with the success of the JLUS and the relative need for such a study to be made (refer to the section labeled "Logic" of this report). The following risk classifications were defined for JLUS. 
Very Low Vulnerability

Low Vulnerability

Moderate Vulnerability

Vulnerable

High Vulnerability
(1): JLUS Completed, Underway, or Technical Assistance

(2): Not Applicable

(3): Not Applicable

(4): Not Applicable

(5): JLUS Not Completed, Underway, or no Technical Assistance

Overall, there are 33 installations that have completed a JLUS, 34 with a JLUS underway, and four installations receiving technical assistance.

Rules: Since this data is collected by installation, there is no calculation to determine installation classification.

\section{Indicator: Proximity to Metropolitan Statistical Areas (MSA) (UD7) Variables: MSA, Mile Buffers \\ Scale: Installation \\ Year: $\quad 2000$ \\ Data Source:}

Bureau of the Census, U.S. Department of Commerce. (2000). About Metropolitan and Micropolitan Statistical Areas. Office of Management and Budget. Washington, DC, available through URL:

http://www.census.gov/population/www/estimates/aboutmetro.html

Logic: This indicator shows the proximity of Military installations to Metropolitan Statistical Areas (MSA), which indicates the potential for encroachment on military facilities. MSAs are a geographic entity designated by the Federal Office of Management and Budget for use by Federal statistical agencies (Bureau of the Census 2000). An MSA consists of one or more counties, except in New England, where MSAs are defined in terms of county subdivisions (primarily cities and towns) (Bureau of the Census 2000). Encroachment is a strong indicator of pressures on the future use and vulnerability of military installations. Encroachment places the military installation in a vulnerable state, affecting the type and intensity of training that could take place on the installation due to greater demands and limitations on military developments.

Replicable: This indicator could be replicated every year based on Census population estimates or every decade based on actual, verifiable counts. It is recommended that the data be replicated only once a decade due to the inaccuracy of census estimates. The GIS compatible layer containing MSAs (Bureau of the Census 2000). is available through URL: 
Directions: Download the GIS layer containing MSAs from the U.S. Census Bureau (Bureau of the Census 2000). Import the data into a GIS program to create a Proximity to MSA indicator layer. Create buffers at 20-miles from the edge of each MSA to show a level of risk.

Indicator Measure: Proximity to MSA is defined as the distance from the nearest MSA to an installation. All areas within an MSA were classified as highly vulnerable, while all areas not within an MSA, but within 20 miles of an MSA were classified as moderately vulnerable. All areas outside of the 20-mile buffer were considered not vulnerable. Proximity to MSA classifications were defined as follows.

Very Low Vulnerability (1): Areas greater than 20 miles away from any MSA

Low Vulnerability

(2): Not Applicable

Moderate Vulnerability

(3): Areas not within an MSA, but within 20 miles of one or more MSAs

Vulnerable

(4): Not Applicable

High Vulnerability

(5): Within a Census designated MSA

Rules: This indicator measures an installations' proximity to an MSA. If only part of an installation is located within an MSA, then that region surrounding the installation takes on the highly vulnerable classification. The same follows if an installation straddles the 20 mile buffer - half of the installation within 20 miles the other half greater than 20 miles, the region takes on the "moderate" vulnerability classification. 


\title{
Sustainability Issue: Threatened and Endangered Species (TES)
}

\author{
Indicator: Number of TES per State (TE1) \\ Variables: Number of TES per square mile \\ Scale: $\quad$ State \\ Year: $\quad 2004$ \\ Data Sources:
}

Bak, J.M., S. Sekscienski, and B. Woodson. (2002). FY 2000 Survey of Threatened and Endangered Species on Army Lands. U.S. Army Environmental Center. Aberdeen Proving Ground, MD. (21010-5401. SFIM-AEC-EQ-TR-20018. U.S. Navy HQ NAVFAC. U.S. Air Force AFCEE), available through URL:

http://clients.emainc.com/navfac/

Sikes Act, 16 USC 670a-670o, 74 Stat. 1052 (1960), available through URL: http://laws.fws.gov/lawsdigest/sikes.html

U.S. Department of Defense, and the U.S. Fish and Wildlife Service, U.S. Department of the Interior. (2002). Integrated Natural Resources Management Plans. Washington, DC, available through URL: http://endangered.fws.gov/DoD/inrmp.pdf

U.S. Fish and Wildlife Service, U.S. Department of the Interior. (2004). Threatened and Endangered Species System. The Endangered Species Program. Washington, DC. (Species Information), available through URL:

http://endangered.fws.gov

Logic: This indicator gives an indication of the comparative number of TES in each state. The presence of TES is highly sought after as a sustainability indicator due to the possible limitations they may put on certain land use actions, military or otherwise, in time or in space. In addition, other Federal requirements (e.g., Sikes Act) may require consideration and protection of state listed or other identified species identical or comparable to that required by the Endangered Species Act ("Sikes Act," 1960). Overall, the presence of TES on a military installation may result in legal and other requirements regarding the conservation and management of those species (DoD et al. 2002).

Replicable: This information could be replicated daily based on updates from the U.S. Fish and Wildlife Service, Endangered Species Program (2004). It can be anticipated that the individual state lists will increase over time and that the removal of species from state lists will be uncommon and infrequent. However, changes in numbers can be anticipated to be relatively small and replication every day, or even year, should not be universally necessary. 
Directions: Download the number of TES in each state from the U.S. Fish and Wildlife Service, Endangered Species Program (2004). Import the resulting data into a GIS program and join it with state boundary files to create a Number of TES per State indicator layer.

Indicator Measure: Download the U.S. Fish and Wildlife Service's state listed TES data from their Species Information website and then divide by its respective state area (square miles) resulting in Number of TES per State per Square Mile. This distributes the data by area. Distributing the data by area allows for an equal comparison between large and small-area states. In other words, it protects against a large-area state from a more vulnerable classification because it naturally has more occurrences compared to a small-area state. The number TES per state per square mile were statistically classified by determining the mean $(0.003298$ species per square mile) and standard deviation (0.009745). Using this logic, the following classifications were defined.

Very Low Vulnerability $\quad(1): \quad<=0.0005$ species per square mile

Low Vulnerability $\quad(2): \quad>0.0005-<=0.0017$ species per square mile

Moderate Vulnerability $\quad(3): \quad>0.0017-<=0.0028$ species per square mile

Vulnerable $\quad(4): \quad>0.0028-<=0.0038$ species per square mile

High Vulnerability $\quad(5): \quad>0.0038$ species per square mile

Rules: Every installation is located primarily in one state, although several installations do cross state boundaries. A region around an installation takes on the classification of the state in which the installation is primarily located.

\section{Indicator: Species at Risk (TE2) \\ Variable: Number of Species \\ Scale: Watershed \\ Year: $\quad 1997$ \\ Data Sources:}

USEPA. (1997). The Index of Watershed Indicators, EPA-841-R-97-010. Office of Water. Washington, DC, available through URL: http://www.epa.gov/wateratlas/geo/maplist.html

Hurd, B., N. Leary, R. Jones, and J. Smith. (1999). "Relative Regional Vulnerability of Water Resources to Climate Change." Journal of the American Water Resources Association, 35(6), pp.1399-1409, available through URL: http://www.awra.org

Sikes Act, 16 USC 670a-670o, 74 Stat. 1052 (1960), available through URL: http://laws.fws.gov/lawsdigest/sikes.html

16 USC 670a-670o, 74 Stat. 1052, available through URL: http://laws.fws.gov/lawsdigest/sikes.html 
Logic: This indicator measures the number of threatened and endangered aquatic and wetland species known to be in a watershed based on Federal Threatened and Endangered species (TES) counts as given by the U.S. EPA in 1997 (USEPA 1997). This indicator characterizes the degree of relative stress that a watershed may be currently experiencing from a variety of sources, including habitat loss, pollution, predation, and disease by counting the number of at-risk, water-dependant species within a watershed (B. Hurd et al. 1999).

According to the Sikes Act, the DoD and Department of Interior (DoI) must cooperate with local state agencies for the planning, management, and maintenance of fish and wildlife populations and their associated habitat on military installations ("Sikes Act," 1960). Watersheds with a high number of TES will significantly increase the possibility of regulatory restrictions on the installation's mission. This would then place the military installation in a vulnerable state, possibly affecting the type and intensity of training that would take place on the installation. Reduction and or change in military training activities may result if state and Federal agencies question military training impacts on TES and associated habitat. Restrictions, reductions, and change of training could result, including the permanent removal of land parcels from training. (Supplementary applicable laws and regulations can be found at http://www.epa.gov/win/law.html.)

A watershed is the area of land where all of the water that is under it or drains off of it goes into the same place. Watersheds are delineated by USGS using a nationwide system based on surface hydrologic features. This system divides the country into 21 regions, 222 subregions, 352 accounting units, and 2,262 cataloguing units. A hierarchical hydrologic unit code (HUC) consisting of 2 digits for each level in the hydrologic unit system is used to identify any hydrologic area. The 6-digit accounting units and the 8-digit cataloguing units are generally referred to as basin and sub-basin. There are many states that have defined down to 16-digit HUCs (USEPA 1997).

Replicable: Efforts are being made to replicate this analysis so it can be updated when new EPA data is available using the methodologies generated by the original study. This data is found in the EPA's Index of Water Quality Indicators at http://www.epa.gov/wateratlas/geo/maplist.html (USEPA 1997). The EPA intends to replicate the effort and produce new data, although the timeline is unclear at this point due to lack of funding.

Directions: Download "species at risk" from the EPA Index of Watershed Indicators at http://www.epa.gov/wateratlas/geo/maplist.html (USEPA 1997). Import the data into a GIS program and join it with watershed boundary files to create a GIS Species at Risk indicator layer. 
Indicator Measure: Number of aquatic and wetland species identified were defined as either threatened or endangered, at-risk, or water-dependant, as estimated by EPA IWI (USEPA 1997). The species at risk ratings were grouped into the following classifications based on definitions assigned by the EPA (USEPA 1997) as well as expert opinion. A complete explanation of the EPA ranges is available at http://www.epa.gov/wateratlas/geo/maplist.html.

Very Low Vulnerability

Low Vulnerability

Moderate Vulnerability

Vulnerable

High Vulnerability
(1): 0 species at risk per square mile

(2): Not Applicable

(3): 1 species at risk per square mile

(4): Not Applicable

(5): 2 or more species at risk per square mile

Rules: Every installation is located primarily in one watershed, although several installations do cross watershed boundaries. The area around an installation takes on the rating of the watershed where the installation is primarily located (area basis).

\section{Indicator: Federally Listed TES by Ecoregion (TE3) \\ Variables: Year-round presence/resident, Seasonal, Migratory, Contiguous, and Accidental per square mile \\ Scale: $\quad$ Ecoregion \\ Year: 2004 \\ Data Sources:}

Sikes Act, 16 USC 670a-670o, 74 Stat. 1052 (1960), available through URL: http://laws.fws.gov/lawsdigest/sikes.html

U.S. Department of Defense, and the U.S. Fish and Wildlife Service, U.S. Department of the Interior. (2002). Integrated Natural Resources Management Plans. Washington, DC, available through URL: http://endangered.fws.gov/DoD/inrmp.pdf

NatureServe Central Databases (2004). TNC Ecoregion Threatened and Endangered Species. Arlington, VA.

Logic: The species included in this analysis consist of all species with Federal status under the U.S. Endangered Species Act (USESA) for which NatureServe has associated Element Occurrence (EO) data. This indicator is important as a TES indicator because the presence of TES on or near a military installation may result in legal and other requirements regarding the conservation and management of those species (DoD et al. 2002). The presence of TES may limit certain land use actions, military or otherwise, in time or in space. In addition, other Federal requirements (e.g., Sikes Act) may require consideration and protection of state listed or other identified species identical or comparable to that required by the Endangered Species Act ("Sikes Act," 1960). Reporting TES by ecoregions as opposed to States have 
certain advantages in naming species by habitat. In other words, classifying by state may result in the entire state classified as high TES vulnerability regardless of the characteristics of the majority of the state.

Replicable: Although this information could be replicated every year from the NatureServe Central Database there would be relatively little reason to do so. TES presence, once identified, would not be expected to change unless the species was extirpated, or its status changed. If the species were extirpated, other political and social concerns and considerations would raise themselves.

Directions: Data was ordered from the NatureServe Central Database (NatureServe 2004). Since data comes with a fee, it is recommended that the data be reproduced no more often than annually. The data will arrive in a spreadsheet format. Import the data into a GIS program and join with ecoregion boundary files to create a TES by Ecoregion indicator layer.

Indicator Measure: NatureServe collects species occurrence data from local Natural Heritage Programs across the United States. It is important to note that the following data is missing in the NatureServe Central Databases and the dataset used for this analysis.

Most Washington animal data - with the exception of some select species, animal data in Washington is tracked by an agency outside the Washington Natural Heritage Program and the methodology of that animal location data is not currently compatible with Heritage EO Methodology.

Alaska animal data - NatureServe is unable to provide Alaska animal data until they complete their next data exchange with their Heritage program in the coming year.

Massachusetts data - NatureServe has an incomplete EO dataset for Massachusetts that is also a couple of years old. While these records were included in the crosstab tallies, the numbers for Ecoregions that intersect with Massachusetts may be low.

Arizona data - NatureServe does not currently store the coordinates for Arizona species location data in their Central Database. The crosstab tallies for Ecoregions that intersect with Arizona do not include counts of species locations within the state of Arizona.

NatureServe grouped the location of sited TES species by ecogregion. The number of TES per ecoregion was then divided by its respective ecoregion area (square miles) resulting in Federally Listed TES by Ecoregion per Square Mile. This dis- 
tributes the data by area. Distributing the data by area allows for an equal comparison between large and small-area ecoregions. In other words, it protects against a large-area ecoregion from a more vulnerable classification because it naturally has more occurrences compared to a small-area ecoregion. Federally Listed TES by Ecoregion per square mile were statistically classified around natural breaks in the mean (0.0018) and standard deviation (0.0086) values.

Very Low Vulnerability Low Vulnerability Moderate Vulnerability Vulnerable High Vulnerability
(1): $\quad<=0.00016$ species per square mile

(2): $>0.00016-<=0.00031$ species per square mile

(3): $>0.00031-<=0.00086$ species per square mile

(4): $>0.00086-<=0.0015$ species per square mile

(5): $>0.0015$ species per square mile

Rules: Every installation is located primarily in one ecoregion, although several installations do cross ecoregion boundaries. The area around an installation takes on the rating of the ecoregion where the installation is primarily located (area basis).

\section{Indicator: Species of Concern (TE4)}

Variables: Species with a Global Conservation Status Rank of G1/T1 - G2/T2 and having no Federal Status per square mile

Scale: $\quad$ Ecoregion

Year: $\quad 2004$

\section{Data Sources:}

Sikes Act, 16 USC 670a-670o, 74 Stat. 1052 (1960), available through URL: http://laws.fws.gov/lawsdigest/sikes.html

U.S. Department of Defense, and the U.S. Fish and Wildlife Service, U.S. Department of the Interior. (2002). Integrated Natural Resources Management Plans. Washington, DC, available through URL:

http://endangered.fws.gov/DoD/inrmp.pdf

NatureServe Central Databases (2004). TNC Ecoregion Species of Concern. Arlington, VA.

Logic: The species included in this analysis consist of all species with a Global Conservation Status Rank of G1/T1 - G2/T2 and having no Federal status. In other words, the data only includes location records in the counts for which that status does NOT apply and those records do NOT have Federal protection. For example, if a species only has Federal status within 50 miles of a coastline, then only records for that species that are further then 50 miles from the coast would be included. This indicator is important as a TES indicator because the presence of TES on or near a military installation may result in legal and other requirements regarding the conservation and management of those species (DoD et al. 2002). The presence of TES may limit certain land use actions, military or otherwise, in time or in space. 
In addition, other Federal requirements (e.g., Sikes Act) may require consideration and protection of state listed or other identified species identical or comparable to that required by the Endangered Species Act ("Sikes Act," 1960). Reporting TES by ecoregions as opposed to States have certain advantages in naming species by habitat. In other words, classifying by state may result in the entire state classified as high TES vulnerability regardless of the characteristics of the majority of the state.

Replicable: Although this information could be replicated every year from the NatureServe Central Database there would be relatively little reason to do so. TES presence, once identified, would not be expected to change unless the species was extirpated, or its status changed. If the species were extirpated, other political and social concerns and considerations would raise themselves.

Directions: Data was ordered from the NatureServe Central Database (NatureServe 2004). Since data comes with a fee, it is recommended that the data be reproduced no more often than annually. The data will arrive in a spreadsheet format. Import the data into a GIS program and join with ecoregion boundary files to create a Species of Concern indicator layer.

Indicator Measure: NatureServe collects species occurrence data from local Natural Heritage Programs across the United States. It is important to note that the following data is missing in the NatureServe Central Databases and the dataset used for this analysis.

Most Washington animal data - with the exception of some select species, animal data in Washington is tracked by an agency outside the Washington Natural Heritage Program and the methodology of that animal location data is not currently compatible with Heritage EO Methodology.

Alaska animal data - NatureServe is unable to provide Alaska animal data until they complete their next data exchange with their Heritage program in the coming year.

Massachusetts data - NatureServe has an incomplete EO dataset for Massachusetts that is also a couple of years old. While these records were included in the crosstab tallies, the numbers for Ecoregions that intersect with Massachusetts may be low.

Arizona data - NatureServe does not currently store the coordinates for Arizona species location data in their Central Database. The crosstab tallies for Ecoregions that intersect with Arizona do not include counts of species locations within the state of Arizona. 
NatureServe grouped the location of species of concern by ecogregion. The number of species of concern per ecoregion was then divided by its respective ecoregion area (square miles) resulting in Species of Concern by Ecoregion per Square Mile. This distributes the data by area. Distributing the data by area allows for an equal comparison between large and small-area ecoregions. In other words, it protects against a large-area ecoregion from a more vulnerable classification because it naturally has more occurrences compared to a small-area ecoregion. Species of Concern by Ecoregion per square mile were statistically classified around natural breaks in the mean (0.0023) and standard deviation (0.0042) values.

Very Low Vulnerability

Low Vulnerability

Moderate Vulnerability

Vulnerable

High Vulnerability
(1): $\quad<=0.0006$ species per square mile

(2): $>0.0006-<=0.00195$ species per square mile

(3): $>0.00195-<=0.0033$ species per square mile

(4): $>0.0033-<=0.00466$ species per square mile

(5): $>0.00466$ species per square mile

Rules: Every installation is located primarily in one ecoregion, although several installations do cross ecoregion boundaries. The area around an installation takes on the rating of the ecoregion where the installation is primarily located (area basis). 


\title{
Sustainability Issue: Locational
}

\author{
Indicator: Federally Declared Floods (LO1) \\ Variable: Number of Federally declared floods per Square Mile \\ Scale: $\quad$ County \\ Year: $\quad$ 12/24/1964 through 6/15/2004, totaled \\ Data Sources:
}

Federal Emergency Management Agency, U.S. Department of Homeland Security. (2004).

Federally Declared Disasters by Calendar Year. FEMA GIS and Data Solutions Branch.

Washington, DC, available through URL:

http://www.fema.gov/library/drcys.shtm

International Federation of Red Cross and Red Crescent Societies (IRRCRCS). (2002). World

Disasters Report: Focus on Reducing Risk 2002, available through URL:

http://www.ifrc.org/publicat/wdr2002/

Logic: Every year flood disasters cause damage amounting to billions of dollars world-wide. Floods inflict the greatest loss in money than any other Federally declared disaster in the United States. Floods are a threat to both built structures and human health and safety. Thus, the military must be sensitive to potential threats from the natural and built environment. The mission of the installation can be severely impacted by a flood if proper provisions are not in place.

This indicator measures the number of Federally Declared Floods occurring between 1964 and 2004. Federally Declared Floods are those floods declared by communities to the Federal government. Often times on declaration, the Federal government offers some form of relief to the community (IFRCRCS 2002). Thus whether or not a flood is declared depends largely on the resources of the community and the aggressiveness of community leaders. Many floods of significant consequences are not declared while some of relatively little consequences are declared. In other words, declaration may have little to do with severity. Nonetheless, Federally Declared Floods offer the best indication of a community's flood risk reduction efforts. It is simply vital to use local knowledge in interpreting the Federally Declared Floods classifications.

Replicable: This indicator can be updated annually based on Federally Declared Disasters by Calendar Year data, as collected in the National Emergency Management Information System (NEMIS) maintained by the Federal Emergency Management Agency (FEMA 2004). 
Directions: FEMA database, "declarations by type," is sorted by disaster type. Eliminate all disasters except flooding. Download and compile the data for all U.S. counties. Import the data into a GIS program and join it with county boundary files to create a Federally Declared Floods indicator layer.

Indicator Measure: The number of Federally declared floods for each county was summed to obtain a 38-year total for floods (FEMA 2004). This sum was then divided by its respective county area (square miles) resulting in Federally declared floods per square mile. This distributes the data by area. Distributing the data by area allows for an equal comparison between large and small-area counties. In other words, it protects against a large-area county from a more vulnerable classification because it naturally has more occurrences compared to a small-area county. Statistical analysis resulted in a mean of 0.0058 floods per square mile and a standard deviation of 0.0259. The following classifications were defined using the mean and standard deviation values.

Very Low Vulnerability $\quad(1)$ : $\quad<0.0059$ floods per square mile

Low Vulnerability $\quad(2): \quad>=0.0059-<0.0189$ floods per square mile

Moderate Vulnerability $\quad(3): \quad>=0.0189-<0.0317$ floods per square mile

Vulnerable $\quad(4):>=0.0317-<0.046$ floods per square mile

High Vulnerability $\quad(5): \quad>=0.046$ floods per square mile

Rules: Installations are often in two or more counties. Therefore, regional classifications are determined by a weighted average. The weighted average calculation determines what percentage of the installation is in each county, and that percentage is multiplied by that county's value. The values for each county the installation lies in are then totaled to arrive at a value for the region. This value is then subject to the same metric that determined the classification for the individual counties.

Example:

Indicator Value for the Installation $=\left(\right.$ Percentage of Installation in County $A^{*}$ Indicator Value for County $A)+\left(\right.$ Percentage of Installation in County $B^{*}$ Indicator Value for County B)...etc.

\footnotetext{
Indicator: Seismicity (LO2)

Variables: Spectral acceleration for 0.2 second period with 2 percent probability of exceedance in 50 years

Scale: National

Year: 2002
} 


\section{Data Sources:}

Frankel, Arthur, Charles Mueller, Theodore Barnhard, David Perkins, E.V. Leyendecker, Nancy Dickman, Stanley Hanson, and Margaret Hopper. (2002). Seismic-Hazard Maps for the Conterminous United States: Document for 2002 Update of National Seismic Hazard Map, U.S. Geological Survey Open-File Report 02-420 U.S. Geological Survey Bureau, U.S. Department of the Interior. Reston, VA. (Map F - Horizontal spectral response acceleration for 0.2 second period [ $5 \%$ of critical damping] with $2 \%$ probability of exceedance in 50 years), available through URL:

http://earthquake.usgs.gov/hazmaps/

Sweeney, Steven. (2002). Structural Engineer, U.S. Army Engineer Research and Development Center, Construction Engineering Research Laboratory. In Adam Sagert (Ed.).

Champaign, IL.

Logic: Earthquakes are a threat to both built structures and human health and safety. Thus, the military must be sensitive to potential threats from the natural environment. The mission of the installation can be severely impacted by an earthquake.

Replicable: This indicator can be replicated as often as the USGS updates their Seismic Risk data. The trend seems to be that these maps are updated every 5 or 6 years.

Directions: Download the horizontal spectral response acceleration for 0.2 second period ( $5 \%$ of critical damping) with $2 \%$ probability of exceedance in 50 years. Import the data into a GIS program to create a Seismicity Risk area indicator layer. GIS data (A. Frankel et al. 2002) concerning seismicity is available through URL: http://earthquake.usgs.gov/hazmaps/

Indicator Measure: The values found on the map are the horizontal spectral response acceleration for 0.2 second period ( $5 \%$ of critical damping) with $2 \%$ probability of exceedance in 50 years. USGS documentation (A. Frankel et al. 2002) separates the data into various seismic classifications, which were then translated into a vulnerability scale with the assistance of seismic expert and structural engineer, Steven Sweeney, at ERDC-CERL (2002).
Very Low Vulnerability
(1): $\quad<=7 \%$ g (gravity)
Low Vulnerability
(2): $\quad>7-<=8 \%$ g (gravity)
Moderate Vulnerability
(3): $>8-<=16 \%$ g (gravity)
Vulnerable
(4): $>16-<=24 \%$ g (gravity)
High Vulnerability
(5): $>24 \%$ g (gravity)

Rules: This indicator measures seismicity for a certain location. The region around an installation takes on the rating of the highest seismicity classification 
area that the installation touches. For instance, if an installation is partly in a moderate vulnerability classified area, and partly in a high vulnerability classified area, then the region around the installation has a high vulnerability classification.

Indicator: Weather Related Damage (LO3)

Variable: Damage in dollars due to weather (crop and property) per square mile

Scale: $\quad$ State

Year: $\quad$ 1995-2004 data, totaled

Data Source:

National Oceanographic and Atmospheric Administration (NOAA): National Weather Service, U.S. Department of Commerce. (2005). Summary of Natural Hazard Statistics in the United States. Office of Climate, Water, and Weather Services. Silver Spring, MD, available through URL http://www.nws.noaa.gov/om/hazstats.shtml

Logic: The United States suffered nearly $\$ 200$ billion in economic losses due to extreme weather in the 1990s, including $\$ 14$ billion in damage in 1999 (NOAA 2005). The insurance industry is worried about the soaring costs of severe weather damage and is already refusing to cover various weather events in certain regions. The DoD lost an installation with Hurricane Andrew's destruction of Homestead AFB in Florida in August 1992. By examining historical weather related damage trends, one can see the vulnerability of the military mission to extreme weather. Thus, the military must be sensitive to potential threats from the natural environment. Weather conditions are a threat to built structures, human health and safety, and the mission of the installation. This indicator provides a measurement of the cost of the loss of crops and damage due to natural disasters for the past 7 years.

Replicable: This indicator could be updated annually as new data is posted to the National Weather Service website (NOAA 2005).

Directions: From the NOAA website, select a year from the "State Summaries" pull-down menu (NOAA 2005). This opens an Adobe acrobat document for that year containing fatalities, injuries, property damage, and crop damage for each state and U.S. territory. Download and compile the data into a spreadsheet for 1995 through 2004 for all U.S. counties. Import the totals into a GIS program and join it with county boundary files to create a Weather Related Damage indicator layer.

Indicator Measure: The damage in dollars due to weather for each state and territory was summed to obtain a 7-year total for weather related crop and property damage (NOAA 2005). This sum was then divided by its respective state area (square miles) resulting in weather damage in dollars per square mile. This distributes the data by area. Distributing the data by area allows for an equal com- 
parison between large and small-area states. In other words, it protects against a large-area state from a more vulnerable classification because it naturally has more occurrences compared to a small-area state. Statistical analysis resulted in a median of $\$ 25,730$ per square mile and a standard deviation of 33,506 . Using these statistics, the following classification were determined.

Very Low Vulnerability

(1): $\quad<\$ 8,977$

Low Vulnerability

(2): $>=\$ 8,977-<\$ 25,730$ per square mile

Moderate Vulnerability

(3): $\quad>=\$ 25,730-<\$ 42,483$ per square mile

Vulnerable

(4): $>=\$ 42,483-<\$ 59,236$ per square mile

High Vulnerability

(5): $>=\$ 59,236$ per square mile

Rules: Every installation is located primarily in one state, although several installations do cross state boundaries. The region around an installation takes on the classification of the state in which the installation is primarily located.

\section{Indicator: Federally Declared Disasters (LO4)}

Variables: Number of Federally declared natural disasters in the categories of tsunami, coastal storm, drought, earthquake, flood, freezing, hurricane, typhoon, dam/levee break, mud/landslide, severe ice storm, fire, snow, tornado, volcano, and severe storm per square mile

Scale: $\quad$ County

Year: $\quad$ 12/24/1964 through 6/15/2004, totaled

\section{Data Sources:}

Federal Emergency Management Agency (FEMA), U.S. Department of Homeland Security. (2004). Federally Declared Disasters by Calendar Year. FEMA GIS and Data Solutions Branch. Washington, DC, available through URL http://www.fema.gov/library/drcys.shtm

International Federation of Red Cross and Red Crescent Societies (IRRCRCS). (2002). World Disasters Report: Focus on Reducing Risk 2002, available through URL http://www.ifrc.org/publicat/wdr2002/

Logic: In the 1990s, some 2 billion people were affected by disasters world-wide (IFRCRCS 2002). No one is immune from disasters. Everyone is vulnerable, but some are more vulnerable than others. By examining historical disaster trends, one can see that it is not only weather related damage causing disasters. Flawed development patterns (e.g., rapid unplanned urbanization, deforestation, installation of non-flood-proof dykes, no early warning systems, etc.) are also exposing more people to disasters (IFRCRCS 2002). For example, earthquake fatalities are not necessarily the result of an earthquake but rather ineffective building codes. Tornados sweeping away homes may not be a sign of strong winds as much as poorly sited housing. There is no doubt disasters are a threat to both built structures and human health and safety. Thus, the military must be sensitive to potential threats 
from the natural and built environment. The mission of the installation can be severely impacted by disasters if proper provisions are not in place.

This indicator measures the number of Federally Declared Disasters occurring between 1964 and 2004. Federally declared disasters are those disasters declared by communities to the Federal government. Often times on declaration, the Federal government offers some form of relief to the community (IFRCRCS 2002). Thus whether or not a disaster is declared depends largely on the resources of the community and the aggressiveness of community leaders. Many disasters of significant consequences are not declared while some of relatively little consequences are declared. In other words, declaration may have little to do with severity. Nonetheless, Federally declared disasters offer the best indication of a community's disaster vulnerability reduction efforts. It is simply vital to use local knowledge in interpreting the Federally Declared Disasters classifications.

Replicable: This indicator can be updated annually based on Federally Declared Disasters by Calendar Year data, as collected in the National Emergency Management Information System (NEMIS) maintained by FEMA (FEMA 2004).

Directions: The database, "declarations by type," is sorted by disaster type (FEMA 2004). Eliminate those disasters that are not in the categories of tsunami, coastal storm, drought, earthquake, flood freezing, hurricane, typhoon, dam/levee break, $\mathrm{mud} /$ landslide, severe ice storm, fire, snow, tornado, volcano, or severe storm. Download and compile the data by U.S. counties. Import the data into a GIS program and join it with county boundary files to create a Federally Declared Disasters indicator layer.

Indicator Measure: The number of Federally declared natural disasters in the categories of tsunami, coastal storm, drought, earthquake, flood, freezing, hurricane, typhoon, dam/levee break, mud/landslide, severe ice storm, fire, snow, tornado, volcano, and severe storm for each county was summed to obtain a 38-year total for natural disasters (FEMA 2004). This sum was then divided by its respective county area (square miles) resulting in Federally declared disasters per square mile. This distributes the data by area. Distributing the data by area allows for an equal comparison between large and small-area counties. In other words, it protects against a large-area county from a more vulnerable classification because it naturally has more occurrences compared to a small-area county. Statistical analysis resulted in a mean of 0.0239 disasters per square mile and a standard deviation of 0.1136 . Using these statistics along with natural breaks in the data, the following classifications were determined. 
Very Low Vulnerability

Low Vulnerability

Moderate Vulnerability

Vulnerable

High Vulnerability
(1): $<0.0245$ disasters per square mile

(2): $>=0.0245-<0.0183$ disasters per square mile

(3): $>=0.0183-<0.1375$ disasters per square mile

(4): $>=0.1375-<0.1945$ disasters per square mile

(5): $>=0.1945$ disasters per square mile

Rules: Installations are often in two or more counties. Therefore, regional classifications are determined by a weighted average. The weighted average calculation determines what percentage of the installation is in each county, and that percentage is multiplied by that county's value. Those values for each county around the installation are then totaled to arrive at a regional value. This value is then subject to the same metric that determined the classification for the individual counties.

Example:

Indicator Value for the Installation $=\left(\right.$ Percentage of Installation in County $A^{*}$ Indicator Value for County $A)+\left(\right.$ Percentage of Installation in County $B^{*}$ Indicator Value for County B)...etc.

\section{Indicator: Tornado Occurrences (LO5)}

Variable: $\quad$ Tornado County-Segments per Square Mile

Scale: $\quad$ County

Year: $\quad 1992-2002$

\section{Data Source:}

National Oceanic and Atmospheric Administration (NOAA). (2004). Tornados. U.S. Department of Commerce, Washington, DC, available through URL

http://www.noaa.org/tornadoes.html

Logic: Tornadoes are one of nature's most violent storms. In an average year, about 1,000 tornadoes are reported across the United States, resulting in 80 deaths and over 1,500 injuries. A tornado is a violently rotating column of air extending from a thunderstorm to the ground. The most violent tornadoes are capable of tremendous destruction with wind speeds of $250 \mathrm{mph}$ or more. Damage paths can be in excess of 1 mile wide and 50 miles long (NOAA 2004). Thus, the military must be sensitive to potential threats from tornadoes. Tornadoes, just as any other severe weather conditions, are a threat to built structures, human health and safety, and the mission of the installation.

This indicator measures the number and strength of tornadoes segments that passed through a county in a given year. It is not a measure of the number of total tornadoes by strength. If a tornado stays in one county, then a "tornado" is the same as a "segment." However, if a tornado that passes through two counties, it is then counted twice. If a tornado passes through three counties, it is then counted 
three times, and so forth. Tornadoes come in all shapes, sizes, and strengths and can occur anywhere in the United States at any time of the year. Yet, there are several geographic and climatic characteristics that may increase the probability of experiencing a tornado. For instance, in the southern states, peak tornado season is March through May, while peak months in the northern states are during the summer (NOAA 2004).

Tracking the occurrence and strength of tornadoes provides an indication of the likelihood of similar tornado damage re-occurring in the area. Yet there is an inherent inaccuracy in attempting to summarize expectations about what will happen in the future-weather forecasting. When predicting tornadoes, forecasters look for the development of temperature and wind flow patterns in the atmosphere that can cause enough moisture, instability, lift, and wind shear for tornadic thunderstorms. Those are the four needed ingredients. But it is not as easy as it sounds. "How much is enough" of those is not a hard fast number, but varies significantly from situation to situation - and is sometimes unknown. A large variety of weather patterns can lead to tornadoes; and often, similar patterns may produce no severe weather at all. To further complicate it, the various computer models can have major biases and flaws when the forecaster tries to interpret them on the scale of thunderstorms. In other words, what may have caused several tornadoes one year may not result in any tornadoes the next year, or vice versa (NOAA 2004). The best anyone can do is to make an educated guess where the most favorable combination of ingredients tends to occur and classify the vulnerability.

Lastly, it is important to note this data is on the county level. Tornadoes typically only hit a relatively small portion of land, especially compared at the county level. Yet, to name that specific piece of land more than several hours in advance is impossible. Thus, it is often an area much greater than county borders that are highly vulnerable to tornado occurrences. In other words, if a neighboring county to the study county has a high occurrence of tornadoes; it may be wise to regard the study county as a higher potential county. Because of the inaccuracy of forecasting and large high-potential areas, it is important to use local knowledge in interpreting the tornado classifications.

Replicable: This indicator is updated annually by the NOAA Storm Prediction Center (NOAA 2004), and is available through URL http://www.spc.noaa.gov/software/svrplot2/

Directions: Query tornado occurrences for 1992-2002 from the NOAA Storm Prediction Center's SeverePlot system is available online through URL: 
Download the file in a tabular format and import it into a GIS program. The file should contain an "ID" for each tornado occurrence and a latitude/longitude for the beginning of the event and latitude/longitude for the end. Single touchdowns have the same beginning and ending latitude/longitude. Use the GIS software to form a polyline shapefile from the beginning to the end of the tornado's path. Finally, intersect the tornado paths with county boundary files to note which counties the path crossed through, and use the GIS count function to get a number of tornadoes per county.

Indicator Measure: The number of tornado segments for each county was summed to obtain the total number of tornado segments occurring within a county from 1992 to 2002 (NOAA 2004). This sum was then divided by its respective county area (square miles) resulting in tornado segments per square mile. This distributes the data by area. Distributing the data by area allows for an equal comparison between large and small-area counties. In other words, it protects against a large-area county from a more vulnerable classification because it naturally has more occurrences compared to a small-area county. Statistical analysis resulted in a mean of 0.0072 tornadoes per square mile and a standard deviation of 0.0112 . Using these statistics along with natural breaks in the data, the following classifications were determined.

Very Low Vulnerability

Low Vulnerability

Moderate Vulnerability

Vulnerable

High Vulnerability
(1): $<0.0027$ tornadoes per square mile

(2): $>=0.0027-<0.0083$ tornadoes per square mile

(3): $>=0.0083-<0.0139$ tornadoes per square mile

(4): $>=0.0139-<0.0195$ tornadoes per square mile

(5): $>=0.0195$ tornadoes per square mile

Rules: Installations are often in two or more counties. Therefore, regional classifications are determined by a weighted average. The weighted average calculation determines what percentage of the installation is in each county, and that percentage is multiplied by that county's value. The values for each county around the installation are then totaled to arrive at a regional value. This value is then subject to the same metric that determined the classification for the individual counties.

Example:

Indicator Value for the Region around an Installation = (Percentage of Installation in County $A^{*}$ Indicator Value for County A) + (Percentage of Installation in County $B^{\star}$ Indicator Value for County B)...etc. 


\title{
Sustainability Issue: Water
}

\author{
Indicator: Level of Development (WA1) \\ Variables: Water withdrawal, Stream flow levels \\ Scale: Watershed \\ Year: $\quad 1990$ \\ Data Sources:
}

USEPA. (1997). The Index of Watershed Indicators, EPA-841-R-97-010. Office of Water. Washington, DC, available through URL http://www.epa.gov/wateratlas/geo/maplist.html

Hurd, B., N. Leary, R. Jones, and J. Smith. (1999). "Relative Regional Vulnerability of Water Resources to Climate Change." Journal of the American Water Resources Association, 35(6), pp.1399-1409, available through URL

http://www.awra.org

Logic: This indicator measures the ratio of current water withdrawal to mean annual unregulated streamflow. Watersheds with low water availability and high demand are vulnerable, i.e., in areas of development intensive use of off-stream water generally occurs resulting in decreased water availability (B. Hurd et al. 1999). With a reduction in streamflow, either via seasonal or dramatic climatic change, an increase in both in-stream and off-stream uses will occur, especially in areas of high development and high irrigation (B. Hurd et al. 1999). This indicator has an impact on the military mission if and when an installation is in an area with vulnerable watersheds. Water availability could be compromised resulting in a negative impact on soldiers, training, carrying capacity, and threatened and endangered species.

A watershed is the area of land where all of the water that is under it or drains off of it goes into the same place. Watersheds are delineated by USGS using a nationwide system based on surface hydrologic features. This system divides the country into 21 regions, 222 subregions, 352 accounting units, and 2,262 cataloguing units. A hierarchical hydrologic unit code (HUC) consisting of 2 digits for each level in the hydrologic unit system is used to identify any hydrologic area. The 6-digit accounting units and the 8-digit cataloguing units are generally referred to as basin and sub-basin. There are many states that have defined down to 16-digit HUC.

Replicable: The EPA Watershed Atlas is no longer available. Current watershed information is being made available from the EPA through the Watershed Information Network (http://www.epa.gov/win/). Efforts are being made to replicate this analysis with updated data. 
Directions: Download "level of development" from the EPA Index of Watershed Indicators at http://www.epa.gov/wateratlas/geo/maplist.html (USEPA 1997). Import the data into a GIS program and join it with watershed boundary files to create a GIS Level of Development indicator layer.

Indicator Measure: Ranges were defined as the ratio of total annual surface and groundwater withdrawals in $1990(\mathrm{Qw})$ to unregulated mean annual streamflow (Qs).

$$
\text { Level of Development }=\left(\mathrm{Q}_{w} / \mathrm{Q}_{S}\right)
$$

The level of development ratings were grouped into the following classifications based on definitions created by the EPA Watershed Atlas (USEPA 1997).

Very Low Vulnerability

Low Vulnerability

Moderate Vulnerability

Vulnerable

High Vulnerability
(1): Low Level of Development $(<20$ percent)

(2): Not Applicable

(3): Average Level of Development (20 to 85 percent)

(4): Not Applicable

(5): High Level of Development (>85 percent)

Rules: Every installation is located primarily in one watershed, although several installations do cross watershed boundaries. The area around an installation takes on the rating of the watershed where the installation is primarily located (area basis).

\section{Indicator: Groundwater Depletion (WA2)}

Variables: Groundwater Outflow, Groundwater Withdrawals (annual)

Scale: Watershed

Year: $\quad 1990$

\section{Data Sources:}

USEPA. (1997). The Index of Watershed Indicators, EPA-841-R-97-010. Office of Water. Washington, DC, available through URL: http://www.epa.gov/wateratlas/geo/maplist.html

Hurd, B., N. Leary, R. Jones, and J. Smith. (1999). "Relative Regional Vulnerability of Water Resources to Climate Change." Journal of the American Water Resources Association, 35(6), pp.1399-1409, available through URL:

http://www.awra.org

Logic: This indicator shows the level of groundwater withdrawal within watersheds of the continental U.S. Groundwater depletion characterizes the extent to which rates of groundwater withdrawals exceed long-run average recharge rates, resulting in overdraft and a condition referred to as "groundwater mining" (B. Hurd et al. 1999). Average groundwater withdrawals in excess of natural baseflows indi- 
cate an unsustainable rate of groundwater use. Excessive groundwater withdrawals suggest that increased groundwater use may not be a viable adaptation to changes in surface water supply or increases in water demand (B. Hurd et al. 1999).

A watershed is the area of land where all of the water that is under it or drains off of it goes into the same place. Watersheds are delineated by USGS using a nationwide system based on surface hydrologic features. This system divides the country into 21 regions, 222 subregions, 352 accounting units, and 2,262 cataloguing units. A hierarchical hydrologic unit code (HUC) consisting of 2 digits for each level in the hydrologic unit system is used to identify any hydrologic area. The 6-digit accounting units and the 8-digit cataloguing units are generally referred to as basin and sub-basin. There are many states that have defined down to 16-digit HUC.

Replicable: The EPA Watershed Atlas is no longer available. Current watershed information is being made available from the EPA through the Watershed Information Network (http://www.epa.gov/win/). Efforts are being made to replicate this analysis with updated data.

Directions: Download "groundwater outflow" and "annual groundwater withdrawals" from the EPA Index of Watershed Indicators (USEPA 1997) through URL: http://www.epa.gov/wateratlas/geo/maplist.html

Import the data into a GIS program and join it with watershed boundary files to create a GIS Ground Water Depletion indicator layer.

Indicator Measure: Ranges were defined as the ratio of average groundwater withdrawals $\left(\mathrm{Q}_{\mathrm{GW}}\right)$ in 1990 to annual average baseflow (QBase), reflecting the extent that groundwater use rates may exceed recharge.

Ground Water Depletion $=\left(\mathrm{Q}_{\mathrm{GW}} / \mathrm{Q}_{\mathrm{Base}}\right)$

The groundwater depletion ratings were grouped into the following classifications based on definitions created by the EPA Watershed Atlas (USEPA 1997).

Very Low Vulnerability (1): Low Ground Water Depletion (<8 percent)

Low Vulnerability $\quad$ (2): Not Applicable

Moderate Vulnerability (3): Average Ground Water Depletion (8 to 25 percent)

Vulnerable

(4): Not Applicable

High Vulnerability

(5): $\quad$ High Ground Water Depletion (>25percent)

Rules: Every installation is located primarily in one watershed, although several installations do cross watershed boundaries. The area around an installation takes 
on the rating of the watershed where the installation is primarily located (area basis).

\section{Indicator: Flood Risk (WA3) \\ Variable: Population \\ Scale: Watershed \\ Year: $\quad 1990$ \\ Data Source:}

USEPA. (1997). The Index of Watershed Indicators, EPA-841-R-97-010. Office of Water. Washington, DC, available through URL: http://www.epa.gov/wateratlas/geo/maplist.html

Hurd, B., N. Leary, R. Jones, and J. Smith. (1999). "Relative Regional Vulnerability of Water Resources to Climate Change." Journal of the American Water Resources Association, 35(6), pp.1399-1409, available through URL:

http://www.awra.org

Logic: This indicator is based on the current population living within a 500-Year flood plain. The flood risk indicator characterizes the extent to which lives and property are at risk of flood damages. The 500-Year Floodplain was selected over the more commonly used 100-Year standard because most, if not all, zoning standards and building practices have been based on the 100-Year standard (B. Hurd et al. 1999). This means that those living within the 100-Year Flood plain have generally taken the necessary precautions to mitigate flood risks. There is more concern and risk for populations and property that lie just beyond the margin of the 100Year Floodplain, where people have not had regulations that have required modifications to properties to mitigate flood risks generally (B. Hurd et al. 1999). This takes into consideration the pressures on the future of negative impacts on water quality and availability. Training mission and carrying capacity would be negatively impacted as a result of a 500-Year flood. This would then place the military installation in a vulnerable state, possibly affecting the type and intensity of training that would take place on the installation. Applicable laws and regulations can be found through URL:

http://www.epa.gov/win/law.html

Replicable: The EPA Watershed Atlas is no longer available. Current watershed information is being made available from the EPA through the Watershed Information Network (http://www.epa.gov/win/). Efforts are being made to replicate this analysis with an analysis of an installation's proximity to the 100 and 500-Year Floodplain once that data is released in its entirety by FEMA.

Directions: Download "flood risk" from the EPA Index of Watershed Indicators through URL: http://www.epa.gov/wateratlas/geo/maplist.html (USEPA 1997). Import 
the data into a GIS program and join it with watershed boundary files to create a GIS Flood Risk indicator layer.

Indicator Measure: Ranges were classified as an estimated number of people within the 500-year 1990 defined floodplain. The flood vulnerability was grouped into the following classifications based on definitions created by the EPA Watershed Atlas (USEPA 1997).

Very Low Vulnerability

(1): Low Flood Vulnerability $(<20,000$ people)

Low Vulnerability

(2): Not Applicable

Moderate Vulnerability

(3): Average Flood Vulnerability (20,000-200,000 people)

Vulnerable

(4): Not Applicable

High Vulnerability

(5): High Flood Vulnerability $(<200,000$ people)

Rules: Every installation is located primarily in one watershed, although several installations do cross watershed boundaries. The area around an installation takes on the rating of the watershed where the installation is primarily located (area basis).

\section{Indicator: Low Flow Sensitivity (WA4)}

Variables: Streamflow in cubic feet squared per second

Scale: Watershed

Year: $\quad 2002-2004$

\section{Data Sources:}

USEPA. (1997). The Index of Watershed Indicators, EPA-841-R-97-010. Office of Water. Washington, DC, available through URL: http://www.epa.gov/wateratlas/geo/maplist.html

Hurd, B., N. Leary, R. Jones, and J. Smith. (1999). "Relative Regional Vulnerability of Water Resources to Climate Change." Journal of the American Water Resources Association, 35(6), pp.1399-1409, available through URL:

http://www.awra.org

U.S. Geological Survey (USGS). (2004). National Water Information System (NWIS): SurfaceWater Data for the Nation, Daily Streamflow for the Nation. Washington, DC, available through URL: http://nwis.waterdata.usgs.gov/usa/nwis/discharge

Logic: Streamflows are critical to many riparian areas, and falling below safe threshold levels can threaten individual species or potentially endanger entire aquatic ecosystems. Riparian ecosystems where seasonal periods of extreme low flow occur are the most vulnerable to climatic and hydrologic changes. This further diminishes streamflows during the low flow seasons, since there is less capacity for enduring additional stresses (B. Hurd et al. 1999). 
Impacts to the military mission would include diminished or stressed threatened and endangered species (TES) habitat and population, which in turn could negatively impact the ability for certain training and other missions. Diminished carrying capacity across training may result due to the increased erosion, as a result. Finally, the availability of water would significantly decrease resulting in resource vulnerability.

A watershed is the area of land where all of the water that is under it or drains off of it goes into the same place. Watersheds are delineated by USGS using a nationwide system based on surface hydrologic features. This system divides the country into 21 regions, 222 subregions, 352 accounting units, and 2,262 cataloguing units. A hierarchical hydrologic unit code (HUC) consisting of 2 digits for each level in the hydrologic unit system is used to identify any hydrologic area. The 6-digit accounting units and the 8-digit cataloguing units are generally referred to as basin and sub-basin. There are many states that have defined down to 16-digit HUC.

Replicable: USGS surface-water data includes more than 850,000 stations recording time-series data that describe stream levels, streamflow (discharge), reservoir and lake levels, surface-water quality, and rainfall. The data is collected by automatic recorders and manual measurements by field personnel and relayed through telephones or satellites to offices where it is stored and processed. The data relayed through the Geostationary Operational Environmental Satellite (GOES) system are processed automatically in near real time, and in many cases, real-time data are available online within minutes. Annually, the USGS finalizes and publishes the daily data in a series of water-data reports. Daily streamflow data and peak data are updated annually following publication of the reports.

Due to extensive downloading and numerous calculations of streamflow data to create the Low Flow Sensitivity indicator, it is recommended that this indictor be updated annually or every other year.

Directions: Download average annual streamflow by hydrologic region for 2002 through 2004 from USGS NWIS at:

http://nwis.waterdata.usgs.gov/usa/nwis/discharge

Save files as tab-separated data. Import and join all files into a spreadsheet program. Average streamflows for each data station for 2002 through 2004. Group all data stations by HUC. Average streamflows for 2002 through 2004 by HUC. Since not all basin and sub-basin HUC have data stations, compute averages for the largest HUC units first then for smaller HUC units as data allows. Import the HUC streamflow averages from 2002-2004 into a GIS program and join them with watershed (HUC) boundary files to create a GIS Low Flow Sensitivity indicator layer. 
Note, downloading average annual streamflow measurements for over 850,000 stations over 2 years results in millions of data points. Due to query limitation of the NWIS webserver, it is recommended to contact USGS Surface-Water Data Department for assistance in these queries.

Indicator Measure: This indicator measures the unregulated mean streamflow in cubic feet squared per second. Streamflow is defined as the mean value of discharge that occurs in a natural channel. This measurement is mostly independent of levels and changes in surface runoff. The low flow sensitivity indicator averages streamflows over a 2-year period. Ratings of low flow sensitivity were grouped into the following classifications based on definitions created by the EPA (USEPA 1997). A complete explanation of the EPA ranges, available through URL:

http://www.epa.gov/win/

Very Low Vulnerability

Low Vulnerability

Moderate Vulnerability

Vulnerable

High Vulnerability
(1): $>=0.236$ cubic feet squared per second

(2): Not Applicable

(3): $>=0.065$ cubic feet squared per second and $<0.236$ cubic feet squared per second

(4): Not Applicable

(5): $\quad<0.065$ cubic feet squared per second

Rules: Every installation is located primarily in one watershed, although several installations do cross watershed boundaries. The area around an installation takes on the rating of the watershed where the installation is primarily located (area basis).

\section{Indicator: Water Quality Index (WA5)}

Variables Waters meeting designated uses, Source water condition for drinking water systems, Fish \& wildlife consumption advisories, Indicators of source water condition, Contaminated sediments, Ambient water quality - toxics, Water quality - conventional, Wetlands loss, Aquatic and wetlands species at risk, Loads over limits toxics, over limits - conventional, Urban runoff potential, Agriculture runoff potential, Population change, Hydrologic modification

Scale: $\quad$ Watershed

Year: $\quad 1999$

\section{Data Source:}

USEPA. (1999). EPA Overall Watershed Characterization: September 1999 IWI Release. Office of Water. Washington, DC, available through URL: http://www.epa.gov/iwi/1999sept/catalog.html 
Logic: The Index of Watershed Indicators (IWI) characterizes the condition and vulnerability of aquatic systems in each of the 2,262 watersheds in the 50 states and Puerto Rico (USEPA 1999). This involves an assessment of condition, vulnerability, and data sufficiency. All variables taken into consideration are strong indicators of pressures in the future on water quality and vulnerability, leading to greater demands and risks to water supplies (USEPA 1999). This would then place the military installation in a vulnerable state, possibly affecting the type and intensity of training that would take place on the installation. (Supplementary applicable laws and regulations can be found at http://www.epa.gov/win/law.html.)

A watershed is the area of land where all of the water that is under it or drains off of it goes into the same place. Watersheds are delineated by USGS using a nationwide system based on surface hydrologic features. This system divides the country into 21 regions, 222 subregions, 352 accounting units, and 2,262 cataloguing units. A hierarchical hydrologic unit code (HUC) consisting of 2 digits for each level in the hydrologic unit system is used to identify any hydrologic area. The 6 -digit accounting units and the 8-digit cataloguing units are generally referred to as basin and sub-basin. There are many states that have defined down to 16-digit HUC.

Replicable: Efforts are being made to replicate this analysis so it can be updated when new data is available using similar methodologies of the original study. The EPA intends to replicate the effort and produce new data, although the timeline is unclear at this point due to lack of funding. Replicability depends heavily on current and future monitoring programs.

Directions: Download "water quality" from the EPA Overall Watershed Characterization: September 1999 IWI Release (USEPA 1999), available through URL: http://www.epa.gov/iwi/1999sept/catalog.html

Import the data into a GIS program and join it with watershed boundary files to create a GIS Water Quality indicator layer.

Indicator Measure: This map combines 17 disparate data layers as listed above; layers were weighted and then combined by the EPA (1999). The approach taken by the EPA can be found through URL: http://oaspub.epa.gov/eims/direntrpt.report?p deid=9996\&p chk=9186

Indicators of the condition of the watershed were scored and assigned to one of three categories: better water quality, water quality with less serious problems, and water quality with more serious problems (USEPA 1999). It is important to note that the strength of monitoring programs varies across the country and is reflected in the map. Areas with strong monitoring programs may show more problems than 
those with weaker programs. The water quality IWI ratings were defined as follows by the EPA (USEPA 1999).

Very Low Vulnerability

Low Vulnerability

Moderate Vulnerability

Vulnerable

High Vulnerability
(1): Better Water Quality

(2): Not Applicable

(3): Less Serious Water Quality Problems

(4): Not Applicable

(5): More Serious Water Quality Problems

Rules: Every installation is located primarily in one watershed, although several installations do cross watershed boundaries. The area around an installation takes on the rating of the watershed where the installation is primarily located (area basis). 


\title{
Sustainability Issue: Economic
}

\author{
Indicator: DoD Local Employment (EC1) \\ Variables: Military Employment, Total Employment \\ Scale: $\quad$ County \\ Year: $\quad 2003$ \\ Data Sources:
}

Bureau of Economic Analysis (BEA), U.S. Department of Commerce. (2005). Regional Economic Information System. Washington, DC. (Detailed county annual tables of income and employment by SIC industry: CA25-Total Full-Time and Part-Time Employment by Industry), available through URL:

http://www.bea.gov/bea/regional/reis/

National Governors Association Center for Best Practices. (2003). State Strategies to Address

Encroachment at Military Installations. Natural Resources Policy Studies. Washington, DC, available through URL:

http://www.nga.org/cda/files/032403MILITARY.PDF

Logic: DoD local employment provides a measurement of the economic impact of military installations on the local economy. Military installations are often critical to local economies, accounting for thousands of jobs and for generating billions of dollars in economic activity and tax revenue (NGA Center for Best Practices 2003).

Military installations provide many benefits to their local region in terms of economic impact. Installations in areas with a strong independent economy or significant resource constraints may be economically less important to the area. This indicator is a measure of the economic investment of military employment within each county's economy. The assessment is based on the percentage of military employment within a county's total employment. It is assumed that the higher the percentage of military employment within an economy, the more likely the DoD will be looked on as a friend and field fewer complaints pertaining to stationing and mission decisions.

Replicable: Since 1969 REIS updates its datasets annually. Updated employment figures are downloadable from http://www.bea.gov/bea/regional/reis/ (BEA 2005).

Directions: Download the most recent military and total employment figures by county (BEA 2005). Import the data into a GIS program and join it with county boundary files to create a GIS DoD Local Employment indicator layer.

Indicator Measure: The DoD local employment indicator provides a measure of the percent of military employment at a county level. The indicator is calculated by 
dividing the total military employment within a county by its total employment then multiplying the result by 100 . This yields a percentage of military employment per county.

DoD Local Employment $=[$ (total military employment $) /($ total employment $)]^{\star 100}$

This data has evident natural breaks that have been used to classify the data into vulnerability ranges. Very Low Vulnerability is the lowest level of military involvement, Moderate Vulnerability is the middle classification, and High Vulnerability indicates the highest level of military involvement, usually a major installation. Statistical analysis of the data reveals a county average of 1.15 percent of total local employment with a standard deviation value of 3.06.

Very Low Vulnerability

Low Vulnerability

Moderate Vulnerability

Vulnerable

High Vulnerability
(1): 0-0.54 percent of total local employment

(2): 0.55-1.07 percent of total local employment

(3): 1.08-2.62 percent of total local employment

(4): 2.63-4.17 percent of total local employment

(5): $>4.17$ percent of total local employment

Rules: Installations are often in two or more counties. Therefore, regional classifications are determined by a weighted average. The weighted average calculation determines what percentage of the installation is in each county and multiplies that percentage by that county's value. The values for each county surrounding the installation are then totaled to arrive at a value for the region. This value is subjected to the same metric that determined the classification for the individual counties.

Example:

Indicator Value for the Region Around an Installation = (Percentage of Installation in County $A^{*}$ Indicator Value for County A) + (Percentage of Installation in County $B^{*}$ Indicator Value for County B)...etc.

\section{Indicator: Job Availability/Unemployment (EC2) \\ Variables: Unemployment Rate \\ Scale: $\quad$ County \\ Year: $\quad 2004$ \\ Data Sources:}

Bureau of Labor Statistics (BLS), U.S. Department of Labor. (2003). Employment Situation Explanatory Note. Washington, DC, available through URL: http://www.bls.gov/news.release/empsit.tn.htm

Bureau of Labor Statistics (BLS), U.S. Department of Labor. (2005). Local Area Unemployment Statistics. Washington, DC, available through URL: 
Department of the Army, U.S.. (2002). FY03 Army Well-Being Action Plan. Deputy Chief of Staff for Personnel. Washington, DC, available through URL: http://www.odcsper.army.mil/Directorates/wb/FY03 WBAP Vol 1.pdf

Logic: The most common measure of job availability is the unemployment rate. Theoretically, the unemployment rate characterizes the job-market in a particular area. However, the system for gathering employment data is not perfect. Unemployment surveys miss self-employed and discouraged job seekers. Other workers hold temporary jobs when they want permanent jobs, working part-time when they want to work full time, or holding jobs below their skill and education levels. Some workers counted as unemployed may be halfheartedly job-hunting to keep unemployment benefits (BLS 2003). Regretfully, there is not some quality of job measure available - comparing minimum and living wage and part-time and full-time employment.

Unemployment rates do, however, characterize the quality of life. The Army has recognized in its Well-Being Action Plan that "Soldier and family satisfaction help to retain Soldiers" (USDA 2002). Part of being "satisfied" is having the financial stability and employment needed to meet that. The military is beginning to move aggressively into addressing family member employment. Initial efforts are focused on establishing public partnerships with private corporations to provide training and career continuity to military spouses. A Spouse Telework Employment Program (STEP) is nearing completion and the Department of Defense is working with the Department of Labor to explore opportunities in the public sector. In the interim, the military's Spouse Employment Program is developing capabilities in the following areas: job search assistance, private sector job bank, and career counseling. Mid and long-term objectives focus on capturing lessons learned from the initial partnerships and expanding the program to more corporations (USDA 2002).

Characteristics of the labor market reveal a lot about the economy and quality of life of a community. Although the job market may seem not to affect service members, it will affect their family members and the overall economic growth of the area. Like most economic news, a low unemployment rate is a mixed blessing. It is good news for workers and their families in terms of prosperity. But it means that employers must scramble to fill their openings, and prospective employers may be a bit wary about locating in areas where workers are hard to find and they have to offer higher wages to compete with other employers. Thus, economists have determined an ideal unemployment rate range of 4 to 5.6 percent (BLS 2003). Some level of unemployment is normal. Yet, too low or too high unemployment rates leads to problems. 
Replicable: The U.S. Department of Labor, Bureau of Labor Statistics, provides unemployment statistics for the latest year available for download through URL: http://www.bls.gov/lau/home.htm

Directions: Download unemployment rate county data from the U.S. Department of Labor, Bureau of Labor Statistics, Local Area Unemployment Statistic website available online at http://www.bls.gov/lau/home.htm (BLS 2005). Import the data into a GIS program and join it with county boundary files to create a GIS Job Availability/Unemployment indicator layer.

Indicator Measure: The rationale for the legend is based on unemployment levels around the ideal or "natural" unemployment rate (4-5.6 percent). Scholars disagree about what the exact natural rate of unemployment is and how it should be derived. From data and papers accessible through the Bureau of Labor Statistics, most scholars commonly agree on 5.5 percent natural unemployment (BLS 2003). From this, levels of unemployment that are acceptable were designated Very Low Vulnerability, and outside of this range natural breaks occurred to designate Moderate and High Vulnerability classifications.

Very Low Vulnerability

Low Vulnerability

Moderate Vulnerability

Vulnerable

High Vulnerability
(1): $>=4$ and $<5.7$ percent

(2): Not Applicable

(3): $>=2.4$ and $<4$ or $>=5.7$ and $<9.1$ percent

(4): Not Applicable

(5): $>=0$ and $<2.4$ or $>9.1$ and $<=25$ percent

Rules: In the case where an installation is in two or more counties, regional classifications are determined by a weighted average. The weighted average calculation determines what percentage of the installation is in each county and multiplies that percentage by that county's classification value. The values for each county of the installation are then totaled to arrive at a value for the region around the installation. This value is subjected to the same metric that determined the classification for the individual counties.

Example:

Indicator Value for the Installation Region = (Percentage of Installation in County $A^{*}$ Indicator Value for County A) + (Percentage of Installation in County $B^{\star}$ Indicator Value for County B)...etc.

$\begin{array}{ll}\text { Indicator: } & \text { Housing Affordability (EC3) } \\ \text { Variables: } & \text { Net Rents, Net Income } \\ \text { Scale: } & \text { County } \\ \text { Year: } & 1999\end{array}$




\section{Data Sources:}

Bureau of the Census, U.S. Department of Commerce. (2000). Summary File 3: Table H69, Gross Rent as a Percentage of Household Income. American FactFinder. Washington, DC, available through URL: http://factfinder.census.gov

Department of Housing and Urban Development, U.S.. (2003). Buying a Home: Find out How Much Mortgage Can You Afford. Washington, DC http://www.hud.gov/buying/index.cfm

Department of the Army, U.S.. (2002). FY03 Army Well-Being Action Plan. Deputy Chief of Staff for Personnel. Washington, DC http://www.hud.gov/buying/index.cfm

National Association of REALTORS. (2003). Housing Affordability. Chicago, IL http://www.hud.gov/buying/index.cfm

Logic: Housing affordability is "the ratio of median family income to the income needed to purchase the median priced home based on current interest rates and underwriting standards, expressed as an index" (National Association of REALTORS 2003). The National Association of Realtors compiles such an index at the national level annually. The proportion of income spent on housing can be used as a broad measure of the ease (or difficulty) that people experience in meeting their housing commitments. However to the extent that higher housing payments may reflect discretionary savings among home purchasers, care should be exercised in the use of such a measure. In the rental sector, households may choose to pay a higher rent to live close to employment and so reduce travel time and cost. Nevertheless, a comparison of the proportion of income spent on housing for different types of households and levels of income provides insight into those groups most likely to be under financial pressure through housing costs.

Housing affordability is also a characteristic of the overall cost of living. Referenced from the U.S. Department of Housing and Urban Development (HUD 2003), people typically allocate 30 percent of their income to housing. This is the largest amount allocated to any one good or service. In other words, it is a large portion of a households' spending. If housing costs are high, it detracts from an individual's ability to afford other goods and services. People living where housing costs are high are more likely to not be able to afford a standard of living as high as those living where housing costs are lower. If standard of living is lower, quality of life is lowercannot afford the social and cultural aspects of personal enrichment (USDA 2002). More specifically to the military are DoD housing allowances. With many military employees forced to choose off-base housing, local cost of living is an important indicator in determining the DoD housing allowance. 
Housing costs are determined based on gross rent within a community due to their high flexibility to change with rapidly changing market conditions.

Replicable: The U.S. Census provides housing statistics every decade reported in Summary File 3 available for download at http://www.census.gov (Bureau of the Census 2000). Housing statistics are also replicated every 5 years in a Decennial Supplementary Survey. It is recommended that the data is replicated only once a decade due to the non-comprehensiveness of the supplementary surveys.

Directions: Download table H69 Gross Rent as Percentage of Household Income: 1999 from the U.S. Census 2000 Summary File 3 at the county level available online at http://factfinder.census.gov/ (Bureau of the Census 2000). Import the data into a GIS program and join with county boundary files to create a GIS Housing Affordability indicator layer.

Indicator Measure: Gross rent as a percentage of household income in 1999 is a computed ratio of monthly gross rent to monthly household income (total household income in 1999 divided by 12). The ratio is computed separately for each unit and is rounded to the nearest tenth. Units for which no rent is paid and units occupied by households that reported no income or a net loss in 1999 comprise the category "Not computed." The sample is assumed to be relatively normal; the classifications were configured around HUD's recommended 30 percent allocation. The national average is 29.86 percent.

$\begin{array}{ll}\text { Very Low Vulnerability } & (1):<30.00 \text { percent } \\ \text { Low Vulnerability } & (2):>=30.01-<33.15 \text { percent } \\ \text { Moderate Vulnerability } & (3):>=33.15-<36.28 \text { percent } \\ \text { Vulnerable } & (4):>=36.28-<39.4 \text { percent } \\ \text { High Vulnerability } & (5):>=39.4 \text { percent }\end{array}$

Rules: Installations are often in two or more counties. Therefore, the region around an installation is classified by a weighted average. The weighted average calculation determines what percentage of the installation is in each county and multiplies that percentage for each county by that county's classification value. The values for each county are then totaled to arrive at a value for the installation. This value is subjected to the same metric that determined the classification for the individual counties.

Example:

Indicator Value for the Installation $=$ (Percentage of Installation in County $A^{\star}$ Indicator Value for County $A)+\left(\right.$ Percentage of Installation in County $B^{*}$ Indicator Value for County B)...etc. 


\section{Indicator: Poverty (EC4) \\ Variables: Population Under 18 Years Below Poverty, Population 18-65 \\ Years Below Poverty, Population Above 65 Years Below Poverty, Total Population \\ Scale: $\quad$ County \\ Year: $\quad 2000$ \\ Data Sources:}

Bureau of the Census, U.S. Department of Commerce. (2000). Glossary. American FactFinder. Washington, DC. (Poverty), available through URL: http://www.hud.gov/buying/index.cfm

Kids Count, Annie E. Casey Foundation. (2000). The High Cost of Being Poor: Another Perspective on Helping Low-Income Families Get By and Get Ahead. Kids Count Online Database. Baltimore, MD. (Census Data Online) http://www.hud.gov/buying/index.cfm

Logic: This indicator measures the economic sustainability in a particular county based on the economic indicator of income. The amount of disposable income a household or individual has to provide the basic needs determine the extent to which economic development is either self-undermining or self-renewing. Many military installations depend on the economic resources of the surrounding community. Thus, it is important that current economic practices occurring around military installations focus on providing positive options and choices of future generations. Economic development thrives when there is sufficient income and stagnates without sufficient income.

Poverty rates measure the sufficiency of income to provide basic needs. Poverty rates are most easily accessible through the U.S. Census Bureau. The U.S. Census Bureau defines poverty by following the Office of Management and Budget's (OMB's) Directive 14. The Census Bureau uses a set of money income thresholds that vary by family size and composition to detect who is poor. If the total income for a family or unrelated individual falls below the relevant poverty threshold, then the family or unrelated individual is classified as being "below the poverty level" (Bureau of the Census 2000). The Kids Count project compiles these census figures into a comprehensive database addressing poverty for each U.S. County. By using these statistics, this study identifies areas with relatively high proportion of individuals without a sufficient disposable income to provide the basic needs and services (Kids Count 2000).

Lastly, it is important to note this data is on the county level, not community. Hence, it may be skewed by local "hotspots." In other words, if a county has one community ranking high in poverty, the entire county is classified as high poverty regardless of the characteristics of the remaining majority of the county. Because of 
this concern, it is important to use local knowledge in interpreting the poverty classifications.

Replicable: The Kids Count database is maintained by the Annie E. Casey Foundation. The database includes a comprehensive source of population poverty status at the state and county level obtained from the U.S. Census Bureau (Kids Count 2000). This indicator could be replicated every year from the U.S. Census Bureau small income and poverty estimates program based on population estimates, or every decade based on actual, verifiable counts. It is recommended that the data be replicated only once a decade due to the inaccuracy of census estimates. Poverty statistics may be obtained directly from the U.S. Census Bureau at http://factfinder.census.gov, or a "cleaned" version downloaded from the Kids Counts at http://www.aecf.org/kidscount/data.htm.

Directions: Download Population Under 18 Years Below Poverty, Population 1865 Years Below Poverty, Population Above 65 Years Below Poverty, and Total Population for all U.S. counties from the Kids Count 2003 Database (Kids Count 2000). Import the data into a GIS program and join it with county boundary files to create a GIS Poverty indicator layer.

Indicator Measure: The poverty indicator provides a measure of the percent of the total population below the poverty level at a county level. The indicator is calculated by summing population under 18 years below poverty, population 18-65 years below poverty, and population above 65 years below poverty within a county and then dividing the total by the county's total population and finally multiplying the result by 100 . This yields a percentage of poverty within a county.

Poverty $=[($ Population Under 18 Years Below Poverty+Population 18-65 Years Below

Poverty+Population Above 65 Years Below Poverty)/Total Population] ${ }^{\star 100}$

The data is assumed to be relatively normal and thus classification is statistically based on the standard deviation (6.33) and national mean (13.65 percent). The classes are as follows.

Very Low Vulnerability

(1): $\quad<=12.08$ percent

Low Vulnerability

(2): $>12.08-<=13.65$ percent

Moderate Vulnerability

(3): $\quad>13.65-<=16.83$ percent

Vulnerable

(4): $>16.83-<=18.40$ percent

High Vulnerability

(5): $\quad>18.40$ percent

Rules: Installations are often in two or more counties. Therefore, the region around an installation is classified by a weighted average. The weighted average 
calculation determines what percentage of the installation is in each county and multiplies that percentage for each county by that county's classification value. The values for each county are then totaled to arrive at a value for the installation. This value is subjected to the same metric that determined the classification for the individual counties.

Example:

Indicator Value for the Installation $=$ (Percentage of Installation in County $A^{*}$ Indicator Value for County $A)+\left(\right.$ Percentage of Installation in County $B^{*}$ Indicator Value for County B)...etc.

\section{Indicator: Residential Construction Value (EC5) \\ Variables: Annual Average value per unit \\ Scale: $\quad$ County \\ Year: $\quad 2004$ \\ Data Source:}

Bureau of the Census, U.S. Department of Commerce. (2005). New Residential Construction, Building Permits by County or Place. Manufacturing, Mining, and Construction Statistics. Washington, DC

http://www.hud.gov/buying/index.cfm

Logic: This indicator along with Housing Affordability provides an idea of the overall cost of living. If housing costs are high, it detracts from an individual's ability to afford other goods and services. People living where housing costs are high are more likely to not be able to afford a standard of living as high as those living where housing costs are lower. If the standard of living is lower, the quality of life is lower and residents are less likely to afford the social and cultural aspects of personal enrichment. More specifically to the military are DoD housing allowances. With increasing numbers of military employees living off-base, local housing cost is an important indicator in determining the DoD housing allowance.

Additionally, the cost of local housing may be an indicator of the economic and political influence of the regional population. A more forceful and influential regional population (accustomed to a higher standard of living) competing with the military installation for services, access, resources, and land can affect the type and intensity of training that can take place on the installation.

Lastly, it is important to note this data is on the county level, not community. Hence, it may be skewed by local "hotspots." In other words, if a county has one community with a high residential construction value, the entire county is classified as high vulnerability regardless of the characteristics of the remaining majority of 
the county. Because of these concerns, it is important to use local knowledge in interpreting the residential construction value classifications.

Replicable: The U.S. Census provides residential construction statistics by county on new privately-owned residential housing units authorized by building permits. Data items include number of buildings, units, and construction cost for monthly new privately-owned residential building permits. This data is updated monthly. County level data are totals provided for each county in which every permit office is requested to report monthly. Data is available for download through URL:

http://www.hud.gov/buying/index.cfm

It is recommended that this indicator be updated on an annual basis. The U.S. Census, Building Permits by County or Place webserver limits queries to one county or place at a time. Thus, it is more time effective to request annual county level residential building statistics directly from the U.S. Census for a minimal fee.

Directions: Request "Annual County Level Residential Building Permits" for 2004 in ASCII format from the U.S. Census through URL:

http://www.hud.gov/buying/index.cfm

(Note, this file will include construction value.) Import the data into a spreadsheet program and sum "value" and "units" columns for each county. Calculate the residential construction value as follows.

Residential Construction Value $=($ Total Value of Construction in 2004/Total Units for which permits were issued in 2004)

Import the resulting math into a GIS program and join it with county boundary files to create a Residential Construction Value indicator layer.

Indicator Measure: This indicator provides a measure of the value of residential construction at a county level. The data is assumed to be relatively normal and thus classification is statistically based on the standard deviation $(50,089)$ and national mean ( $\$ 124,220$ per unit) excluding 294 of 3,141 counties not reporting residential construction values in 2004 . The classes are as follows.

Very Low Vulnerability

Low Vulnerability

Moderate Vulnerability

Vulnerable

High Vulnerability
(1): $\quad<\$ 74,131$ per unit

(2): $>=\$ 74,131-<\$ 99,175$ per unit

(3): $>=\$ 99,175-<\$ 149,264$ per unit

(4): $>=\$ 149,264-<\$ 174,308$ per unit

(5): $>=\$ 174,308$ per unit 
In random instances, the County permit office does not report the value or number of issued permits to the U.S. Census. These instances are rare but do occur.

Rules: Installations are often in two or more counties. Therefore, the region around an installation is classified by a weighted average. The weighted average calculation determines what percentage of the installation is in each county and multiplies that percentage for each county by that county's classification value. The values for each county are then totaled to arrive at a value for the installation. This value is subjected to the same metric that determined the classification for the individual counties.

Example:

Indicator Value for the Installation $=\left(\right.$ Percentage of Installation in County $A^{*}$ Indicator Value for County $A)+\left(\right.$ Percentage of Installation in County $B^{*}$ Indicator Value for County B)...etc.

\section{Indicator: Housing Permits Issue Rate (EC6) \\ Variables: Annual Building Permits Issued in1995 and 2004 \\ Scale: $\quad$ County \\ Year: $\quad$ 1995-2004 \\ Data Source:}

Bureau of the Census, U.S. Department of Commerce. (2005). New Residential Construction, Building Permits by County or Place. Manufacturing, Mining, and Construction Statistics. Washington, DC, available through URL:

http://www.hud.gov/buying/index.cfm

Logic: This indicator along with Rental and Housing Availability provides an idea of the availability of housing in a particular county. With an increasing number of military employees living off-base, local housing availability is an important indicator in determining DoD stationing attractiveness and quality of life for military employees and their family. Housing construction rates can directly impact a number of housing availability and quality of life indicators. For example, it may determine housing costs, commute times, access to schools or cultural amenities, or if a family may live with a service member.

Additionally, increasing residential construction may be an indicator of expected regional growth. The degree of regional population growth is a strong indicator of the demand for services, access, resources, and land in competition with the military installation. This can affect the type and intensity of training that can take place on the installation. This indicator assumes that fast growing human populations are less sustainable. 
However, it is also important to note a national trend of decreasing household size (Bureau of the Census 2005). Thus, an increasing housing construction rate may be reflective of the local population consuming more housing as opposed to increasing regional population. In this case, local commercial and industrial land use would remain stable. Regardless, increasing land consumption for housing, commercial, and/or industrial uses is one of the leading causes of environmental degradation.

Lastly, it is important to note this data is on the county level, not community. Hence, it may be skewed by local "hotspots." In other words, if a county has one community with a high building permit issue rate, the entire county is classified as high vulnerability regardless of the characteristics of the remaining majority of the county. Because of these concerns, it is important to use local knowledge in interpreting the building permit issue rate classifications.

Replicable: The U.S. Census provides building permit statistics by county on new privately-owned residential housing units authorized by building permits. Data items include number of buildings, units, and construction cost for monthly new privately-owned residential building permits. This data is updated monthly. County level data are totals provided for each county in which every permit office is requested to report monthly. Data is available for download through URL http://www.hud.gov/buying/index.cfm

It is recommended that this indicator be updated on an annual basis. The U.S. Census, Building Permits by County or Place webserver limits queries to one county or place at a time. Thus, it is more time effective to request annual county level residential building permits directly from the U.S. Census for a minimal fee.

Directions: Request "Annual County Level Residential Building Permits" for 1995 and 2004 in ASCII format from the U.S. Census at: http://www.census.gov/const/www/permitsindex.html

Import the data into a spreadsheet program and sum total units for each county in 1995 and 2004 separately. Calculate the housing permit issue rate from 1995 to 2004 as follows.

Housing Permit Issue Rate $=$ [(Total Issued Permits in 2004 -Total Issued Permits in 1995)/Total Issued Permits in 1995] ${ }^{* 100}$

Import the resulting math into a GIS program and join it with county boundary files to create a Housing Permit Issue Rate indicator layer. 
Indicator Measure: This indicator provides a measure of residential construction growth rate at a county level. The data is assumed to be relatively normal and thus classification is statistically based on the standard deviation (407) and national mean (99.1 percent) excluding 263 of 3,141 counties not reporting permit data for 1995,2004 , or both years. The classes are as follows.

$\begin{array}{ll}\text { Very Low Vulnerability } & (1):<=0 \text { percent } \\ \text { Low Vulnerability } & (2):>0-<=100 \text { percent } \\ \text { Moderate Vulnerability } & (3):>100-<=200 \text { percent } \\ \text { Vulnerable } & (4):>200-<=300 \text { percent } \\ \text { High Vulnerability } & (5):>300 \text { percent }\end{array}$

In random instances, the County permit office does not report the number of issued permits to the U.S. Census. These instances are rare but do occur

Rules: Installations are often in two or more counties. Therefore, the region around an installation is classified by a weighted average. The weighted average calculation determines what percentage of the installation is in each county and multiplies that percentage for each county by that county's classification value. The values for each county are then totaled to arrive at a value for the installation. This value is subjected to the same metric that determined the classification for the individual counties.

Example:

Indicator Value for the Installation $=$ (Percentage of Installation in County $A^{*}$ Indicator Value for County $A)+\left(\right.$ Percentage of Installation in County $B^{*}$ Indicator Value for County B)...etc. 


\title{
Sustainability Issue: Quality of Life
}

\author{
Indicator: Crime Rate (QL1) \\ Variables: Murder, Rape, Robbery, Aggravated Assault, Burglary, Larceny, \\ Auto Theft, and Arson Counts, Population \\ Scale: $\quad$ County \\ Year: $\quad 2002$ \\ Data Sources:
}

Bureau of Investigation, U.S. Department of Justice. (2005). Uniform Crime Reporting Program Data: County-Level Detailed Arrest and Offense Data. National Archive of Criminal Justice Data/Inter-university Consortium for Political and Social Research. Washington, DC/Ann Arbor, MI, available through URL: http://www.hud.gov/buying/index.cfm

Wilson, James Q., and George Kelling. (1982). Broken Windows: The Police and Neighborhood Safety. The Atlantic Monthly. Boston, MA, available through URL: http://www.hud.gov/buying/index.cfm

Logic: For years, practitioners and experts in the field of law enforcement assert the crime rate as an indicator of the overall quality of life and level of public services offered in a particular area. The U.S. Department of Justice supports the theory that higher incidences of crime tend to reflect economic stagnation, sprawl, and lack of community resources. If crime is prevalent in an area, people do not wish to live there, land is used inefficiently, and economic resources are spent fighting crime. The result is diverted resource away from other priorities such as protecting the environment. For these reasons, crime statistics are highly sought after as an indicator in the decisionmaking process for location of families and military development. The hosts of social and economic pressures that high crime incidences create result in large limitation on development potential of an area to military installations. These military installations are where soldiers and their families are housed. Thus, any installation must provide for their safe and secure future.

Supporting studies for these overall quality of life and level of public services assertions can be traced to a relatively simple theory referred to as "broken windows," which was first discussed by James Q. Wilson and George Kelling in 1982 (J.Q. Wilson et al. 1982). Wilson and Kelling prove that on a community level, disorder and crime are inextricably linked. Their analogy is simple-linking social disorder to the condition of windows in a vacant building. If a single window is broken and goes un-repaired, it is a symbol that no one cares and thus is an acceptable act within the community. It is then only a matter of time before all of the windows are broken. The failure to repair the broken window is evidence of a social failure that results in disorder and inevitably leads to more serious disorder and crime and 
overall lack of stability. People move to new areas excluding themselves from others, and public services decline as more resources are put into crime defense. The overall environment declines-decreased quality of life (J.Q. Wilson et al. 1982). Therefore, high incidences of crime should indicate a non-ideal location for military personnel, their families, and military operations.

The Uniform Crime Reporting Program Data: County-Level Detailed Arrest and Offense Data, 2002 reports counts of arrests and offenses for the Uniform Crime Reports (UCR) of the National Archive of Criminal Justice Data (NACJD) index (Part I) crimes: murder, rape, robbery, aggravated assault, burglary, larceny, auto theft, and arson (Bureau of Investigation 2005). The UCR County-level Arrest files also report arrests for additional (Part II) crimes such as forgery, fraud, vice offenses, and drug possession or sale. The Federal Bureau of Investigation (FBI) originally collected the data from reports submitted by agencies and states participating in the UCR Program. Detailed discussions of reporting procedures are found in the Uniform Crime Reporting Handbook (Washington, DC: U.S. Government Printing Office 1980), and in the codebooks for the Inter-university Consortium for Political and Social Research (ICPSR) data collections available through URL:

http://www.hud.gov/buying/index.cfm

The FBI maintains the data in the NACJD, which is hosted by the ICPSR (Bureau of Investigation 2005).

Only Part I data-murder, rape, robbery, aggravated assault, burglary, larceny, auto theft, and arson-were used for this indicator. This data was summed by the ICPSR index and is a comprehensive list relevant to military installation quality of life assessment.

In one sense this crime data is complete because it accurately describes the accountancy of each event. Yet, in another sense, it is incomplete because it may not easily be used to explore circumstance patterns. Missing from this data is the day-to-day social context of crime, which may be understood more completely by community residents than by statistics because of the resident's expertise concerning neighborhood problems and activity patterns. For community residents, there is a wealth of information that affects their perceptions of the safety of their community. These perceptions are formed not only by crime data, but graffiti, rowdiness, public drunkenness, abandoned autos, and other such factors may be as influential in coloring perceptions and appear as threatening as murder, rape, robbery, aggravated assault, burglary, larceny, auto theft, and arson.

Lastly, it is important to note this data is on the county level, not community. Hence, it may be skewed by local "hotspots." In other words, if a county has one 
community ranking high in crime, the entire county is classified as high crime regardless of the characteristics of the remaining majority of the county. Because of these two concerns, it is important to use local knowledge in interpreting the crime classifications.

Replicable: The FBI provides estimations of national reported crime activity and arrest statistics from law enforcement agencies periodically. These statistics are managed by the NACJD, and are updated through the ICPSR. The NACJD data are available from the ICPSR at http://www.icpsr.umich.edu (Bureau of Investigation 2005).

Directions: Download Study No. 4009 Uniform Crime Reporting Program Data [United States]: County-Level Detailed Arrest and Offense Data, 2002 from the NACJD/ICPSR website http://www.icpsr.umich.edu/ (Bureau of Investigation 2005). Import Dataset 4: Crimes Reported data into a GIS program and join it with county boundary files to create a GIS Crime Rate indicator layer.

Indicator Measure: The Crime indicator provides a measure of murder, rape, robbery, aggravated assault, burglary, larceny, auto theft, and arson arrests at a county level. The indicator is calculated by dividing the total number of the abovementioned arrests within a county by its population and then multiplying the result by 1,000 . This yields a rate of crime per 1,000 residents per county.

Crime Rate $=[($ murder+rape + robbery+aggravated assault + burglary+larceny + auto theft+arson arrests)/population] ${ }^{\star 1,000}$

Crime data was statistically classified using the standard deviation around a relatively normal mean. The national average is 46 crimes per 1,000 persons, and the standard deviation is 31 . Thus, the scale is as follows.

Very Low Vulnerability $\quad(1)$ : $\quad<31$ crimes per 1,000 persons

Low Vulnerability

(2): $>=31-<46$ crimes per 1,000 persons

Moderate Vulnerability

(3): $>=46-<62$ crimes per 1,000 persons

Vulnerable

(4): $>=62-<77$ crimes per 1,000 persons

High Vulnerability

(5): $>=77$ crimes per 1,000 persons

Rules: Installations are often in two or more counties. Therefore, regional rating around those installations is determined by a weighted average. The weighted average calculation determines the percentage of the installation in each county and multiplies that percentage by that county's value. The values for each county surrounding an installation are then totaled to arrive at a value for the region. This 
value is subjected to the same metric that determined the classification of the individual counties.

Example:

Indicator Value for the Region around an Installation = (Percentage of Installation in County $A^{*}$ Indicator Value for County A) + (Percentage of Installation in County $B^{*}$ Indicator Value for County B)...etc.

\section{Indicator: Housing Availability (QL2) \\ Variables: Homeowner Vacancy Rate \\ Scale: County \\ Year: $\quad 2000$ \\ Data Sources:}

Bureau of the Census, U.S. Department of Commerce. (2000). Summary File 1: Homeowner Vacancy Rate. American FactFinder. Washington, DC, available through URL: http://www.hud.gov/buying/index.cfm

Heumann, Leonard F. (2002). Professor of Urban at Regional Planning and Psychology, University of Illinois at Urbana-Champaign. PhD, University of Pennsylvania, 1973. Adam Hall (Ed.). Champaign, IL.

Logic: This indicator along with Rental Availability provides an idea of the housing availability in a particular county and its neighboring area. Referenced in consultation with housing expert and professor at the University of Illinois Leonard Heumann, the homeownership and rental vacancy rate is relatively tight and small movements in one direction or another can have large effects in the surrounding economy. It is important to examine owner and rental availability separately to grasp a realistic picture of available housing in a given area (L.F. Heumann 2002).

With many service members required to use off base housing, housing availability is an important indicator in determining DoD stationing attractiveness and quality of life for the military and their families. Housing availability can directly impact a number of quality of life indicators. For example, it may determine commute times, access to schools or cultural amenities, or if a family may live with a service member.

Replicable: The U.S. Census provides vacancy statistics every decade reported in Summary File 1 available for download at http://www.census.gov (Bureau of the Census 2000). Vacancy statistics are also replicated as estimates annually. It is recommended that the data be replicated only once a decade due to the inaccuracy of census estimates. 
Directions: Download Homeowner Vacancy Rate from the U.S. Census 2000 Summary File 1 at the county level. Available online at http://factfinder.census.gov/ (Bureau of the Census 2000). Import the data into a GIS program and join it with state boundary files to create a GIS Housing Availability indicator layer.

Indicator Measure: Housing Availability illustrates homeowner vacancy rate per county. It should be noted that some areas of high owner occupied vacancy might possibly be seasonal housing not occupied at the time of the census.

The rationale for the legend is that too high or too low of an owner vacancy rate can be an indicator of difficulty of obtaining housing (too low) or serious problems in the housing market and surrounding economy (too high). These rough classifications were provided from Leonard Heumann, a professor at the University of Illinois with expertise in housing issues, through a personal interview in 2002 (L.F. Heumann 2002).

$\begin{array}{ll}\text { Very Low Vulnerability } & (1):>=2.1-<3.5 \text { percent } \\ \text { Low Vulnerability } & (2): \text { Not Applicable } \\ \text { Moderate Vulnerability } & (3): \quad>=1.5-<2.1 \text { or }>=3.5-<6.1 \text { percent } \\ \text { Vulnerable } & (4): \text { Not Applicable } \\ \text { High Vulnerability } & (5): \quad>=0-<1.5 \text { or }>=6.1 \text { percent }\end{array}$

Rules: Installations are often in two or more counties. Therefore, the region around an installation is classified by a weighted average. The weighted average calculation determines what percentage of the installation is in each county and multiplies that percentage for each county by that county's classification value. The values for each county are then totaled to arrive at a value for the installation. This value is subjected to the same metric that determined the classification for the individual counties.

Example:

Indicator Value for the Installation $=\left(\right.$ Percentage of Installation in County $A^{*}$ Indicator Value for County $A)+\left(\right.$ Percentage of Installation in County $B^{*}$ Indicator Value for County B)...etc.

\section{Indicator: Rental Availability (QL3) \\ Variables: Rental Vacancy Rate \\ Year: $\quad 2000$ \\ Data Sources:}

Bureau of the Census, U.S. Department of Commerce. (2000). Summary File 1: Rental Vacancy Rate. American FactFinder. Washington, DC, available through URL: 
Heumann, Leonard F. (2002). Professor of Urban at Regional Planning and Psychology, University of Illinois at Urbana-Champaign. PhD, University of Pennsylvania, 1973. Adam Hall (Ed.). Champaign, IL.

Logic: This indicator along with Homeowner Availability provides an idea of the rental availability in a particular county and its neighboring area. Referenced in consultation with housing expert and professor at the University of Illinois Leonard Heumann, the homeownership and rental vacancy rate is relatively tight and small movements in one direction or another can have large effects in the surrounding economy. It is important to examine owner and rental availability separately to grasp a realistic picture of available housing in a given area (L.F. Heumann 2002).

Many military members are required to choose off base housing. Rental availability is an important indicator in determining DoD stationing attractiveness and quality of life for military members and their families. Similar to housing availability, rental availability also directly impacts a number of quality of life indicators. For example, it may determine commute times, access to schools or cultural amenities, or if a family may live with a service member.

Replicable: The U.S. Census provides vacancy statistics every decade reported in Summary File 1 available for download at http://www.census.gov (Bureau of the Census 2000). Vacancy statistics are also replicated as estimates annually. It is recommended that the data be replicated only once a decade due to the inaccuracy of census estimates.

Directions: Download Rental Vacancy Rate from the U.S. Census 2000 Summary File 1 at the county level. Available online at http://factfinder.census.gov/ (Bureau of the Census 2000). Import the data into a GIS program and join it with county boundary files to create a GIS Rental Availability indicator layer.

Indicator Measure: Map rental vacancy rate per county. It should be noted that some areas of high rental occupied vacancy might possibly be seasonal housing not occupied at the time of the census.

The rationale for the legend is that too high or too low a rental vacancy rate can be an indicator of difficulty of obtaining housing (too low) or serious problems in the housing market and surrounding economy (too high). These rough classifications were provided from Leonard Heumann, a professor at the University of Illinois with expertise in housing issues, through a personal interview in 2002 (L.F. Heumann 2002). 
Very Low Vulnerability

Low Vulnerability

Moderate Vulnerability

Vulnerable

High Vulnerability
(1): $>=7-<11.4$ percent

(2): Not Applicable

(3): $>=4.4-<7$ percent or $>=11.4-<13.8$ percent

(4): Not Applicable

(5): $>=0-<4.4$ percent or $>=13.8-<=100$ percent

Rules: Installations are often in two or more counties. Therefore, the region around an installation is classified by a weighted average. The weighted average calculation determines what percentage of the installation is in each county and multiplies that percentage for each county by that county's classification value. The values for each county are then totaled to arrive at a value for the installation. This value is subjected to the same metric that determined the classification for the individual counties.

Example:

Indicator Value for the Installation $=\left(\right.$ Percentage of Installation in County $A^{*}$ Indicator Value for County A) + (Percentage of Installation in County $B^{\star}$ Indicator Value for County B)...etc.

\section{Indicator: Healthcare Availability (QL4) \\ Variables: Health Professional Shortage Area (ratio of primary medical care physicians per 1,000 population) \\ Scale: $\quad$ ZIP Code \\ Year: $\quad 2004$ \\ Data Sources:}

DA. (2002). FY03 Army Well-Being Action Plan. Deputy Chief of Staff for Personnel. Washington, DC, available through URL: http://www.odcsper.army.mil/Directorates/wb/FY03 WBAP Vol 1.pdf

Health Resources and Services Administration, U.S. Department of Health and Human Services. (2005). HRSA Geospatial Data Warehouse: ZIP Code Tabulation Areas. Washington, DC, available through URL:

http://datawarehouse.hrsa.gov/pcsa.htm

Health Resources and Services Administration (HRSA), U.S. Department of Health and Human Services. (2003). What We Do. Washington, DC, available through URL: http://www.hhs.gov/news/press/2002pres/profile.html

Ringel, Jeanne S., Susan D. Hosek, Ben A. Vollaard, and Sergej Mahnovski. (2002). The Elasticity of Demand for Health Care: A Review of the Literature and Its Application to the Military Health System. National Defense Research Institute/RAND Health. Washington, DC, available through URL:

http://www.rand.org/publications/MR/MR1355/MR1355.pdf

Logic: The U.S. Department of Health and Human Service (HHS) defines healthcare as an "essential human service" (HRSA 2005). Access to preventive healthcare 
and treatment for families and individuals can affect both their personnel and the region's quality of life. The Army's Well-Being Program acknowledges that low availability to healthcare can diminish quality of life as populations go without preventive care such as immunizations, often leading to disease (USDA 2002). Unfortunately, healthcare is not provided equally across the nation nor do all individuals use it similarly. DoD-paid healthcare differs in several important ways from the demand for healthcare services in general (J.S. Ringel et al. 2002). These differences derive from the unusual organization structure of the Military Health System (MHS). Three key differences exist. First, active duty personnel have less discretion in seeking care than their civilian counterparts and some military duties involve higher risk. Moreover, "to ensure that active duty personnel are healthy and fit for duty, they are provided more frequent preventive and routine care than would be typical for civilian the same age" (J.S. Ringel et al. 2002). Second, TRICARE, insurance provider to DoD, treats military treatment facilities (MTF) differently than civilian care. In other words, a recipient may receive more benefits if using a MTF instead of civilian care, thus allocation between the MTF and civilian providers is a factor. Third, military beneficiaries typically use substantially more healthcare service than comparable civilians do. Thus, increased demand for prescriptions and the like (J.S. Ringel et al. 2002).

Therefore, it is important to the well-being of military installations to identify areas where healthcare is underserved. Underservice is an indication of the current health status for military operations and the lives of military personnel and their families.

The HHS' indices of Health Professional Shortage Area (HPSA) and Medical Underservice (IMU) are currently the most comprehensive sources of secondary data to characterize the health and resource capacity of communities in the United States (HRSA 2005). Both indices are compiled by the HRSA, and are used to allocate resources for Federal and sometimes state programs including the assignment of National Health Service Corps Physicians or allowing International Medical Graduates with $\mathrm{J}-1$ visas to practice in a community (HRSA 2005). An HPSA is a geographically defined area having an inadequate ratio of full-time primary care, mental health, and dental practitioners to total population. IMU designation weights HPSA calculations based on regional infant mortality rates, percentage of the population with incomes below the poverty level, and percentage of the population age 65 or older. The HHS' HPSA national dataset is more complete compared to the IMU national dataset. Thus, HPSA is the selected indicator. However, because differenced do exist between communities' healthcare needs, it is important to use local knowledge in interpreting healthcare availability. A complete definition of these measures and methods. Available through URL: 
HPSA data is reported at the ZIP code level. Health analysis experts recognize that there are many potential geographic units to use in the monitoring of our health system, yet there is no agreement or evidence to suggest a preferred geography. The reason for mentioning the units is that significant disparities among neighbors and community groups exist. Health is not expressed by political boundary, gender, age, occupation, etc. In other words, there is no ideal standard for expressing the degree of need in a community or at what scale to address those needs. Therefore, it must be understood that the HPSA indicator is an aggregate measure of the availability ZIP codes have to healthcare. A particular ZIP code may have many designations, yet the map aggregates all designations within any given code. Therefore, with spatially large or populous ZIP codes, the data may be skewed by local "hotspots." Again, user knowledge of an area should be applied to the use of healthcare measurements.

Replicable: HRSA updates HPSA designations quarterly and is accessible through the HHS website at URL:

http://datawarehouse.hrsa.gov/pcsa.htm

Directions: Download HPSA designations from the HHS website. After downloading the data, "clean" the data by aggregating (averaging) rankings for ZIP codes with more than one HPSA designation. Note that some ZIP codes have insufficient data. Import the cleaned data set into a GIS program and join it with ZIP code boundary files to form a Healthcare Availability indicator layer.

Indicator Measure: This indicator identifies areas (ZIP codes) where populations are medically underserved. To be designated as an HPSA, an area must exceed a population to full-time provider ratio of 3,000 to 3,500 or more people per primary care, mental health, and dental practitioners. The lower threshold ideally apples to areas with unusually high need for providers (HRSA 2005). The indicator was calculated as a ratio of primary medical care physicians per 1,000 population as follows.

Health Professional Shortage Area $=($ Number of full-time primary care, mental health, and dental practitioners/total population $)^{\star} 1,000$

Using the HRSA's recommendations, the following classifications were defined.

Very Low Vulnerability

Low Vulnerability

Moderate Vulnerability

Vulnerable

High Vulnerability
(1): >2.01 physicians per 1,000 population

(2): $\quad<=2.01->0.53$ physicians per 1,000 population

(3): $\quad<=0.53->0.33$ physicians per 1,000 population

(4): $\quad<=0.33->0.28$ physicians per 1,000 population

(5): $>=0.28$ physicians per 1,000 population 
Rules: Installations are often in two or more counties. Therefore, the region around an installation is classified by a weighted average. The weighted average calculation determines what percentage of the installation is in each county and multiplies that percentage for each county by that county's classification value. The values for each county are totaled to arrive at a value for the region around the installation. This value is subjected to the same metric that determined the classification for the individual counties.

Example:

Indicator Value for the Installation $=$ (Percentage of Installation in County $A^{*}$ Indicator Value for County $A)+\left(\right.$ Percentage of Installation in County $B^{*}$ Indicator Value for County B)...etc.

\section{Indicator: Educational Attainment (QL5)}

Variables: Persons 25 years of age and older, Percent high school graduate or higher

Scale: $\quad$ County

Year: $\quad 2000$

Data Sources:

Bureau of the Census, U.S. Department of Commerce. (2000). Summary File 3: Geographic Comparison Table P-11, Language, School Enrollment, and Educational Attainment. American FactFinder. Washington, DC. (Population 25 years and over: Percent High School Graduate or Higher), available through URL:

http://factfinder.census.gov

DA. (2002). FY03 Army Well-Being Action Plan. Deputy Chief of Staff for Personnel. Washington, DC, available through URL:, available through URL: http://www.odcsper.army.mil/Directorates/wb/FY03 WBAP Vol 1.pdf

National Center for Educational Statistics, U.S. Department of Education. (2003). Condition of Education. Washington, DC, available through URL: http://nces.ed.gov/programs/coe/

Logic: Educational opportunities allow individuals to grow and enrich their life. The Army places high priority on the well-being — the "personal, physical, material, mental, and spiritual state of soldiers, civilians, and their families that contributes to their preparedness to perform the Army's mission" (USDA 2002). Each year the Army updates an Army Well-Being Action Plan. This plan is dedicated to providing resources to meet the well-being needs of the Army as well as the entire U.S. military. These needs include the personal needs and aspirations of military personnel and family members to which education is a significant factor. The FY03 Army Well-Being Action Plan focuses on education and academic excellence for its personnel and their families (USDA 2002). Thus, educational attainment is a highly sought after indicator for the sustainability of military installations. 
The U.S. military provides all necessary education to its members. Currently, through the Education Transition Study Memorandum of Agreement, the military education focus in now shifting to nurturing relationships between civilian institutions and military institutions to ensure swift implementation of agreements for their personnel and their families (USDA 2002). The military recognizes that it is easier to provide for education when there are resources to build off from within the surrounding community (USDA 2002). Therefore, for this indicator, the quality of an educational environment is determined by the overall educational attainment of the surrounding community. It is assumed that the percentage of the population with a high school diploma or higher is an indicator of societal support for education (including the parental and community support). With strong support, it is then assumed the educational system will be strong and have a large amount of resources put into it.

In addition to having the framework for educational opportunities for military employees, a high percentage of the population with a high school diploma or higher creates a strong pool of qualified employees for military operations.

Replicable: The U.S. Census provides educational attainment statistics every decade reported in Summary File 3 available for download at http://www.census.gov (Bureau of the Census 2000). Every year the U.S. Census provides estimated educational attainment statistics available for download at http://factfinder.census.gov/ through the American Community Survey Summary Tables (PCT-034). However, due to the inaccuracy of U.S. Census estimates, it is recommended that the data be replicated only once a decade.

Directions: Download Geographic Comparison Table P-11. Language, School Enrollment, and Educational Attainment: 2000 from the U.S. Census website http://factfinder.census.gov/ (Bureau of the Census 2000). Import Population 25 years and over: Percent High School Graduate or Higher into a GIS program and join it with county boundary files to create a GIS Educational Attainment indicator layer.

Indicator Measure: Educational Attainment measures the percent of the population 25 years or older with a high school degree or higher (as calculated by the U.S. Census), and is available online at http://factfinder.census.gov/ (Bureau of the Census 2000).

The sample is assumed to be relatively normal. Therefore, the national average of 69.5 percent was used to figure class breaks. The classifications for percent population with a high school diploma or higher are as follows. 
Very Low Vulnerability

Low Vulnerability

Moderate Vulnerability

Vulnerable

High Vulnerability
(1): $>89.4$ percent

(2): $\quad<=89.4->82.7$ percent

(3): $<=82.7->76.1$ percent

(4): $<=76.1->69.4$ percent

(5): $\quad<=69.4$ percent

Rules: Installations are often in two or more counties. Therefore, regional classifications are determined by a weighted average. The weighted average calculation determines what percentage of the installation is in each county and multiplies that percentage for each county by that county's classification value. The values for each county are then totaled to arrive at a value for the region around the installation. This value is subjected to the same metric that determined the classification for the individual counties.

Example:

Indicator Value for the Installation = (Percentage of Installation in County $A^{*}$ Indicator Value for County A) + (Percentage of Installation in County $B^{*}$ Indicator Value for County B)...etc.

\section{Indicator: Commute Time (QL6) \\ Variables: Commute Time \\ Scale: $\quad$ County \\ Year: $\quad 2000$ \\ Data Sources:}

Bureau of the Census, U.S. Department of Commerce. (2000). Summary File 3: Geographic Comparison Table P-12, Employment Status and Commuting to Work. American FactFinder. Washington, DC. (Workers 16 years and over: Who did not work at homeMean travel time to work (minutes), available through URL: http://factfinder.census.gov

DA. (2002). FYO3 Army Well-Being Action Plan. Deputy Chief of Staff for Personnel. Washington, DC, available through URL: http://www.odcsper.army.mil/Directorates/wb/FY03 WBAP Vol 1.pdf

Surface Transportation Policy Project. (2003). Transportation and Economic Prosperity. Washington, DC, available through URL: http://www.transact.org/library/factsheets/transportation\%20and\%20economic\%20ros perity\%20.doc

Logic: Commute time relates to congestion of the local road network surrounding a military installation. Road congestion is an indicator of potential problems using the highway near installations. This addresses traffic from the military operations standpoint. Commute time addresses traffic from the quality of life standpoint. Individuals demand the conveniences of easy access between home and work with 
minimal time "wasted." Commute time also indicates the lag time in an off-post service member's ability to respond to alerts and emergencies. The natural tendency of a city is to prosper, grow, and expand outward. By nature, transportation improvements often do not keep pace with rapid population growth. Thus, commute time is a strong indicator of local quality of life. It is a measure of the inefficiency of the transportation system, which makes for happy or unhappy users (Surface Transportation Policy Project 2003).

The Surface Transportation Policy Project is a non-for-profit organization that advocates transportation systems as a component of quality of life (Surface Transportation Policy Project 2003). They cite:

The transportation system should provide for the efficient and reliable delivery and distribution of goods and services to all markets, serve employer needs for recruitment and retention of a high-quality workforce, and be redundant, resilient, reliable, and resistant to service and system disruptions. In addition, transportation investments should support local and regional economic objectives and recognize efficient activity centers as the drivers of economic prosperity and sustainable growth.

— Surface Transportation Policy Project 2003

In terms of the military, installations and their environs are where the military personnel and their families live. Excessive commute times may negatively impact reenlistment rates (USDA 2002). Thus commute times are sought after as an indicator of the local quality of life.

Replicable: The U.S. Census provides commuter statistics every decade reported in Summary File 3 available for download at http://www.census.gov (Bureau of the Census 2000). Commuter statistics are also replicated annually based on Census of Population estimates. It is recommended that the data be replicated only once a decade due to the inaccuracy of the census estimates.

Directions: Download GCT-P12 Employment Status and Commuting to Work: 2000 from the U.S. Census 2000 Summary File 3 at the county level available online at http://factfinder.census.gov/ (Bureau of the Census 2000). Import Workers 16 years and over: Who did not work at home-Mean travel time to work (minutes) data into a GIS program and join it with county boundary files to create a GIS Commute Time indicator layer.

Indicator Measure: The U.S. Census Bureau reports average commute-time in minutes for each county (Bureau of the Census 2000). The national average was reported at 23 minutes for 2000 . Since the sample is assumed to be relatively nor- 
mal, the classifications were statistically configured using the standard deviation (1.5) around the national average.

Very Low Vulnerability

Low Vulnerability

Moderate Vulnerability

Vulnerable

High Vulnerability
(1): $\quad<=23$ minutes

(2): $>23-<=24.5$ minutes

(3): $>24.5-<=26$ minutes

(4): $>26-<=27$ minutes

(5): $>27$ minutes

Rules: Installations are often in two or more counties. Therefore, installation classifications are determined by a weighted average. The weighted average calculation determines what percentage of the installation is in each county and multiplies that percentage for each county by that county's classification value. The values for each county are then totaled to arrive at a value for the installation. This value is subjected to the same metric that determined the classification for the individual counties.

Example:

Indicator Value for the Installation $=\left(\right.$ Percentage of Installation in County $A^{*}$ Indicator Value for County $A)+\left(\right.$ Percentage of Installation in County $B^{*}$ Indicator Value for County B)...etc. 


\title{
Sustainability Issue: Transportation
}

\author{
Indicator: Airport Capacity (TR1) \\ Variables: Total Enplanement, Mile Buffers \\ Scale: $\quad$ Airport \\ Year: $\quad 2003$ \\ Data Sources:
}

AirNav.Com. (2004). "Airports”. (Complete list of airport codes), available through URL: http://www.airnav.com/

Digital Aeronautical Flight Information File, National Imagery and Mapping Agency. (2005).

DAFIF Edition 7. Bethesda, MD, available through URL:

https://164.214.2.62/products/digitalaero/index.cfm

Terminal Area Forecast System, Federal Aviation Administration. (2005). Air Mobility Command, Scott AFB. Unclassified Corporate Database, available through URLs:

http://www.apo.data.faa.gov/faatafall.HTM

https://www.afd.scott.af.mil

U.S. General Accounting Office, Report to Congressional Committees. (1995). C-17 Aircraft: Cost and Performance Issues. National Security and International Affairs Division.

Washington, DC, available through URL:

http://www.fas.org/man/gao/gao9526.htm

Logic: This indicator provides a measurement of the amount of access available to the military at commercial airports. The DoD has identified a need to augment military airfields with access to commercial airports (USGAO 1995). Often it is unnecessary to duplicate the provisions of a nearby civilian airport on a military airfield. Thus, identification of commercial airport capacity is a highly sought after indicator in the decisionmaking process for military development. Air space pressures created from high use levels result in large limitation on development potential of an area to military installations' air space missions. Airport operations (takeoffs and landings) are often reported for regions verses specific airports. Annual enplanements (persons boarding an airplane including certified, commuter, air-taxi, foreign, and in-transit planes) are reported at the airport level. Therefore, for the purposes of this study, total enplanements were used to measure airport capacity.

Total enplanements, however, have some limitations. Because it is a measure of the number of people using the airspace and not the number of planes using the airspace, it is not an adequate representation of the airspace capacity. For instance, two identical airports may both enplane 400 persons per day, but one airport enplanes all 400 persons onto one plane while the other airport enplanes the 400 persons among three planes. The airport enplaning three planes theoretically should 
have a lower availability to support military air operations, yet within this system both airports are rated equally. Although, this is a critical limitation of the data, the limitations of using available aircraft operation data are greater. Aircraft operations are not reported nationally at the airport level. The lowest level available is at the state level (TAF 2005). Because of this, airport capacity ratings are heavily skewed by local "hotspots." In other words, if a state has one community ranking low in airport capacity, the entire state is classified as low capacity regardless of the characteristics of the remaining majority of the state. Aircraft operations data additionally does not take into consideration that installations located near state boundaries use airports located in more than one state. Because of these two concerns, the amount of people using an airport (total enplanements) is the preferred method to measuring airport capacity as long as local knowledge of activity patterns is understood in interpreting the capacity classifications of commercial airports.

Total enplanement data is most readily and widely available from the Federal Aviation Administration's (FAA) Terminal Area Forecast System (TAF). TAF is the official aviation activity forecast of the FAA. It contains historical aviation activity data and FAA's forecasts for 474 airports receiving FAA contract tower and radar service. This database also includes projections for more than 3,000 other airports in the National Integrated Airport Plan. The forecasts, covering fiscal years 20002030, project activity of four major users of the U.S. air traffic system: air carriers, air taxi and commuters, general aviation, and the military (TAF 2005). The FAA uses these forecasts to meet its budget and planning needs. It may be useful to refer to these forecasts when interpreting local airport capacity ratings. Additionally, since the TAF does not track all U.S. commercial airports, it is recommended to have an understanding of which airports near the installation in question are not included in the TAF database.

Finally, this indicator may be used in conjunction with Airspace Demand indicators to provide a greater understanding of airspace availability in a particular region.

Replicable: This indicator could be replicated every year based on information updated in the TAF System (TAF 2005).

Directions: Download the GIS airport boundary files from the Digital Aeronautical Flight Information File (AVDAFIF>ARPT.ZIP) (DAFIF 2005), available through URL:

https://164.214.2.62/products/digitalaero/index.cfm

These boundary files include all active civil, military, joint (civil and military), and private airports for the world. Delete all non-U.S. airports for the purposes of this indicator-keeping only civil, joint, and private airports in the United States. 
Download total annual enplanements for all commercial airports from the TAF System. Import the TAF commercial airport data into a GIS program and join it with the DAFIF airports boundary files by airport code to create an Airport Capacity indicator layer. Create "buffers" around these airports at 25 miles to form vulnerability-rating classifications.

Indicator Measure: This indicator provides insight into the ability of a commercial airport within 25 miles of an installation and receiving FAA contract tower and radar service to supplement military installation air operations. Not all U.S. commercial airports are tracked by total annual enplanements. Therefore, it is vital to have an understanding of which airports near to the installation in question are not included in the study. This information may be obtained from the DAFIF airport boundary files or AirNav.com at http://www.airnav.com/airports. AirNav.com provides the 3-letter codes for all airports (e.g., ORD for Chicago O'Hare International Airport) by airport type and/or geographic location (AirNav.Com 2004).

Airport Capacity classifications were defined by natural breaks in the data. The national average is 2,644,376 total annual enplanements and the standard deviation is 5,733.024. The logic remains that the more people using the airport; the less available it will be to the military.

\begin{tabular}{|c|c|c|}
\hline Very Low Vulnerability & (1): & $<2,262,633$ Total Annual Enplanements \\
\hline Low Vulnerability & (2): & $\begin{array}{l}>=2,262,633-<3005916 \text { Total Annual Enplane- } \\
\text { ments }\end{array}$ \\
\hline Moderate Vulnerability & (3): & $\begin{array}{l}>=3,005,916-<5,979,049 \text { Total Annual Enplane- } \\
\text { ments }\end{array}$ \\
\hline Vulnerable & (4): & $\begin{array}{l}>=5,979,049-<6,722,332 \text { Total Annual Enplane- } \\
\text { ments }\end{array}$ \\
\hline High Vulnerability & (5): & $>=6,722,332$ Total Annual Enplanements \\
\hline
\end{tabular}

Rules: Installations typically have only one commercial airport located within a 25mile radius. However, several installations do have two or more airports located within 25 miles. In this instance, the region around an installation takes on the airport classification of the lowest vulnerability. For instance, if two airports are located within 25 miles of an installation and one is classified as high vulnerability and the other as moderate vulnerability, the region would be classified as moderate vulnerability.

\author{
Indicator: Proximity to Airports Suitable for C-5 Aircraft (TR2) \\ Variables: Suitability for C-5 Aircraft, Mile Buffers \\ Scale: $\quad$ Airports \\ Year: 2001
}




\section{Data Sources:}

AirNav.Com. (2003). “Airports”. (Complete list of airport codes), available through URL: http://www.airnav.com/

Digital Aeronautical Flight Information File, National Imagery and Mapping Agency. (2005). DAFIF Edition 6. Bethesda, MD, available through URL: https://164.214.2.62/products/digitalaero/index.cfm

Terminal Area Forecast System, Federal Aviation Administration. (2001). Air Mobility Command, Scott AFB. Unclassified Corporate Database, available through URLs:

http://www.apo.data.faa.gov/faatafall.HTM https://www.afd.scott.af.mil

U.S. General Accounting Office, Report to Congressional Committees. (1994). Military Airlift: Comparison of C-5 and C-17 Airfield Availability. National Security and International Affairs Division. Washington, DC, available through URL: http://www.globalsecurity.org/military/library/report/gao/152088.pdf

Logic: Not all aircraft types have the capability to land at every airfield due to runway strength, runway size, and runway type. Landing requirements will also vary, whether it is based on wartime or peacetime criteria. According to the July 1994 General Accounting Office (GAO) Report to Congressional Committees, Military Airlift: Comparison of C-5 and C-17 Airfield Availability the C-5 aircraft can land on a paved runway 5,000 ft long by $90 \mathrm{ft}$ wide during wartime, while normal performance is defined as landing on a paved runway $6,000 \mathrm{ft}$ long by $147 \mathrm{ft}$ wide (USGAO 1994).

Access to a C-5 capable runway is typically a necessity for military shipments, mobilization, and training. If access is inadequate (measured by geographical distance), then it is a strong indicator of pressures on the future use and vulnerability of air space, leading to greater demands and limitations on Military development and missions. This would then place the military installation in a vulnerable state, affecting the type and intensity of training that could take place on the installation.

The DoD has identified a need to augment military airfields with access to commercial airports (USGAO 1994). Often it is unnecessary to duplicate the provisions of a nearby civilian airport on a military airfield. Thus, identification of commercial airports suitable for C-5 aircraft is a highly sought after indicator. Specifically, this indicator provides suitability for C-5 aircraft at all commercial airports receiving Federal Aviation Administration (FAA) contract tower and radar service within a prescribed distance. Thus, not all U.S. commercial airports are tracked for C-5 suitability. It is recommended to have an understanding of which airports near the installation in question are not included in the study. 
Replicable: This indicator could be replicated every year based on information updated in FAA's Terminal Area Forecast (TAF) System and Scott AFB's Airport Search Database (TAF 2001).

Directions: Download complete airport GIS boundary files from the Digital Aeronautical Flight Information File (DAFIF 2005) available through URL, available through URL:

https://164.214.2.62/products/digitalaero/index.cfm

These boundary files include all active civil, military, joint (civil and military), and private airports for the world. Delete all non-U.S. airports for the purposes of this indicator-keeping only civil, joint, and private airports in the United States.

Download C-5 suitability airport data from the TAF System at https://www.afd.scott.af.mil/ (TAF 2001). As previously mentioned, TAF does not track all U.S. commercial airports. Therefore, it is critical to use local knowledge when interpreting this indicator. Further local information may be obtained from the DAFIF airport boundary files or AirNav.com at http://www.airnav.com/airports. AirNav.com provides the 3-letter codes for all airports (e.g., ORD for Chicago O'Hare International Airport) by airport type and/or geographic location (AirNav.Com 2003). Airfield information is obtainable from the Air Mobility Command (Scott AFB) to determine whether each airfield is suitable for specific types of aircraft (i.e., C-141B, C-5, C-130, C-17, KC-10, KC-135, and C-9) (TAF 2005).

Import the TAF commercial airport data into a GIS program and join it with the DAFIF airports boundary files by airport code to create an Airport Suitability for C5 Aircraft indicator layer. Create "buffers" around these airports at 5 and 25 miles to form vulnerability classifications.

Indicator Measure: Airport Suitability for C-5 Aircraft classifications were defined as follows.

Very Low Vulnerability (1): Within 5 miles of a C-5 Aircraft Suitable Airport

Low Vulnerability

(2): Not Applicable

Moderate Vulnerability

(3): Within 25 miles but greater than 5 miles of a C-5 Aircraft Suitable Airport

Vulnerable

(4): Not Applicable

High Vulnerability

(5): Greater than 25 miles of a C-5 Aircraft Suitable Airport

Rules: Installations typically have only one commercial airport located within a 25mile radius. However, several installations do have two or more airports located 
within 25 miles. In this instance, an installation takes on the airport classification of the closest airport. For instance, if an installation were located within 5 miles of one airport and within 25 miles of another airport, the installation would be classified as very low vulnerability.

\section{Indicator: Proximity to Airports Suitable for C-141 Aircraft (TR3) Variables: Suitability for C-141 Aircraft, Mile Buffers \\ Scale: $\quad$ Airports \\ Year: $\quad 2001$ \\ Data Sources:}

AirNav.Com. (2003). "Airports". (Complete list of airport codes), available through URL: http://www.airnav.com/

Digital Aeronautical Flight Information File, National Imagery and Mapping Agency. (2005). DAFIF Edition 6. Bethesda, MD, available through URL: https://164.214.2.62/products/digitalaero/index.cfm

Terminal Area Forecast System, Federal Aviation Administration. (2001). Air Mobility Command, Scott AFB. Unclassified Corporate Database, available through URL: http://www.apo.data.faa.gov/faatafall.HTM (https://www.afd.scott.af.mil)

U.S. General Accounting Office, Report to Congressional Committees. (1995). C-17 Aircraft: Cost and Performance Issues. National Security and International Affairs Division. Washington, DC, available through URL: http://www.fas.org/man/gao/gao9526.htm

Logic: Not all aircraft types have the capability to land at every airport due to runway strength, runway size, and runway type. Landing requirements will also vary, whether it is based on wartime or peacetime criteria. According to a January 1995 General Accounting Office (GAO) report entitled, C-17 Aircraft: Cost and Performance Issues, only the C-141 and C-130 aircraft have the capability of routinely performing airdrop missions (USGAO 1995).

Access to a C-141 capable runway is typically a necessity for military shipments, mobilization, and training. If access in inadequate (measured by geographical distance), then it is a strong indicator of pressures on the future use and vulnerability of air space, leading to greater demands and limitations on Military development and missions. This would then place the military installation in a vulnerable state, affecting the type and intensity of training that could take place on the installation.

The DoD has identified a need to augment military airfields with access to commercial airports (USGAO 1995). Often it is unnecessary to duplicate the provisions of a nearby civilian airport on a military airfield. Thus, identification of commercial airports suitable for C-141 aircraft is a highly sought after indicator. Specifically, this indicator provides suitability for C-141 aircraft at all commercial airports receiving 
Federal Aviation Administration (FAA) contract tower and radar service within a prescribed distance. Thus, not all U.S. commercial airports are tracked for C-141 suitability. It is recommended to have an understanding of which airports near to the installation in question are not included in the study.

Replicable: This indicator could be replicated every year based on information updated in FAA's Terminal Area Forecast (TAF) System and Scott AFB's Airport Search Database (TAF 2001).

Directions: Download complete airport GIS boundary files from the Digital Aeronautical Flight Information File (DAFIF 2005), available through URL: https://164.214.2.62/products/digitalaero/index.cfm

This boundary files identify all active civil, military, joint (civil and military), and private airports for the world. Delete all non-U.S. airports for the purposes of this indicator-keeping only civil, joint, and private airports in the United States.

Download C-141 suitability airport data from the TAF System at https://www.afd.scott.af.mil/ (TAF 2001). As previously mentioned, TAF does not track all U.S. commercial airports. Therefore, it is critical to use local knowledge when interpreting this indicator. Further local information may be obtained from the DAFIF airport boundary files or AirNav.com at http://www.airnav.com/airports. AirNav.com provides the 3-letter codes for all airports (e.g., ORD for Chicago O'Hare International Airport) by airport type and/or geographic location (AirNav.Com 2003). Airfield information is obtainable from the Air Mobility Command (Scott AFB) to determine whether each airfield is suitable for specific types of aircraft (i.e., C-141B, C-5, C-130, C-17, KC-10, KC-135, and C-9) (TAF 2005).

Import the TAF commercial airport data into a GIS program and join it with the DAFIF airport boundary files by airport code to create an Airport Suitability for C141 Aircraft indicator layer. Create "buffers" around these airports at 5 and 25 miles to form vulnerability classifications.

Indicator Measure: Airport Suitability for C-141 aircraft classifications were defined as:

Very Low Vulnerability

Low Vulnerability

Moderate Vulnerability

Vulnerable

High Vulnerability
(1): Within 5 mi. of a C-141 Aircraft Suitable Airport

(2): Not Applicable

(3): Within 25 miles but greater than 5 miles of a C141 Aircraft Suitable Airport

(4): Not Applicable

(5): > 25 mi. of a C-141 Aircraft Suitable Airport 
Rules: Installations typically have only one commercial airport located within a 25mile radius. However, several installations do have two or more airports located within 25 miles. In this instance, an installation takes on the airport classification of the closest airport. For instance, if an installation were located within 5 miles of one airport and within 25 miles of another airport, the installation would be classified as very low vulnerability.

\section{Indicator: Railroad Capacity (TR4) \\ Variables: Train Movements per Crossing per Day \\ Scale: County \\ Year: $\quad 2004$ \\ Data Source:}

Federal Railroad Administration, U.S. Department of Transportation. (2004). Highway-Rail Crossing Inventory by State. Office of Safety Analysis. Washington, DC, available through URL:

http://safetydata.fra.dot.gov/OfficeofSafety/Downloads/Default.asp?page=downloadbf .asp

Logic: This indicator provides a measurement of the number of trains passing through the terminal per day. The number of daily trains crossing the terminal is an indicator of potential availability problems and congestion on the rail system. The rail system may be required by the military for material shipment and mobilization. This would then place the installation in a vulnerable state, affecting mobilization or, possibly, the type and intensity of training that could take place.

It is important to note this data is on the county level, not community or installation. Hence, it may be skewed by local "hotspots." In other words, if a county has one railroad with numerous train movements, regardless of the movement characteristics, the entire county is classified as low available capacity (high vulnerability) regardless of the characteristics of the remaining majority of the county. Additionally, there are a limited number of counties that do not have a train crossing due to either a lack of railways or a lack of highways intersecting the rails. These counties may inappropriately receive a low-vulnerability rating. Thus, it is critical to interpret data along with an understanding of local characteristics.

Replicable: This indicator could be replicated annually based on information updated in Federal Railroad Administration's Highway-Rail Crossing Inventory by State (FRA 2004).

Directions: Railroad capacity is defined as the number of trains per railroad crossing per day. A complete listing of railroad crossings at the state and county levels can be found using the Highway-Rail Crossing Inventory by State database (FRA 
2004). Download county level trains per railroad per day and number of railroad crossings from the above-mentioned database. The calculation for determining the number of trains per crossing per day by county (or state) is as follows.

Number of Trains per Crossing per Day = Grand Total Number of Trains per Day / Number of Railroad Crossings

Table A3 lists some detailed example calculations for the state of Hawaii.

Table A3. List of Railroad Crossings in the State of Hawaii (USDoT. FRA 2003)

\begin{tabular}{|c|c|c|c|c|c|c|c|c|c|}
\hline $\begin{array}{c}\text { Railroad } \\
\text { Crossing \# }\end{array}$ & $\begin{array}{l}\text { Railroad } \\
\text { Line }\end{array}$ & Street & $\begin{array}{l}\text { Number } \\
\text { of } \\
\text { Railroad } \\
\text { Tracks }\end{array}$ & $\begin{array}{l}\text { Annual } \\
\text { Average } \\
\text { Daily } \\
\text { Traffic } \\
\text { Through } \\
\text { Crossing }\end{array}$ & $\begin{array}{l}\text { No. Of Day } \\
\text { Through } \\
\text { Trains Per } \\
\text { Day }\end{array}$ & $\begin{array}{l}\text { No. Of Day } \\
\text { Switch } \\
\text { Trains Per } \\
\text { Day }\end{array}$ & $\begin{array}{l}\text { No. Of } \\
\text { Night } \\
\text { Through } \\
\text { Trains Per } \\
\text { Day }\end{array}$ & $\begin{array}{c}\text { No. Of } \\
\text { Night } \\
\text { Switch } \\
\text { Trains Per } \\
\text { Day }\end{array}$ & $\begin{array}{c}\text { Total No. } \\
\text { Of Trains } \\
\text { Per Day }\end{array}$ \\
\hline $311009 v$ & & Kapunakea & 1 & 3,800 & 10 & 0 & 0 & 0 & 10 \\
\hline $311010 p$ & & Fleming & 1 & 1,700 & 10 & 0 & 0 & 0 & 10 \\
\hline $311011 w$ & & Wahikuli & 1 & 25 & 10 & 0 & 0 & 0 & 10 \\
\hline $311012 d$ & & Kaniau & 1 & 950 & 10 & 0 & 0 & 0 & 10 \\
\hline 311013k & & Civic Center & 1 & 1,500 & 10 & 0 & 0 & 0 & 10 \\
\hline $311014 \mathrm{~s}$ & & Puukolii & 1 & 25 & 10 & 0 & 0 & 0 & 10 \\
\hline $918996 x$ & Hawaiian Railw & Ft Barrette Rd & 1 & 2,000 & 0 & 0 & 0 & 0 & 0 \\
\hline $918997 e$ & Hawaiian Railw & Kalaeloa Blvd & 1 & 17,000 & 0 & 0 & 0 & 0 & 0 \\
\hline \multicolumn{5}{|c|}{ Grand Total No. Of Trains Per Day } & 60 & 0 & 0 & 0 & 60 \\
\hline
\end{tabular}

Based on the information from Table A8, the State of Hawaii has a total of 8 railroad crossings (6 active, 2 non-active) for a grand total of 60 trains per day.

Number of Trains per Crossing per Day $=60 / 6=10$ trains per railroad crossing per day for the state of Hawaii.

Compute the "number of trains per crossing per day" for each county. Import the resulting math into a GIS program and join it to county boundary files to create a Railroad Capacity indicator layer.

Indicator Measure: Railroad Capacity classifications were defined as follows based on definitions provided by the Federal Railroad Administration (FRA 2004).

Very Low Vulnerability

(1): $\quad<10$ Trains per Crossing per Day

Low Vulnerability

(2): Not Applicable

Moderate Vulnerability

(3): $>=10-<20$ Trains per Crossing per Day

Vulnerable

(4): Not Applicable

High Vulnerability

(5): $>=20$ Trains per Crossing per Day

Rules: Installations are often in two or more counties and regional classifications are then determined by a weighted average. The weighted average calculation de- 
termines what percentage of the installation is in each county, and that percentage is multiplied by that county's value. The values for each county around the installation are then totaled to arrive at a value for the region around an installation. This value will then be subjected to the same metric that determined the classifications for the individual counties.

Example:

Indicator Value for the Installation $=$ (Percentage of Installation in County $A^{*}$ Indicator Value for County $A)+\left(\right.$ Percentage of Installation in County $B^{*}$ Indicator Value for County B)...etc.

\section{Indicator: Proximity to Interstate (TR5) \\ Variables: Interstate Highways, Mile Buffers \\ Scale: Installation \\ Year: $\quad 2002$ \\ Data Source:}

ESRI. GIS Data and Maps Media Kit. (2002) http://www.esri.com.

Logic: This indicator provides a measurement of the distance from the nearest interstate highway to an installation. The proximity of an interstate to an installation is an indicator of availability of transportation access. The interstate system is often required by the military for material shipment and mobilization. Lack of interstate access would place the military installation in a vulnerable state, affecting the type and intensity of training that could take place on the installation.

Replicable: This indicator could be replicated every year based on updated interstate highway maps as new construction occurs.

Directions: Download interstates boundary files from http://www.esri.com. Create "buffers" around these interstates at 20 and 50 miles to develop a Proximity to Interstate indicator layer.

Indicator Measure: Proximity to interstates is defined as the distance from the nearest interstate highway to an installation. All areas within 20 miles of an interstate were considered to be well served (very low vulnerability), while all areas more than 20 miles, but less than 50 miles from an interstate were considered to be moderately served (moderate vulnerability). All areas outside of these buffers are considered underserved (high vulnerability). Proximity to Interstate classifications are defined as follows. 
Very Low Vulnerability

Low Vulnerability

Moderate Vulnerability

Vulnerable

High Vulnerability
(1): Within 20 miles of an interstate

(2): Not Applicable

(3): Within 50 miles but greater than 20 miles from an interstate

(4): Not Applicable

(5): Greater than 50 miles from an interstate

Rules: This indicator rates the region around an installation by evaluating its proximity to interstate highways. The region around an installation takes on the lowest vulnerability classification depending on its proximity to an interstate. For instance, if an installation straddles the 20 mile buffer-half of the installation within 20 miles the other half greater than 20 miles, the region resource takes on the "low vulnerability" classification.

\section{Indicator: Roadway Congestion (TR6) \\ Variables: Roadway Congestion Index (RCI) \\ Scale: $\quad$ State \\ Year: $\quad 2003$ \\ Data Sources:}

Chen, Ciao, Zhanfeng Jia, and Pravin Varaiya. (2001). Causes and Cures of Highway Congestion. University of California at Berkeley. Berkeley, CA, available through URL: http://paleale.eecs.berkeley.edu/ varaiya/papers ps.dir/csmpaperv3.pdf

Federal Highway Administration, U.S. Department of Transportation. (2005). Highway Statistics 2003. Office of Highway Policy Information. Washington, DC. (Table PS-1, Selected Measures for Identifying Peer States; Table VM-2, Functional System Travel Annual Vehicle-Miles; Table HM-60, Functional System Lane-Length Lane-Miles), available through URL: available through URL:

http://www.fhwa.dot.gov/policy/ohim/hs03/ps1.htm

http://www.fhwa.dot.gov/policy/ohim/hs03/vm2.htm

http://www.fhwa.dot.gov/policy/ohim/hs03/hm60.htm

Pima Association of Governments. (2004). Roadway Congestion. Tucson, Arizona, available through URL: http://www.pagnet.org/TPD/rsp/default.htm

Texas Transportation Institute (TIT). (2004). 2003 Urban Mobility Study. Texas A\&M University. College Station, Texas. (Methodology - Base UMS Calculations), available through URL: http://mobility.tamu.edu/ums/report/methodology appB.pdf

Texas Transportation Institute (TIT). (2003). The Keys to Estimating Mobility. Texas A\&M University. College Station, Texas. (Chapter 5: Recommended Mobility Measures), available through URL:

http://mobility.tamu.edu/ums/estimating mobility/chapter5.pdf

Logic: This indicator provides a measurement of the congestion of the local road network surrounding a military installation. Road congestion is an indicator of po- 
tential problems using highway system near the installation. This addresses traffic from the military operations standpoint. Congestion problems would place the military installation in a vulnerable state, affecting the type and intensity of training that could take place on the installation. For instance, commute times for work related travel for the local community surrounding and including the installation would be extended longer than normally expected as a result of congestion problems (TIT 2003). Heavy to severe congestion areas also impacts the quality of life for the local community (see Commute Times as a Quality of Life sustainability indicator). Highways and roads within the proximity of a large metropolitan statistical area (MSA) provide higher risks of congested travel and increasing potentials for vehicular accidents (C. Chen et al. 2001).

Additionally, it is important to note this data is on the state level, not community or installation. Hence, it may be skewed by local "hotspots." In other words, if a state has one roadway with relatively high congestion rates, the entire state may be classified as high roadway congestion regardless of the characteristics of the remaining majority of the state. Because of this concern, it is important to use local knowledge in interpreting the roadway congestion classifications. Since congestion is more associated with urban development and sprawl, the proximate to MSA indicator may be considered in conjunction with this indicator to give a better picture of the overall situation.

Replicable: This indicator could be replicated every year based on information updated annually in Federal Highway Administration's Highway Statistics (FHA 2005).

Directions: Road congestion is defined by the Roadway Congestion Index (RCI), which is defined as the ratio of traffic volume to road capacity, based on the 2003 Urban Mobility Study published by the TIT (TIT 2004). The RCI, which varies from city to city, is a function of traffic volume (also defined as annual average daily traffic in vehicles/day), road segment length, and number of lanes in the road segment (TIT 2004). The U.S. Department of Transportation's Federal Highway Administration provides annual highway statistics containing urban and rural data by state on annual vehicle miles traveled (AVMT) and lane-miles (FHA 2005). The calculations for determining the RCI by state are as follows.

Daily Vehicle Miles Traveled $($ DVMT $)=$ Annual Vehicle-Miles Traveled $($ AVMT) $/ 365$

Freeway DVMT = Urban Freeway DVMT + Rural Freeway DVMT

Principal Arterial DVMT = Urban Principal Arterial DVMT + Rural Principal Arterial DVMT 
Freeway DVMT per Lane-Mile = (Urban Freeway DVMT / Urban Freeway Lane-Miles)

+ (Rural Freeway DVMT / Rural Freeway Lane-Miles)

Principal Arterial DVMT per Lane-Mile $=($ Urban Principal Arterial DVMT / Urban Principal Arterial Lane-Miles) + (Rural Principal Arterial DVMT / Rural Principal Arterial Lane-Miles)

Roadway Congestion Index $(\mathrm{RCl})=$ $((($ Freeway DVMT per Lane-Mile $) *$ Freeway DVMT $)+(($ Principal Arterial DVMT per Lane-Mile) * Principal Arterial DVMT)) / ((14,000 * Freeway DVMT) + (5,500 * Principal Arterial DVMT))

Download Annual Freeway Vehicle-Miles Traveled, by State, Annual Rural Principal Arterial Vehicle-Miles Traveled, by State, Annual Urban Principal Arterial Vehicle-Miles Traveled, by State, and Lane-Miles Traveled by State data from the Highway Statistics. Calculate Roadway Congestion based on the equations above. Import the resulting math into a GIS program and join it with state boundary files to create a Roadway Congestion indicator layer. A detailed example calculation follows for the state of New York.

First, Calculate the total freeway DVMT for the state of New York.

Table A4. Annual Freeway Vehicle-Miles Traveled, by State (USDoT. FHA 2002).

\begin{tabular}{|c|c|c|c|}
\hline & Interstate (Rural) & Interstate (Urban) & $\begin{array}{c}\text { Other Freeways and } \\
\text { Expressways }\end{array}$ \\
\hline$\ldots$ & & & \\
\hline New York & 7,558 & 17,568 & 15,982 \\
\hline$\ldots$ & & & \\
\hline
\end{tabular}

Using Table B for the state of New York:

Rural Freeway AVMT = 7,558 million miles

Urban Freeway AVMT $=17,568+15,982=33,550$ million miles

Therefore:

Rural Freeway DVMT $=(7,558 * 1,000,000) / 365=20,706,849.32$ miles

Urban Freeway DVMT $=(33,550 * 1,000,000) / 365=91,917,808.22$ miles

Freeway DVMT $=20,706,849 \cdot 32+91,917,808 \cdot 22=112,624,657 \cdot 54$ miles

Second, calculate the principal arterial Daily Vehicle Miles Traveled (DVMT) for the state of New York. 
Table A5. Annual Rural Principal Arterial Vehicle-Miles Traveled, by State (USDoT. FHA 2002)

\begin{tabular}{|l|l|l|l|l|l|}
\hline & $\begin{array}{l}\text { Principal } \\
\text { Arterial } \\
\text { (Rural) }\end{array}$ & $\begin{array}{l}\text { Minor } \\
\text { Arterial } \\
\text { (Rural) }\end{array}$ & $\begin{array}{l}\text { Major } \\
\text { Collector } \\
\text { (Rural) }\end{array}$ & $\begin{array}{l}\text { Minor } \\
\text { Collector } \\
\text { (Rural) }\end{array}$ & Local (Rural) \\
\hline$\ldots$ & & & & & \\
\hline New York & 5,120 & 6,232 & 5,279 & 8,903 & 4,361 \\
\hline$\ldots$ & & & & & \\
\hline
\end{tabular}

Using Table A5 for the state of New York:

Rural Principal Arterial AVMT = 5,120 + 6,232 + 5,279 + 8,903 + 4,361 = 29,895 million miles.

Therefore:

Rural Principal Arterial DVMT $=(29,895 * 1,000,000) / 365=81,904,109.59$ miles

Table A6. Annual Urban Principal Arterial Vehicle-Miles Traveled, by State (USDoT. FHA 2002).

\begin{tabular}{|c|c|c|c|c|}
\hline & $\begin{array}{c}\text { Principal } \\
\text { Arterial } \\
\text { (Urban) }\end{array}$ & $\begin{array}{c}\text { Minor Arterial } \\
\text { (Urban) }\end{array}$ & $\begin{array}{c}\text { Major } \\
\text { Collector } \\
\text { (Urban) }\end{array}$ & Minor Collector (Urban) \\
\hline$\ldots$ & & & & \\
\hline New York & 16,888 & 21,646 & 7,691 & 13,494 \\
\hline$\ldots$ & & & & \\
\hline
\end{tabular}

Using Table A6 for the state of New York:

Urban Principal Arterial AVMT $=16,888+21,646+7,691+13,494=59,719$ million miles.

Therefore:

Urban Principal Arterial DVMT $=(59,719 * 1,000,000) / 365=163,613,698.63$ miles

The total principal arterial DVMT can now be calculated as:

Principal Arterial DVMT $=81,904,109.59+163,613,698.63=245,517,808.22$ miles

Third, calculate the freeway DVMT per lane-mile and principal arterial DVMT per lane-mile.

Table A7. Lane-Miles Traveled by State (USDoT. FHA 2002).

\begin{tabular}{|c|c|c|c|c|}
\hline State & $\begin{array}{c}\text { Urban } \\
\text { (Freeway) }\end{array}$ & $\begin{array}{c}\text { Urban (Principal } \\
\text { Arterial) }\end{array}$ & $\begin{array}{c}\text { Rural (Principal } \\
\text { Arterial) }\end{array}$ \\
\hline$\ldots$ & & & & \\
\hline New York & 7,543 & 84,876 & 3,875 & 143,114 \\
\hline$\ldots$ & & & & \\
\hline
\end{tabular}


Using Table A7 for the state of New York:

Urban Freeway Lane-Miles $=7,543$ lane-miles

Rural Freeway Lane-Miles = 3,875 lane-miles

Urban Principal Arterial Lane-Miles $=84,876$ lane-miles

Rural Principal Arterial Lane-Miles $=143,114$ lane-miles

Therefore:

Freeway DVMT per Lane-Mile = (Urban Freeway DVMT / Urban Freeway Lane-Miles $)$ + (Rural Freeway DVMT / Rural Freeway Lane-Miles)

Freeway DVMT per Lane-Mile $=(91,917,808.22$ / 7,543) $+(20,706,849.32$ / 3,875)

= 17,529.55 DVMT per Lane-Mile for the State of New York.

Principal Arterial DVMT per Lane-Mile $=($ Urban Principal Arterial DVMT / Urban

Principal Arterial Lane-Miles) + (Rural Principal Arterial DVMT / Rural Principal

Arterial Lane-Miles)

Principal Arterial DVMT per Lane-Mile $=(163,613,698.63 / 84,876)+(81,904,109.59 /$

$143,114)=2,499.98$ DVMT per Lane-Mile for the State of New York.

Finally, calculate the RCI for the state of New York.

Roadway Congestion Index $(\mathrm{RCl})=$

$((($ Freeway DVMT per Lane-Mile) * (Freeway DVMT)) + ((Principal Arterial

DVMT per Lane-Mile $)$ * Principal Arterial DVMT) $/((14,000$ * Freeway DVMT) + $(5,500$ * Principal Arterial DVMT)))

Therefore:

$$
\begin{aligned}
\mathrm{RCI}= & (((17,529.55 * 112,624,657.54)+(2,499.98 * 245,517,808.22)) /((14,000 * \\
& 112,624,657.54)+(5,500 * 245,517,808.22)))=0.884 \text { for the State of New York. }
\end{aligned}
$$

Indicator Measure: Roadway Congestion classifications were defined as follows based on information from Pima Association of Governments (Pima Association of Governments 2004).

Very Low Vulnerability

Low Vulnerability

Moderate Vulnerability

Vulnerable

High Vulnerability
(1): $\quad<0.57$ RCI (Low Roadway Congestion)

(2): Not Applicable

(3): $>=0.57-<2$ RCI (Medium Roadway Congestion)

(4): Not Applicable

(5): >=2 RCI (High Roadway Congestion) 
Rules: Every installation is located primarily in one state, although several installations do cross state boundaries. The region around an installation takes on the classification of the state in which the installation is primarily located.

\author{
Indicator: Traffic Volume (TR7) \\ Variables: Annual Average Daily Traffic per Lane (AADT) \\ Scale: $\quad$ State \\ Year: $\quad 2003$ \\ Data Sources:
}

Chen, Ciao, Zhanfeng Jia, and Pravin Varaiya. (2001). Causes and Cures of Highway Congestion. University of California at Berkeley. Berkeley, CA, available through URL: http://paleale.eecs.berkeley.edu/ varaiya/papers ps.dir/csmpaperv3.pdf

Federal Highway Administration, U.S. Department of Transportation. (2005). Highway Statistics 2003. Office of Highway Policy Information. Washington, DC. (Table HM-62, Average Daily Traffic per Lane on Principal Arterials; Appendix B, Methodology for 2003 Annual Report), available through URL: http://www.fhwa.dot.gov/ohim/hs01/aspublished/hm62.htm; http://mobility.tamu.edu/ums/study/methods/entire methodology.pdf

Texas Transportation Institute (TTI). (2002). Urban Mobility Study. Texas A\&M University. College Station, Texas. (Appendix A Exhibit A-17, 2000 Roadway Congestion Index), available through URL: http://mobility.tamu.edu/ums/study/appendix A/exhibit A-17.pdf

Texas Transportation Institute (TTI). (2003). The Keys to Estimating Mobility. Texas A\&M University. College Station, Texas. (Chapter 5: Recommended Mobility Measures), available through URL:

http://mobility.tamu.edu/ums/estimating mobility/chapter5.pdf

Logic: This indicator provides a measurement of the congestion of the local road network in the region surrounding a military installation in terms of annual average daily traffic per lane. Traffic volume is an indicator of potential problems using the local roads near the installation. This addresses traffic from the military operations standpoint. Congestion problems would place the military installation in a vulnerable state, affecting the type and intensity of training that could take place on the installation. For instance, commute times for work related travel for the local community surrounding and including the installation would be extended longer than normally expected as a result of congestion problems (TTI 2003). Heavy to severe congestion areas also impacts the quality of life for the local community (see Commute Times as a Quality of Life sustainability indicator). Local roads within the proximity of a large metropolitan statistical area (MSA) provide higher risks of congested travel and increasing potentials for vehicular accidents (C. Chen et al. 2001). 
Additionally, it is important to note this data is on the state level, not community or installation. Hence, it may be skewed by local "hotspots." In other words, if a state has one area with high local traffic volumes, it could skew the data for the entire state causing it to be classified as high traffic volumes regardless of the characteristics of the remaining majority of the state. Because of this concern, it is important to use local knowledge in interpreting the traffic volume classifications. This indicator should be taken in context and used in conjunction to proximity to MSA as a corroborating factor.

Replicable: This indicator could be replicated every year based on information updated annually in Federal Highway Administration's Highway Statistics (FHA 2005).

Directions: Road access is defined by annual average daily traffic (AADT), which is the number of vehicles passing through a particular road segment (FHA 2005). The Federal Highway Administration provides annual highway statistics containing urban and rural data by state on AADT. Download the Highway Statistics data into a GIS program and join it with state boundary files to create a Traffic Volume indicator layer.

Indicator Measure: Traffic Volume classifications were defined as follows based on definitions provided in the Texas Transportation Institute's 2002 Urban Mobility Study (TTI 2002). From a statistical analysis of the 2003 data, the national average AADT is 5,060 vehicles.

Very Low Vulnerability

Low Vulnerability

Moderate Vulnerability

Vulnerable

High Vulnerability
(1): $\quad<=5500$ AADT (Low Traffic Volume)

(2): Not Applicable

(3): $>5500-<=7000$ AADT (Medium Traffic Volume)

(4): Not Applicable

(5): $\quad>7000$ AADT (High Traffic Volume)

Rules: Every installation is located primarily in one state, although several installations do cross state boundaries. The region around an installation takes on the classification of the state in which the installation is primarily located. 


\section{Appendix B: Indicator Weighting Matrix by Mission/Function}

\begin{tabular}{|c|c|c|c|c|c|c|c|}
\hline \multirow[t]{3}{*}{ Installation Mission Categories } & \multicolumn{7}{|l|}{ Indicators } \\
\hline & \multicolumn{2}{|c|}{ Air Quality Sustainability } & \multicolumn{5}{|c|}{ Airspace Sustainability } \\
\hline & \begin{tabular}{|l|} 
Criteria \\
Pollutant Non- \\
Attainment
\end{tabular} & $\begin{array}{l}\text { Noise } \\
\text { Complaints }\end{array}$ & $\begin{array}{l}\text { SUA, Fighter } \\
\text { Range }\end{array}$ & $\begin{array}{l}\text { SUA, Bomber } \\
\text { Range }\end{array}$ & $\begin{array}{l}\text { Terminal } \\
\text { Airspace }\end{array}$ & $\begin{array}{l}\text { MTR, Fighter } \\
\text { Range }\end{array}$ & $\begin{array}{l}\text { MTR, Bomber } \\
\text { Range }\end{array}$ \\
\hline Expeditionary Forces Facilities & 3 & 3 & 3 & 3 & 3 & 3 & 3 \\
\hline \multicolumn{8}{|l|}{$\begin{array}{l}\text { These include all installations (land, air, sea) that train and } \\
\text { project forces. Includes airbases with active runways, maneuver } \\
\text { installations, naval air facilities, and selected training } \\
\text { installations. }\end{array}$} \\
\hline Training Facilities & 2 & 3 & 2 & 2 & 2 & 2 & 2 \\
\hline \multicolumn{8}{|l|}{$\begin{array}{l}\text { These include non-expeditionary training installations, remote } \\
\text { ranges, and reserve component training sites. }\end{array}$} \\
\hline Industrial Facilities & 3 & 2 & 1 & 1 & 1 & 1 & 1 \\
\hline \multicolumn{8}{|l|}{$\begin{array}{l}\text { These include storage installations, arsenals, depots, industrial } \\
\text { facilities, ammo plants, and ocean terminals. }\end{array}$} \\
\hline Administrative Support Facilities & 2 & 1 & 1 & 1 & 1 & 1 & 1 \\
\hline $\begin{array}{l}\text { These include command, control and administrative support } \\
\text { installations, military treatment facilities, professional } \\
\text { development installations, and RDT\&E oriented locations. }\end{array}$ & & & & & & & \\
\hline
\end{tabular}

\begin{tabular}{|c|c|c|c|c|c|c|}
\hline \multicolumn{7}{|l|}{ Installation Mission Categories } \\
\hline & \multicolumn{6}{|c|}{ Energy Sustainability } \\
\hline & \begin{tabular}{|l} 
Electrical Grid \\
Congestion
\end{tabular} & \begin{tabular}{|l|} 
Electrical \\
Reserve Margin
\end{tabular} & $\begin{array}{l}\text { Renewable } \\
\text { Energy--Wind }\end{array}$ & $\begin{array}{l}\text { Renewable } \\
\text { Energy--Solar }\end{array}$ & \begin{tabular}{|l} 
Renewable \\
Energy-- \\
Biomass
\end{tabular} & $\begin{array}{l}\text { Electrical Price } \\
\text { Structure } \\
\text { (Dereg) }\end{array}$ \\
\hline Expeditionary Forces Facilities & 2 & 2 & 2 & 2 & 2 & 2 \\
\hline \multicolumn{7}{|l|}{$\begin{array}{l}\text { These include all installations (land, air, sea) that train and } \\
\text { project forces. Includes airbases with active runways, maneuver } \\
\text { installations, naval air facilities, and selected training } \\
\text { installations. }\end{array}$} \\
\hline Training Facilities & 1 & 1 & 1 & 1 & 1 & 1 \\
\hline \multicolumn{7}{|l|}{$\begin{array}{l}\text { These include non-expeditionary training installations, remote } \\
\text { ranges, and reserve component training sites. }\end{array}$} \\
\hline Industrial Facilities & 3 & 2 & 1 & 1 & 1 & 3 \\
\hline \multicolumn{7}{|l|}{$\begin{array}{l}\text { These include storage installations, arsenals, depots, industrial } \\
\text { facilities, ammo plants, and ocean terminals. }\end{array}$} \\
\hline Administrative Support Facilities & 2 & 2 & 2 & 2 & 2 & 1 \\
\hline $\begin{array}{l}\text { These include command, control and administrative support } \\
\text { installations, military treatment facilities, professional } \\
\text { development installations, and RDT\&E oriented locations. }\end{array}$ & & & & & & \\
\hline
\end{tabular}




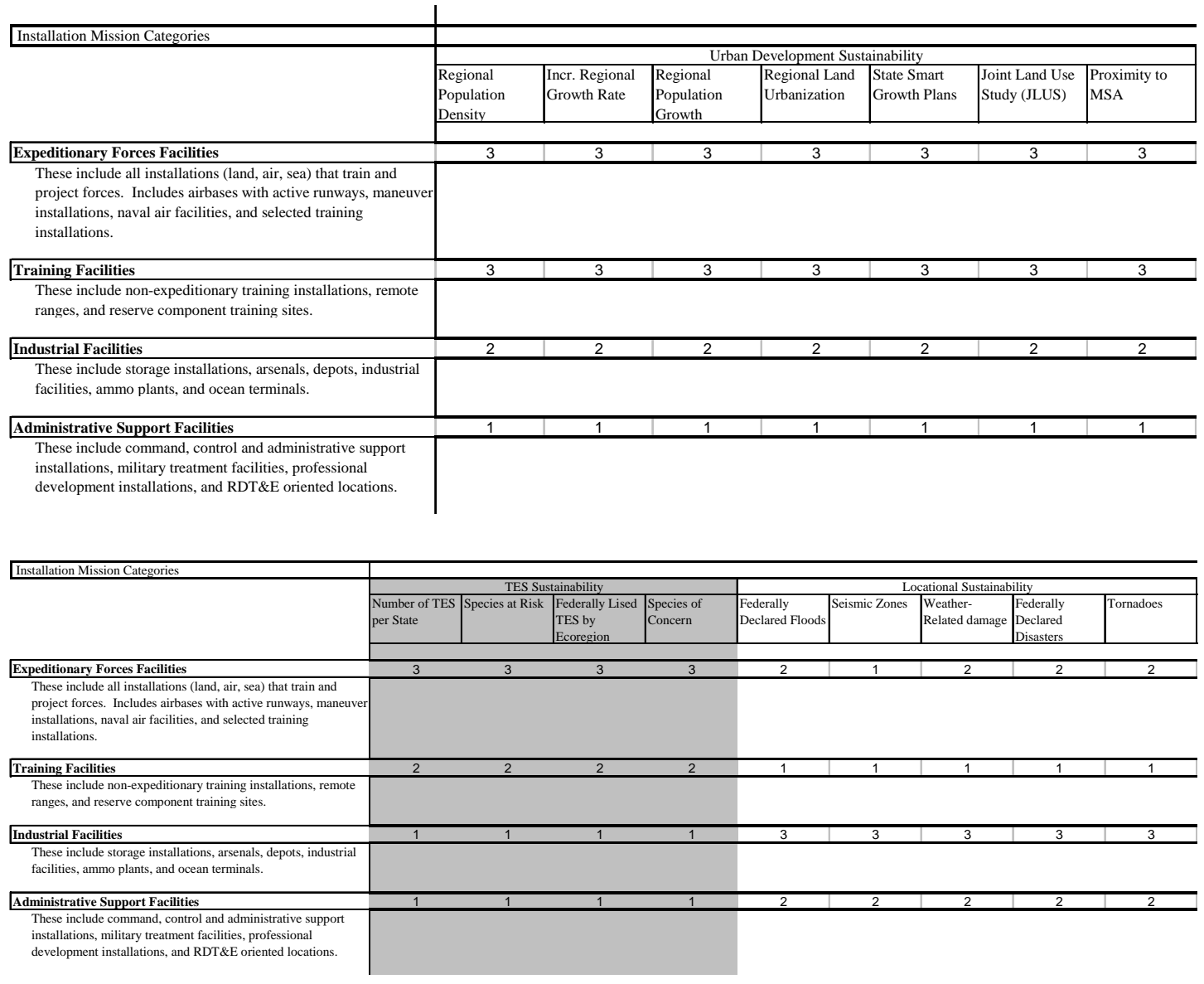

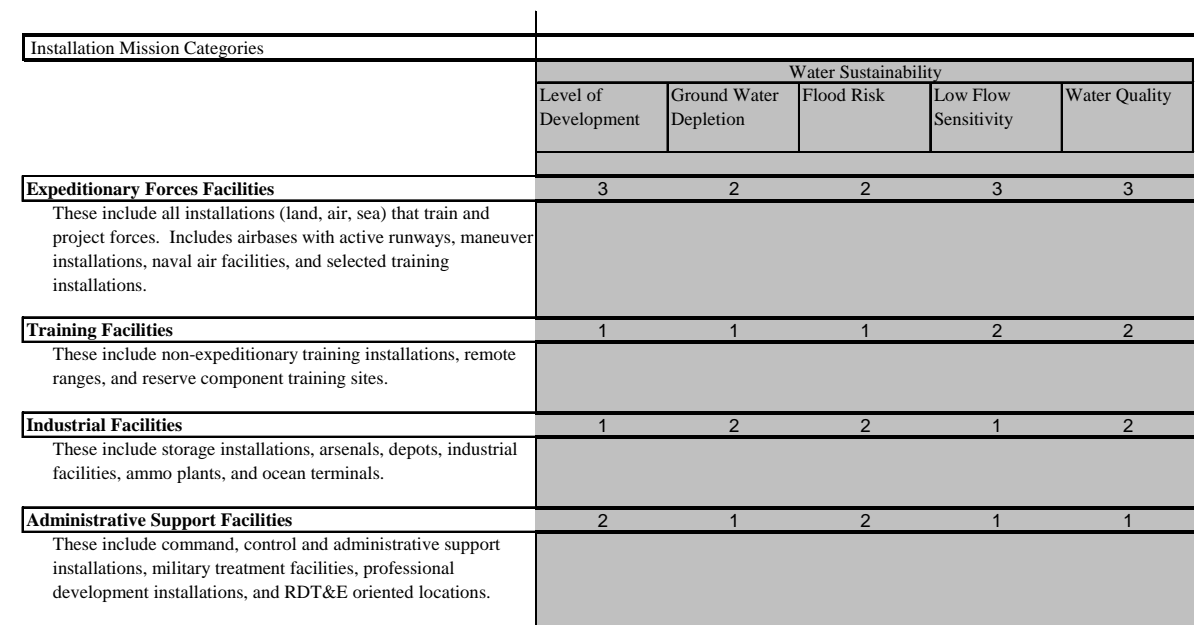




\begin{tabular}{|c|c|c|c|c|c|c|}
\hline \multicolumn{7}{|l|}{ Installation Mission Categories } \\
\hline & \multicolumn{6}{|c|}{ Economic Sustainability } \\
\hline & \begin{tabular}{|l|} 
DoD Local \\
Employment
\end{tabular} & \begin{tabular}{|l|} 
Job \\
Availability/Une \\
mployment
\end{tabular} & $\begin{array}{l}\text { Housing } \\
\text { Affordability }\end{array}$ & Poverty & $\begin{array}{l}\text { Avg Hsg Value } \\
\text { of New } \\
\text { Construction } \\
\end{array}$ & $\begin{array}{l}\text { Housing Permits } \\
\text { Issued }\end{array}$ \\
\hline Expeditionary Forces Facilities & 2 & 1 & 3 & 2 & 3 & 3 \\
\hline \multicolumn{7}{|l|}{$\begin{array}{l}\text { These include all installations (land, air, sea) that train and } \\
\text { project forces. Includes airbases with active runways, maneuver } \\
\text { installations, naval air facilities, and selected training } \\
\text { installations. }\end{array}$} \\
\hline Training Facilities & 1 & 1 & 1 & 1 & 1 & 3 \\
\hline \multicolumn{7}{|l|}{$\begin{array}{l}\text { These include non-expeditionary training installations, remote } \\
\text { ranges, and reserve component training sites. }\end{array}$} \\
\hline Industrial Facilities & 2 & 2 & 1 & 1 & 1 & 2 \\
\hline \multicolumn{7}{|l|}{$\begin{array}{l}\text { These include storage installations, arsenals, depots, industrial } \\
\text { facilities, ammo plants, and ocean terminals. }\end{array}$} \\
\hline Administrative Support Facilities & 2 & 2 & 3 & 2 & 3 & 1 \\
\hline $\begin{array}{l}\text { These include command, control and administrative support } \\
\text { installations, military treatment facilities, professional } \\
\text { development installations, and RDT\&E oriented locations. }\end{array}$ & & & & & & \\
\hline
\end{tabular}

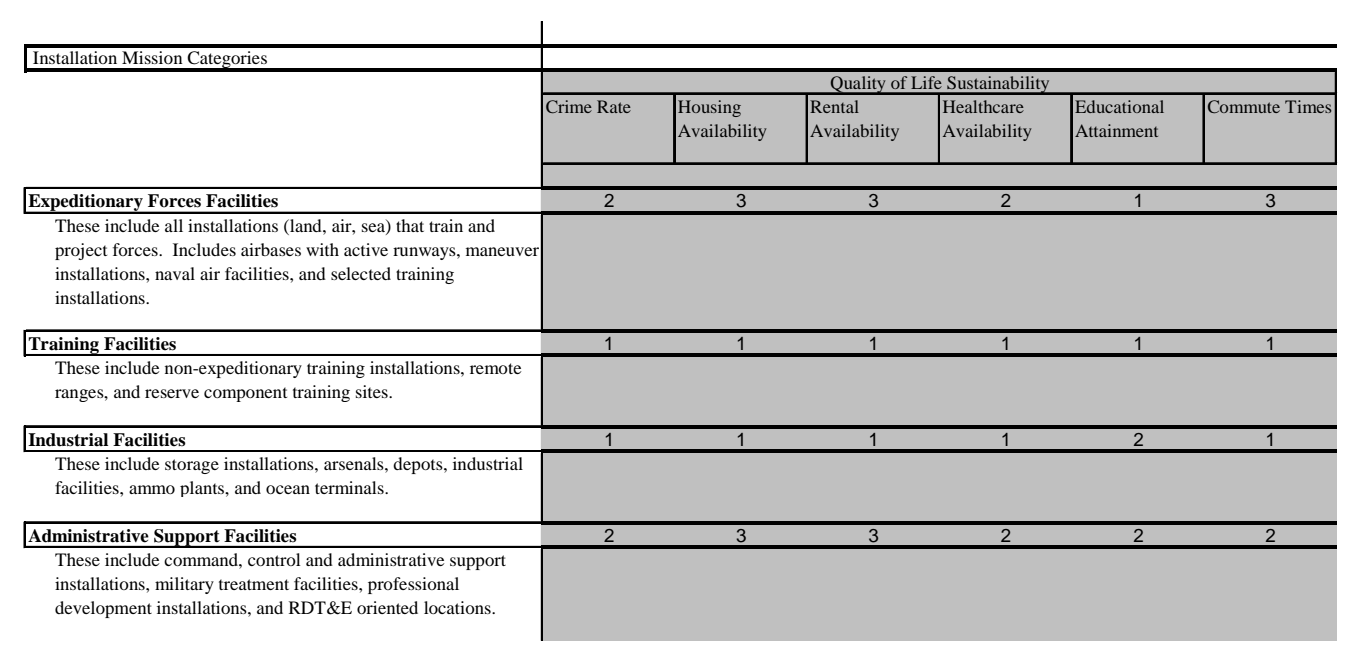

\begin{tabular}{|c|c|c|c|c|c|c|c|}
\hline \multicolumn{8}{|l|}{\begin{tabular}{|l} 
Installation Mission Categories \\
\end{tabular}} \\
\hline & \multicolumn{7}{|c|}{ Transportation Sustainability } \\
\hline & \begin{tabular}{|l|} 
Capacity of \\
Comml Airports
\end{tabular} & \begin{tabular}{|l|} 
Airport \\
Suitability-C5
\end{tabular} & \begin{tabular}{|l|} 
Airport \\
Suitability-C141
\end{tabular} & $\begin{array}{l}\text { Railroad } \\
\text { Capacity }\end{array}$ & $\begin{array}{l}\text { Proximity to } \\
\text { Interstate }\end{array}$ & \begin{tabular}{|l|} 
Roadway \\
Congestion
\end{tabular} & Traffic Volume \\
\hline Expeditionary Forces Facilities & 3 & 3 & 3 & 2 & 2 & 2 & 2 \\
\hline \multicolumn{8}{|l|}{$\begin{array}{l}\text { These include all installations (land, air, sea) that train and } \\
\text { project forces. Includes airbases with active runways, maneuver } \\
\text { installations, naval air facilities, and selected training } \\
\text { installations. }\end{array}$} \\
\hline \begin{tabular}{|l|} 
Training Facilities \\
\end{tabular} & 1 & 1 & 1 & 1 & 1 & 1 & 1 \\
\hline \multicolumn{8}{|l|}{$\begin{array}{l}\text { These include non-expeditionary training installations, remote } \\
\text { ranges, and reserve component training sites. }\end{array}$} \\
\hline Industrial Facilities & 2 & 1 & 1 & 1 & 2 & 2 & 2 \\
\hline \multicolumn{8}{|l|}{$\begin{array}{l}\text { These include storage installations, arsenals, depots, industrial } \\
\text { facilities, ammo plants, and ocean terminals. }\end{array}$} \\
\hline \begin{tabular}{|l|} 
Administrative Support Facilities \\
\end{tabular} & 2 & 1 & 1 & 1 & 2 & 2 & 2 \\
\hline $\begin{array}{l}\text { These include command, control and administrative support } \\
\text { installations, military treatment facilities, professional } \\
\text { development installations, and RDT\&E oriented locations. }\end{array}$ & & & & & & & \\
\hline
\end{tabular}




\section{Appendix C: Installation Region Vulnerability Scores by Service}

Table C1. Installation region vulnerability scores, in rank order (Air Force).

\begin{tabular}{|c|c|c|c|c|c|}
\hline Installation Region & State & Branch & MACOM & Mission & Vulnerability Score \\
\hline Rome Laboratory & New York & Air Force & AFSOC & $A$ & 190 \\
\hline USAF Academy & Colorado & Air Force & USAFA & $A$ & 215 \\
\hline Keesler AFB & Mississippi & Air Force & AETC & $A$ & 223 \\
\hline Portland IAP AGS & Oregon & Air Force & ANG AMC & I & 227 \\
\hline Hill AFB & Utah & Air Force & AFMC & I & 231 \\
\hline Hurlburt Field & Florida & Air Force & AFSOC & $A$ & 241 \\
\hline Arnold AFB & Tennessee & Air Force & AFMC & I & 243 \\
\hline Eglin AFB Main Base & Florida & Air Force & AFMC & I & 247 \\
\hline Pittsburgh IAP ARS & Pennsylvania & Air Force & AFR AMC & 1 & 247 \\
\hline Brooks City Base & Texas & Air Force & AFMC & $A$ & 251 \\
\hline Wright-Patterson AFB & Ohio & Air Force & AFMC & I & 264 \\
\hline Los Angeles AFB & California & Air Force & AFSC & A & 280 \\
\hline Fairchild AFB & Washington & Air Force & AMC & $E$ & 289 \\
\hline F.E. Warren AFB & Wyoming & Air Force & AFSC & $E$ & 306 \\
\hline Sheppard AFB & Texas & Air Force & AETC & $E$ & 309 \\
\hline Vance AFB & Oklahoma & Air Force & AETC & $E$ & 309 \\
\hline Mountain Home AFB & Idaho & Air Force & $\mathrm{ACC}$ & $E$ & 311 \\
\hline Minot AFB & North Dakota & Air Force & ACC & $E$ & 314 \\
\hline Malmstrom AFB & Montana & Air Force & AFSC & $E$ & 319 \\
\hline Ellsworth AFB & South Dakota & Air Force & ACC & $E$ & 322 \\
\hline Maxwell AFB & Alabama & Air Force & AETC & $E$ & 332 \\
\hline Moody AFB & Georgia & Air Force & AFSOC ACC & $E$ & 332 \\
\hline Dyess AFB & Texas & Air Force & $\mathrm{ACC}$ & $E$ & 333 \\
\hline Shaw AFB & South Carolina & Air Force & $\mathrm{ACC}$ & $E$ & 334 \\
\hline McChord AFB & Washington & Air Force & AMC & $E$ & 335 \\
\hline Goodfellow AFB & Texas & Air Force & AETC & $E$ & 337 \\
\hline Barksdale AFB & Louisiana & Air Force & $\mathrm{ACC}$ & $\mathrm{E}$ & 338 \\
\hline Columbus AFB & Mississippi & Air Force & AETC & $E$ & 340 \\
\hline Seymour Johnson AFB & North Carolina & Air Force & ACC & $E$ & 342 \\
\hline Tinker AFB & Oklahoma & Air Force & AFMC & $E$ & 344 \\
\hline Charleston AFB & South Carolina & Air Force & AMC & $E$ & 347 \\
\hline Davis-Monthan AFB & Arizona & Air Force & ACC & $E$ & 347 \\
\hline McEntire AGS & South Carolina & Air Force & ANG & $E$ & 348 \\
\hline Pope AFB & North Carolina & Air Force & AMC & $E$ & 348 \\
\hline Tucson IAP AGS & Arizona & Air Force & ANG AMC & $E$ & 351 \\
\hline General Mitchell IAP ARS & Wisconsin & Air Force & AFR AMC & $E$ & 355 \\
\hline Little Rock AFB & Arkansas & Air Force & AETC & $E$ & 357 \\
\hline Laughlin AFB & Texas & Air Force & AETC & $E$ & 358 \\
\hline Scott AFB & Illinois & Air Force & AMC & $E$ & 359 \\
\hline Westover ARB & Massachusetts & Air Force & AFR & $E$ & 359 \\
\hline
\end{tabular}




\begin{tabular}{|c|c|c|c|c|c|}
\hline McConnell AFB & Kansas & Air Force & AMC & $E$ & 361 \\
\hline Otis AGB & Massachusetts & Air Force & ANG & $E$ & 361 \\
\hline Kirtland AFB & New Mexico & Air Force & AFMC & $E$ & 362 \\
\hline Cannon AFB & New Mexico & Air Force & ACC & $E$ & 365 \\
\hline Springfield-Beckley MPT AGS & Ohio & Air Force & ANG & $E$ & 365 \\
\hline Luke AFB & Arizona & Air Force & AETC & $E$ & 366 \\
\hline Selfridge ANGB & Michigan & Air Force & ANG & $E$ & 367 \\
\hline Tyndall AFB & Florida & Air Force & AETC & $E$ & 370 \\
\hline Offutt AFB & Nebraska & Air Force & ACC & $E$ & 373 \\
\hline Nellis AFB & Nevada & Air Force & $\mathrm{ACC}$ & $E$ & 374 \\
\hline Patrick AFB & Florida & Air Force & AFSC & $E$ & 374 \\
\hline Homestead ARB & Florida & Air Force & AFR & $E$ & 376 \\
\hline Buckley AFB & Colorado & Air Force & AFSC & $E$ & 377 \\
\hline Dobbins ARB & Georgia & Air Force & AFR & $E$ & 377 \\
\hline Dover AFB & Delaware & Air Force & AMC & $E$ & 380 \\
\hline Stewart IAP AGS & New York & Air Force & AMC ANG & $E$ & 386 \\
\hline MacDill AFB & Florida & Air Force & AMC & $E$ & 393 \\
\hline McGuire AFB & New Jersey & Air Force & AMC & $E$ & 395 \\
\hline Andrews AFB & Maryland & Air Force & AMC AFSOC & $E$ & 396 \\
\hline Langley AFB & Virginia & Air Force & ACC & $E$ & 396 \\
\hline Beale AFB & California & Air Force & ACC & $E$ & 398 \\
\hline Willow Grove ARS & Pennsylvania & Air Force & AFR & $E$ & 401 \\
\hline March ARB & California & Air Force & AMC AFR & $E$ & 409 \\
\hline Vandenberg AFB & California & Air Force & AFSC & $E$ & 414 \\
\hline Bolling AFB & Washington DC & Air Force & AMC & $E$ & 416 \\
\hline Travis AFB & California & Air Force & AMC & $E$ & 452 \\
\hline
\end{tabular}

Table C2. Installation region vulnerability scores, in rank order (Army).

\begin{tabular}{|c|c|c|c|c|c|}
\hline Installation Region & State & Branch & MACOM & Mission & Vulnerability Score \\
\hline Camp Guernsey & Wyoming & Army & NGB & $\mathrm{T}$ & 169 \\
\hline Camp Grayling & Michigan & Army & NGB & $\mathrm{T}$ & 180 \\
\hline Camp Grafton & North Dakota & Army & TRADOC & $\mathrm{T}$ & 183 \\
\hline Fort Harrison & Montana & Army & NGB & $\mathrm{T}$ & 190 \\
\hline Camp McCain & Mississippi & Army & NGB & $\mathrm{T}$ & 194 \\
\hline Camp Ethan Allen & Vermont & Army & NGB & $\mathrm{T}$ & 197 \\
\hline Pueblo Chemical Depot & Colorado & Army & AMC & 1 & 197 \\
\hline Camp Ripley & Minnesota & Army & NGB & $\mathrm{T}$ & 198 \\
\hline Umatilla Chemical Depot & Oregon & Army & AMC & I & 198 \\
\hline Fort Chaffee & Arkansas & Army & NGB USARC & $A$ & 199 \\
\hline Camp Shelby & Mississippi & Army & NGB & $\mathrm{T}$ & 200 \\
\hline Camp Dodge & lowa & Army & NGB & $\mathrm{T}$ & 201 \\
\hline Hawthorne Army Depot & Nevada & Army & AMC & 1 & 204 \\
\hline Gowen Field and Orchard Range & Idaho & Army & NGB & $\mathrm{T}$ & 205 \\
\hline Camp Crowder & Missouri & Army & NGB & $\mathrm{T}$ & 206 \\
\hline Fort Gordon & Georgia & Army & TRADOC & A & 206 \\
\hline Iowa AAP & lowa & Army & AMC & 1 & 206 \\
\hline Tooele Army Depot & Utah & Army & AMC & I & 207 \\
\hline Camp Rilea & Oregon & Army & NGB & $\mathrm{T}$ & 208 \\
\hline Fort McCoy & Wisconsin & Army & USARC & A & 208 \\
\hline Kansas AAP & Kansas & Army & AMC & 1 & 209 \\
\hline Fort Pickett & Virginia & Army & NGB & $\mathrm{T}$ & 210 \\
\hline Boise Air Terminal AGS & Idaho & Army & NGB & A & 211 \\
\hline Camp Beauregard & Louisiana & Army & NGB & $\mathrm{T}$ & 212 \\
\hline Camp Edwards & Massachusetts & Army & NGB & $\mathrm{T}$ & 212 \\
\hline Camp Williams & Utah & Army & NGB & $\mathrm{T}$ & 213 \\
\hline Dugway Proving Ground & Utah & Army & ATEC & I & 213 \\
\hline Camp Gruber & Oklahoma & Army & NGB & $\mathrm{T}$ & 217 \\
\hline Fort Custer & Michigan & Army & NGB & $\mathrm{T}$ & 217 \\
\hline Fort McPherson & Georgia & Army & $\begin{array}{l}\text { FORSCOM } \\
\text { USARC }\end{array}$ & $A$ & 217 \\
\hline Camp Robinson & Arkansas & Army & NGB & $\mathrm{T}$ & 218 \\
\hline Fort Indiantown Gap & Pennsylvania & Army & NGB & A & 219 \\
\hline Camp Perry & Ohio & Army & NGB & $\mathrm{T}$ & 220 \\
\hline Deseret Chemical Depot & Utah & Army & AMC & I & 220 \\
\hline Holston AAP & Tennessee & Army & AMC & 1 & 220 \\
\hline Radford AAP & Virginia & Army & AMC & 1 & 220 \\
\hline
\end{tabular}




\begin{tabular}{|c|c|c|c|c|c|}
\hline Fort AP Hill & Virginia & Army & MDW & $\mathrm{T}$ & 221 \\
\hline McAlester AAP & Oklahoma & Army & AMC & 1 & 221 \\
\hline Massachusetts Military Reservation & Massachusetts & Army & & $\mathrm{T}$ & 222 \\
\hline Newport Chemical Depot & Indiana & Army & AMC & 1 & 222 \\
\hline Fort Huachuca & Arizona & Army & TRADOC & A & 223 \\
\hline Pine Bluff Arsenal & Arkansas & Army & AMC & 1 & 223 \\
\hline Carlisle Barracks & Pennsylvania & Army & TRADOC & A & 224 \\
\hline Fort McClellan & Alabama & Army & TRADOC & A & 224 \\
\hline Sierra Army Depot & California & Army & AMC & 1 & 224 \\
\hline Camp Blanding & Florida & Army & NGB & $\mathrm{T}$ & 226 \\
\hline Camp Fogarty & Rhode Island & Army & NGB & $\mathrm{T}$ & 228 \\
\hline Camp Swift & Texas & Army & NGB & $\mathrm{T}$ & 228 \\
\hline Lone Star AAP & Texas & Army & AMC & I & 228 \\
\hline Fort Nathaniel Greene & Rhode Island & Army & USARC & $\mathrm{T}$ & 229 \\
\hline Red River Army Depot & Texas & Army & AMC & 1 & 229 \\
\hline Camp Navajo & Arizona & Army & NGB & $\mathrm{T}$ & 230 \\
\hline Milan AAP & Tennessee & Army & AMC & 1 & 231 \\
\hline Camp Atterbury & Indiana & Army & NGB & $\mathrm{T}$ & 232 \\
\hline Fort Devens & Massachusetts & Army & USARC & A & 233 \\
\hline Blue Grass Army Depot & Kentucky & Army & AMC & 1 & 234 \\
\hline Camp Minden & Louisiana & Army & NGB & $\mathrm{T}$ & 235 \\
\hline Mississippi AAP & Mississippi & Army & AMC & I & 235 \\
\hline Watervliet Arsenal & New York & Army & AMC & 1 & 235 \\
\hline Anniston Army Depot & Alabama & Army & AMC & 1 & 236 \\
\hline White Sands Missile Range NM & New Mexico & Army & ATEC & 1 & 237 \\
\hline Lake City AAP & Missouri & Army & AMC & 1 & 238 \\
\hline Letterkenny Army Depot & Pennsylvania & Army & AMC & 1 & 239 \\
\hline Scranton AAP & Pennsylvania & Army & AMC & 1 & 240 \\
\hline Florence Mil Res & Arizona & Army & NGB & $\mathrm{T}$ & 241 \\
\hline Fort Dix & New Jersey & Army & USARC & A & 242 \\
\hline Fort Lee & Virginia & Army & TRADOC & A & 243 \\
\hline Minneapolis-St Paul IAP ARS & Minnesota & Army & USARC AMC & I & 243 \\
\hline Camp Roberts & California & Army & NGB & $\mathrm{T}$ & 244 \\
\hline Fort Gillem & Georgia & Army & $\begin{array}{l}\text { USARC ANG } \\
\text { CIDC }\end{array}$ & A & 244 \\
\hline Fort Ritchie & Maryland & Army & MDW & A & 244 \\
\hline US Army Garrison Selfridge & Michigan & Army & AMC & A & 244 \\
\hline Detrick Fort & Maryland & Army & MEDCOM & A & 247 \\
\hline Soldier Systems Center (Natick & Massachusetts & Army & AMC & A & 248 \\
\hline Twin Cities AAP & Minnesota & Army & AMC & 1 & 248 \\
\hline Fort Sam Houston & Texas & Army & MEDCOM & A & 249 \\
\hline Military Ocean Tml Sunny Point & North Carolina & Army & MTMC & $\mathrm{I}$ & 249 \\
\hline Rock Island Arsenal & Illinois & Army & AMC & 1 & 249 \\
\hline Camp Bullis & Texas & Army & MEDCOM & A & 250 \\
\hline Redstone Arsenal & Alabama & Army & AMC & 1 & 250 \\
\hline Fort Belvoir & Virginia & Army & MDW & A & 251 \\
\hline Tobyhanna Army Depot & Pennsylvania & Army & AMC & 1 & 251 \\
\hline Louisina AAP & Louisiana & Army & AMC & 1 & 252 \\
\hline Corpus Christi Army Depot & Texas & Army & AMC & 1 & 253 \\
\hline Camp Parks & California & Army & USARC & $\mathrm{T}$ & 255 \\
\hline Fort Leavenworth & Kansas & Army & TRADOC & A & 255 \\
\hline Kelly Support Center & Pennsylvania & Army & USARC & 1 & 256 \\
\hline Lima Army Tank PLT & Ohio & Army & AMC & 1 & 257 \\
\hline Yuma Proving Ground & Arizona & Army & ATEC & 1 & 258 \\
\hline Fort Monmouth Main Post & New Jersey & Army & AMC & A & 262 \\
\hline West Point Mil Reservation & New York & Army & USMA & A & 264 \\
\hline Fort Hamilton & New York & Army & MDW & A & 267 \\
\hline Aberdeen Proving Ground & Maryland & Army & AMC TRADOC & A & 268 \\
\hline USA Adelphi Laboratory Center & Maryland & Army & AMC & A & 271 \\
\hline Tripler Army Medical Center & Hawaii & Army & USARPAC & A & 272 \\
\hline Fort Monroe & Virginia & Army & TRADOC & A & 275 \\
\hline Pinyon Canyon & Colorado & Army & FORSCOM & $E$ & 275 \\
\hline Fort George G Meade & Maryland & Army & MDW & A & 277 \\
\hline Fort Myer & Virginia & Army & MDW & A & 278 \\
\hline Fort Lesley J McNair & Washington DC & Army & MDW & A & 280 \\
\hline Picatinny Arsenal & New Jersey & Army & AMC & 1 & 282 \\
\hline Walter Reed Army Medical Center & Washington DC & Army & MEDCOM & A & 283 \\
\hline Fort Totten & New York & Army & MDW & A & 284 \\
\hline Detroit Arsenal & Michigan & Army & AMC & 1 & 286 \\
\hline Riverbank AAP & California & Army & AMC & I & 286 \\
\hline
\end{tabular}




\begin{tabular}{|c|c|c|c|c|c|}
\hline Concord-CA-0696A & California & Army & MTMC & I & 287 \\
\hline Fort Leonard Wood & Missouri & Army & TRADOC & $E$ & 294 \\
\hline Fort Riley & Kansas & Army & FORSCOM & $E$ & 295 \\
\hline Fort Wainwright & Alaska & Army & USARPAC & $E$ & 298 \\
\hline Yakima Training Center & Washington & Army & FORSCOM & $E$ & 299 \\
\hline Fort Carson & Colorado & Army & FORSCOM & $E$ & 302 \\
\hline Fort Story & Virginia & Army & TRADOC & A & 312 \\
\hline Fort Greely & Alaska & Army & USARPAC & $E$ & 318 \\
\hline Fort Drum & New York & Army & FORSCOM & $E$ & 320 \\
\hline Fort Sill OK & Oklahoma & Army & TRADOC & $E$ & 324 \\
\hline Fort Stewart GA & Georgia & Army & FORSCOM & $E$ & 324 \\
\hline Fort Benning GA & Georgia & Army & TRADOC & $E$ & 326 \\
\hline Mickelsen Stanley R SFG MSR & North Dakota & Army & USASMDC & $E$ & 328 \\
\hline Fort Polk & Louisiana & Army & FORSCOM & $E$ & 337 \\
\hline Fort Bliss & New Mexico & Army & TRADOC & $E$ & 338 \\
\hline Fort Lewis & Washington & Army & FORSCOM & $E$ & 339 \\
\hline Fort Hood & Texas & Army & FORSCOM & $E$ & 342 \\
\hline Fort Rucker AL & Alabama & Army & TRADOC & $E$ & 343 \\
\hline Fort Jackson & South Carolina & Army & TRADOC & $E$ & 344 \\
\hline Fort Campbell & Tennessee & Army & FORSCOM & $E$ & 347 \\
\hline Hunter Army Airfield & Georgia & Army & FORSCOM & $E$ & 347 \\
\hline Fort Bragg & North Carolina & Army & FORSCOM & $E$ & 358 \\
\hline Fort Richardson & Alaska & Army & USARPAC & $E$ & 358 \\
\hline Fort Knox & Kentucky & Army & TRADOC & $E$ & 364 \\
\hline Fort Eustis & Virginia & Army & TRADOC & $E$ & 380 \\
\hline NTC and Fort Irwin CA & California & Army & FORSCOM & $E$ & 380 \\
\hline Hunter Liggett & California & Army & USARC & $E$ & 408 \\
\hline Pohakulua Training Area & Hawaii & Army & USARPAC & $E$ & 409 \\
\hline Schofield Barracks & Hawaii & Army & USARPAC & $E$ & 450 \\
\hline Fort Shafter & Hawaii & Army & USARPAC & $E$ & 454 \\
\hline
\end{tabular}

Table C3. Installation region vulnerability scores, in rank order (Defense Logistics Agency).

\begin{tabular}{|l|l|l|l|l|l|}
\hline Installation Region & State & Branch & MACOM & Mission & Vulnerability Score \\
\hline Susquehanna DDD & Pennsylvania & DLA & OSD AT\&L & I & 235 \\
\hline Columbus DSCC & Ohio & DLA & AMC & I & 253 \\
\hline Richmond DSC & Virginia & DLA & OSD AT\&L & I & 261 \\
\hline Tracy DDJC & California & DLA & OSD AT\&L & I & 283 \\
\hline Sharpe DDJC & California & DLA & OSD AT\&L & I & 284 \\
\hline
\end{tabular}

Table C4. Installation region vulnerability scores, in rank order (Marine Corps).

\begin{tabular}{|l|l|l|l|l|l|}
\hline Installation Region & State & Branch & MACOM & Mission & Vulnerability Score \\
\hline Albany MCLB & Georgia & Marine Corps & MCLC & A & 222 \\
\hline Kansas City MCRSC & Missouri & Marine Corps & MOBCOM & A & 238 \\
\hline Twentynine Palms MAGTFTC & California & Marine Corps & TECOM & A & 247 \\
\hline Beaufort MCAS & South Carolina & Marine Corps & TECOM & A & 249 \\
\hline Blount Island Command & Florida & Marine Corps & MCLC & A & 253 \\
\hline Barstow MCLB & California & Marine Corps & MCLC & A & 254 \\
\hline Washington DC MARBKS & Washington DC & Marine Corps & MCCDC & A & 280 \\
\hline Quantico MCB & Virginia & Marine Corps & MCCDC MCRC & A & 281 \\
\hline San Diego MCRD & California & Marine Corps & TECOM & A & 289 \\
\hline Camp Lejeune MCB & North Carolina & Marine Corps & TECOM & E & 327 \\
\hline Cherry Point MCAS & North Carolina & Marine Corps & TECOM & E & 337 \\
\hline New River MCAS & North Carolina & Marine Corps & TECOM & E & 347 \\
\hline Parris Island MCRD & South Carolina & Marine Corps & TECOM & E & 379 \\
\hline
\end{tabular}




\begin{tabular}{l|l|l|l|l|l|} 
Bridgeport MCMWTC & California & Marine Corps & TECOM & E & 390 \\
\hline Yuma MCAS & Arizona & Marine Corps & TECOM & E & 394 \\
Camp Pendleton MCB & California & Marine Corps & TECOM & E & 432 \\
Camp Pendleton MCAS & California & Marine Corps & TECOM & E & 437 \\
Miramar MCAS & California & Marine Corps & TECOM & E & 450 \\
\hline
\end{tabular}

Table C5. Installation region vulnerability scores, in rank order (Navy).

\begin{tabular}{|c|c|c|c|c|c|}
\hline Installation Region & State & Branch & MACOM & Mission & Vulnerability Score \\
\hline Cutler NRS & Maine & Navy & NAVFAC & A & 208 \\
\hline Sugar Grove NRS & West Virginia & Navy & NCS & A & 210 \\
\hline Puget Sound NSY & Washington & Navy & NAVSUP & $\mathrm{I}$ & 215 \\
\hline Athens Navy Supply Corps School & Georgia & Navy & NETC & A & 225 \\
\hline Crane NWSC & Indiana & Navy & $\begin{array}{l}\text { NAVSEA } \\
\text { NAVFAC }\end{array}$ & 1 & 232 \\
\hline Gulfport CBC & Mississippi & Navy & NAVSUP & 1 & 235 \\
\hline Charleston NWS & South Carolina & Navy & NAVSUP & 1 & 238 \\
\hline Indian Island Naval Magazine & Washington & Navy & NAVSUP & 1 & 238 \\
\hline Mechanicsburg NSPC Center & Pennsylvania & Navy & $\begin{array}{l}\text { NAVSUP } \\
\text { NAVSEA }\end{array}$ & 1 & 245 \\
\hline Midsouth Millington NSA & Tennessee & Navy & NAVFAC & A & 245 \\
\hline San Nicolas Island NR & California & Navy & NAVSEA & $\mathrm{T}$ & 245 \\
\hline Dahlgren NSWC & Virginia & Navy & $\begin{array}{l}\text { NAVSEA } \\
\text { NAVFAC }\end{array}$ & A & 247 \\
\hline Yorktown NWS & Virginia & Navy & $\begin{array}{l}\text { NAVFAC } \\
\text { NAVSUP }\end{array}$ & 1 & 250 \\
\hline Cheatham Annex NSC & Virginia & Navy & NAVSUP & 1 & 251 \\
\hline NSY Portsmouth & Maine & Navy & NAVSUP & 1 & 256 \\
\hline NS Great Lakes & Illinois & Navy & NETC & A & 262 \\
\hline Bethesda Naval Medical Center & Maryland & Navy & NMC & A & 265 \\
\hline Portsmouth Naval Medical Center & Virginia & Navy & NMC & A & 265 \\
\hline Jacksonville FISC & Florida & Navy & NAVSUP & 1 & 267 \\
\hline Monterey NPS & California & Navy & NETC & A & 270 \\
\hline San Clemente Island NR & California & Navy & NAVAIR & $\mathrm{T}$ & 276 \\
\hline Carderock NSWC & Maryland & Navy & $\begin{array}{l}\text { NAVSEA } \\
\text { NAVFAC }\end{array}$ & 1 & 277 \\
\hline Norfolk NSA & Virginia & Navy & NAVFAC & A & 277 \\
\hline Naval Research Laboratory & Washington DC & Navy & NAVFAC & A & 278 \\
\hline Washington NSA & Washington DC & Navy & NAVFAC & A & 278 \\
\hline US Naval Observatory & Washington DC & Navy & USNO & A & 279 \\
\hline Annapolis NS & Maryland & Navy & NETC & A & 281 \\
\hline Norfolk NSY & Virginia & Navy & NAVSUP & 1 & 282 \\
\hline US Naval Academy Annapolis & Maryland & Navy & USNA & A & 283 \\
\hline Indian Head NSWC & Maryland & Navy & NAVSEA & 1 & 286 \\
\hline San Diego Naval Medical Center & California & Navy & NMC & A & 288 \\
\hline Earle NWS & New Jersey & Navy & NAVSUP & 1 & 293 \\
\hline Meridian NAS & Mississippi & Navy & NAVAIR & $E$ & 294 \\
\hline Seal Beach NWS & California & Navy & NAVSUP & 1 & 306 \\
\hline Fallon NAS & Nevada & Navy & NAVAIR & $E$ & 314 \\
\hline Kings Bay NSB & Georgia & Navy & NAVSEA & $E$ & 319 \\
\hline Everett NS & Washington & Navy & NAVSEA & $E$ & 322 \\
\hline Bangor NSB & Washington & Navy & NAVSEA & $E$ & 333 \\
\hline Whidbey Island NAS & Washington & Navy & NAVAIR & $E$ & 336 \\
\hline Whiting Field NAS & Florida & Navy & NAVAIR & $E$ & 337 \\
\hline Keyport NUWC & Washington & Navy & $\begin{array}{l}\text { NAVSEA } \\
\text { NAVSUP }\end{array}$ & $E$ & 340 \\
\hline Ingleside NS & Texas & Navy & NAVSEA & $E$ & 345 \\
\hline Pensacola NAS & Florida & Navy & NAVAIR & $E$ & 351 \\
\hline Corpus Christi NAS & Texas & Navy & NAVAIR & $E$ & 353 \\
\hline Brunswick NAS & Maine & Navy & NAVAIR & $E$ & 357 \\
\hline El Centro NAF & California & Navy & NAVAIR & $E$ & 358 \\
\hline New London NSB & Connecticut & Navy & NAVSEA & $E$ & 360 \\
\hline Fort Worth NAS JRB & Texas & Navy & NAVAIR NETC & $E$ & 361 \\
\hline Kingsville NAS & Texas & Navy & NAVAIR & $E$ & 361 \\
\hline Panama City CSS & Florida & Navy & NAVSEA & $E$ & 363 \\
\hline Atlanta NAS & Georgia & Navy & NAVAIR & $E$ & 375 \\
\hline
\end{tabular}




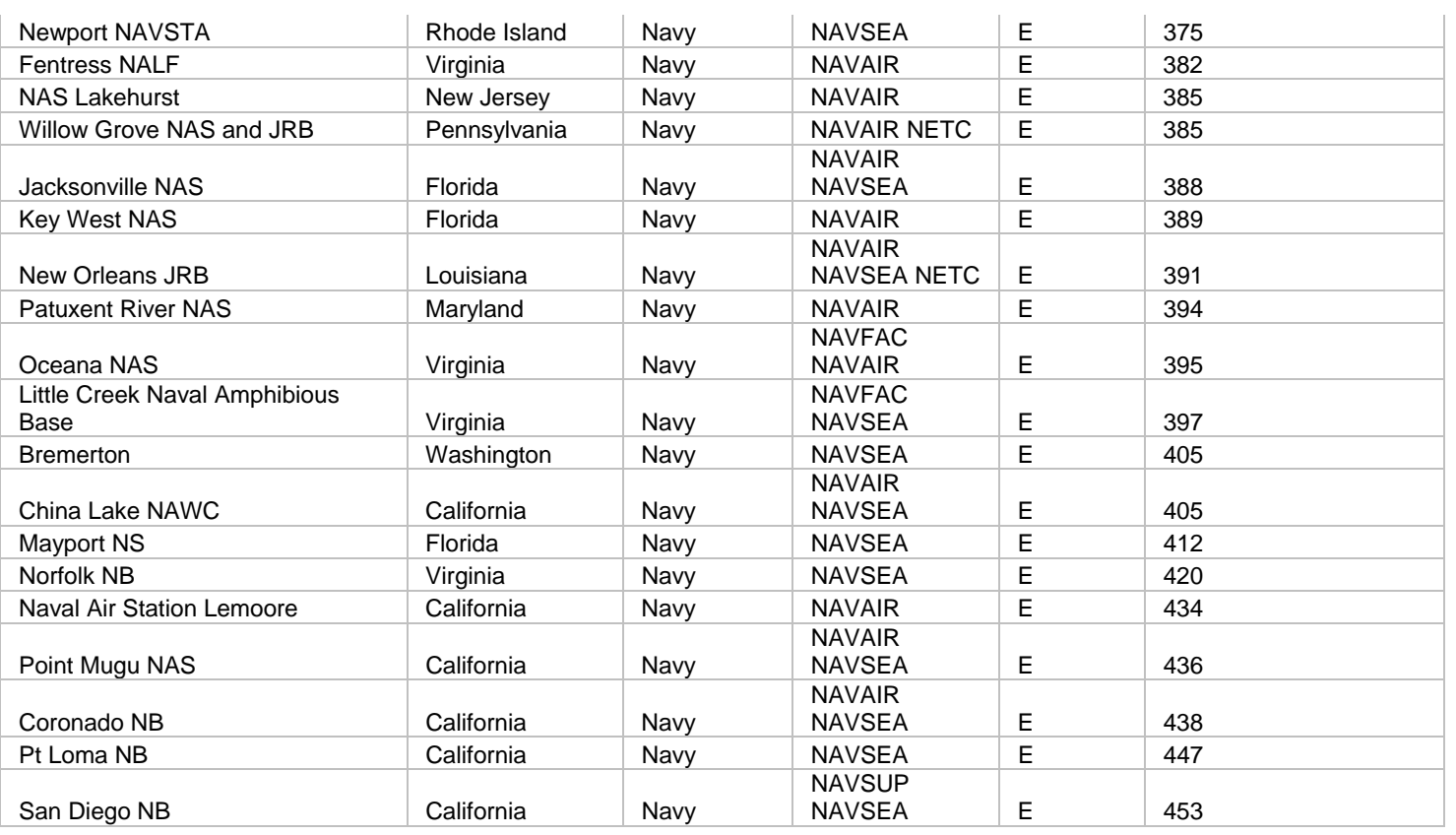




\section{Appendix D: Installation Region Vulnerability Scores by Mission}

Table D1. Installation region vulnerability scores, by mission (Air Force).

\begin{tabular}{|c|c|c|c|c|c|}
\hline Installation Region & State & Branch & MACOM & Mission & Vulnerability Score \\
\hline Brooks City Base & Texas & Air Force & AFMC & $A$ & 251 \\
\hline Hurlburt Field & Florida & Air Force & AFSOC & A & 241 \\
\hline Keesler AFB & Mississippi & Air Force & AETC & $A$ & 223 \\
\hline Lackland AFB & Texas & Air Force & AETC & A & 252 \\
\hline Los Angeles AFB & California & Air Force & AFSC & $A$ & 280 \\
\hline Randolph AFB & Texas & Air Force & AETC & $A$ & 256 \\
\hline USAF Academy & Colorado & Air Force & USAFA & $A$ & 215 \\
\hline Altus AFB & Oklahoma & Air Force & AETC & $E$ & 327 \\
\hline Andrews AFB & Maryland & Air Force & AMC AFSOC & $E$ & 396 \\
\hline Barksdale AFB & Louisiana & Air Force & ACC & $E$ & 338 \\
\hline Beale AFB & California & Air Force & ACC & $E$ & 398 \\
\hline Columbus AFB & Mississippi & Air Force & AETC & $E$ & 340 \\
\hline Davis-Monthan AFB & Arizona & Air Force & ACC & $E$ & 347 \\
\hline Dobbins ARB & Georgia & Air Force & AFR & $E$ & 377 \\
\hline Dover AFB & Delaware & Air Force & AMC & $E$ & 380 \\
\hline Dyess AFB & Texas & Air Force & ACC & $E$ & 333 \\
\hline Ellsworth AFB & South Dakota & Air Force & $\mathrm{ACC}$ & $E$ & 322 \\
\hline F.E. Warren AFB & Wyoming & Air Force & AFSC & $E$ & 306 \\
\hline Fairchild AFB & Washington & Air Force & AMC & $E$ & 289 \\
\hline General Mitchell IAP ARS & Wisconsin & Air Force & AFR AMC & $E$ & 355 \\
\hline Goodfellow AFB & Texas & Air Force & AETC & $E$ & 337 \\
\hline Little Rock AFB & Arkansas & Air Force & AETC & $E$ & 357 \\
\hline Luke AFB & Arizona & Air Force & AETC & $E$ & 366 \\
\hline MacDill AFB & Florida & Air Force & AMC & $E$ & 393 \\
\hline Malmstrom AFB & Montana & Air Force & AFSC & $E$ & 319 \\
\hline March ARB & California & Air Force & AMC AFR & $E$ & 409 \\
\hline Maxwell AFB & Alabama & Air Force & AETC & $E$ & 332 \\
\hline McChord AFB & Washington & Air Force & AMC & $E$ & 335 \\
\hline McConnell AFB & Kansas & Air Force & AMC & $E$ & 361 \\
\hline McEntire AGS & South Carolina & Air Force & ANG & $E$ & 348 \\
\hline McGuire AFB & New Jersey & Air Force & AMC & $E$ & 395 \\
\hline Minot AFB & North Dakota & Air Force & ACC & $E$ & 314 \\
\hline Moody AFB & Georgia & Air Force & AFSOC ACC & $E$ & 332 \\
\hline Mountain Home AFB & Idaho & Air Force & ACC & $E$ & 311 \\
\hline Nellis AFB & Nevada & Air Force & ACC & $E$ & 374 \\
\hline Offutt AFB & Nebraska & Air Force & ACC & $E$ & 373 \\
\hline Otis AGB & Massachusetts & Air Force & ANG & $E$ & 361 \\
\hline Patrick AFB & Florida & Air Force & AFSC & $E$ & 374 \\
\hline Peterson AFB & Colorado & Air Force & AFSC & $E$ & 327 \\
\hline Pope AFB & North Carolina & Air Force & AMC & $E$ & 348 \\
\hline Robins AFB & Georgia & Air Force & AFMC & $E$ & 323 \\
\hline
\end{tabular}




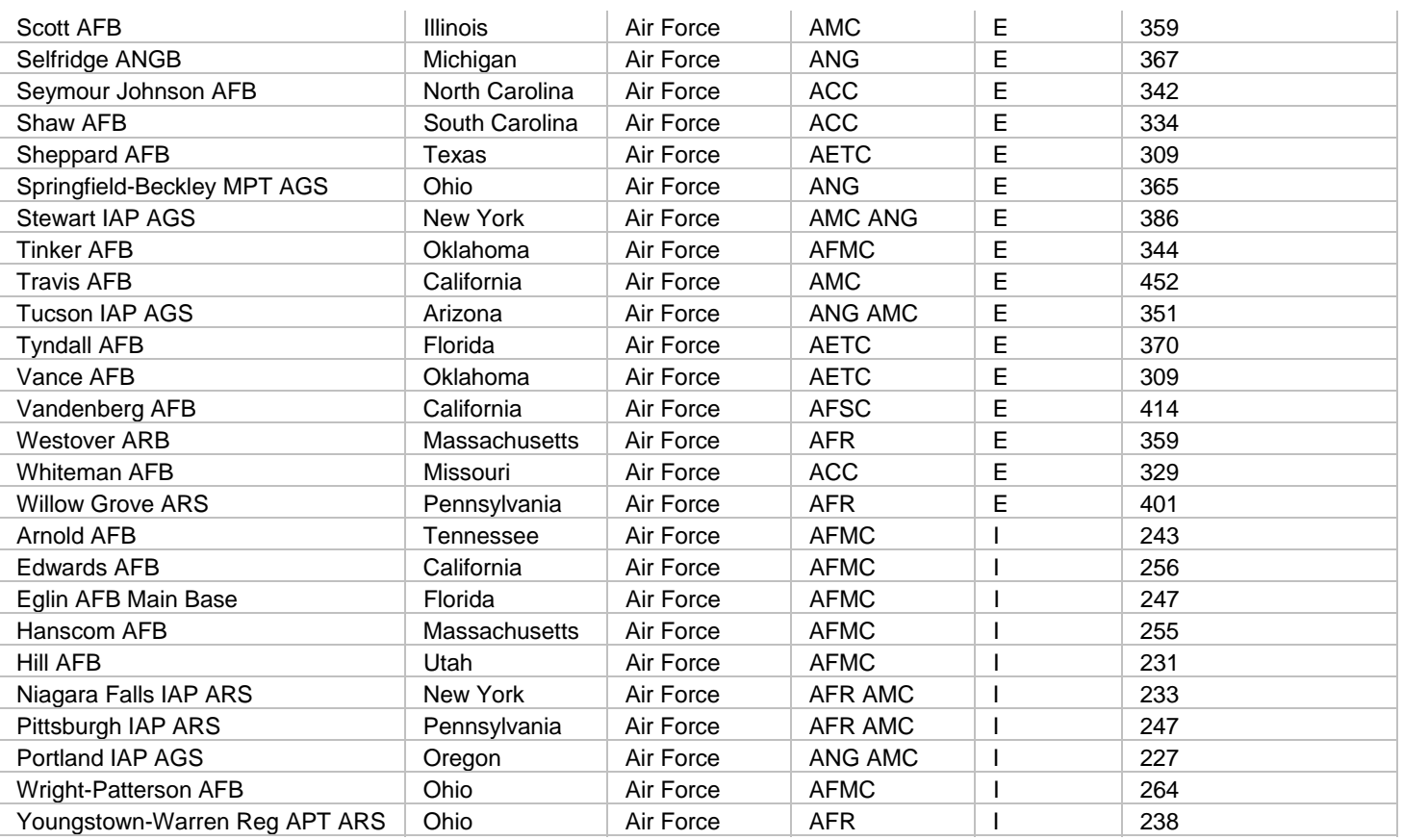

Table D2. Installation region vulnerability scores, by mission (Army).

\begin{tabular}{|c|c|c|c|c|c|}
\hline Installation Region & State & Branch & MACOM & Mission & Vulnerability Score \\
\hline Aberdeen Proving Ground & Maryland & Army & $\begin{array}{l}\text { AMC } \\
\text { TRADOC }\end{array}$ & A & 268 \\
\hline Boise Air Terminal AGS & Idaho & Army & NGB & A & 211 \\
\hline Camp Bullis & Texas & Army & MEDCOM & A & 250 \\
\hline Carlisle Barracks & Pennsylvania & Army & TRADOC & A & 224 \\
\hline Detrick Fort & Maryland & Army & MEDCOM & A & 247 \\
\hline Fort Belvoir & Virginia & Army & MDW & A & 251 \\
\hline Fort Chaffee & Arkansas & Army & NGB USARC & A & 199 \\
\hline Fort Devens & Massachusetts & Army & USARC & A & 233 \\
\hline Fort Dix & New Jersey & Army & USARC & A & 242 \\
\hline Fort George G Meade & Maryland & Army & MDW & A & 277 \\
\hline Fort Gillem & Georgia & Army & $\begin{array}{l}\text { USARC ANG } \\
\text { CIDC }\end{array}$ & A & 244 \\
\hline Fort Gordon & Georgia & Army & TRADOC & A & 206 \\
\hline Fort Hamilton & New York & Army & MDW & A & 267 \\
\hline Fort Huachuca & Arizona & Army & TRADOC & A & 223 \\
\hline Fort Indiantown Gap & Pennsylvania & Army & NGB & A & 219 \\
\hline Fort Leavenworth & Kansas & Army & TRADOC & A & 255 \\
\hline Fort Lee & Virginia & Army & TRADOC & A & 243 \\
\hline Fort Lesley J McNair & Washington DC & Army & MDW & A & 280 \\
\hline Fort McClellan & Alabama & Army & TRADOC & A & 224 \\
\hline Fort McCoy & Wisconsin & Army & USARC & A & 208 \\
\hline Fort McPherson & Georgia & Army & $\begin{array}{l}\text { FORSCOM } \\
\text { USARC }\end{array}$ & A & 217 \\
\hline Fort Monmouth Main Post & New Jersey & Army & AMC & A & 262 \\
\hline Fort Monroe & Virginia & Army & TRADOC & A & 275 \\
\hline Fort Myer & Virginia & Army & MDW & A & 278 \\
\hline Fort Ritchie & Maryland & Army & MDW & A & 244 \\
\hline Fort Sam Houston & Texas & Army & MEDCOM & A & 249 \\
\hline Fort Story & Virginia & Army & TRADOC & A & 312 \\
\hline Fort Totten & New York & Army & MDW & A & 284 \\
\hline Soldier Systems Center (Natick & Massachusetts & Army & AMC & A & 248 \\
\hline Tripler Army Medical Center & Hawaii & Army & USARPAC & A & 272 \\
\hline US Army Garrison Selfridge & Michigan & Army & AMC & A & 244 \\
\hline USA Adelphi Laboratory Center & Maryland & Army & AMC & A & 271 \\
\hline Walter Reed Army Medical Center & Washington DC & Army & MEDCOM & A & 283 \\
\hline West Point Mil Reservation & New York & Army & USMA & A & 264 \\
\hline Fort Benning GA & Georgia & Army & TRADOC & $\mathrm{E}$ & 326 \\
\hline Fort Bliss & New Mexico & Army & TRADOC & $E$ & 338 \\
\hline
\end{tabular}




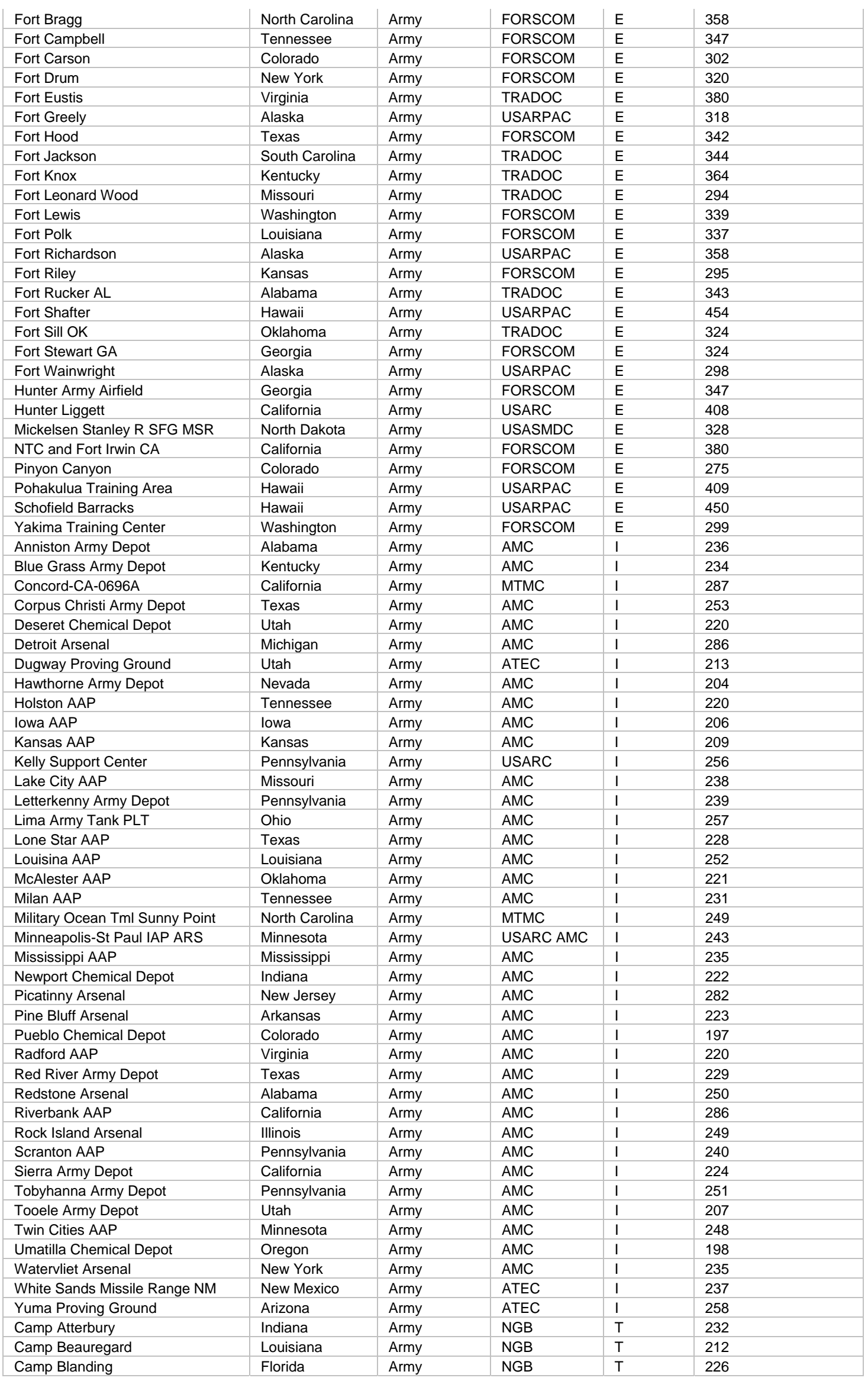




\begin{tabular}{|c|c|c|c|c|c|}
\hline Camp Crowder & Missouri & Army & NGB & $\mathrm{T}$ & 206 \\
\hline Camp Dodge & lowa & Army & NGB & $\mathrm{T}$ & 201 \\
\hline Camp Edwards & Massachusetts & Army & NGB & $\mathrm{T}$ & 212 \\
\hline Camp Ethan Allen & Vermont & Army & NGB & $\mathrm{T}$ & 197 \\
\hline Camp Grafton & North Dakota & Army & TRADOC & $\mathrm{T}$ & 183 \\
\hline Camp Grayling & Michigan & Army & NGB & $\mathrm{T}$ & 180 \\
\hline Camp McCain & Mississippi & Army & NGB & $\mathrm{T}$ & 194 \\
\hline Camp Minden & Louisiana & Army & NGB & $\mathrm{T}$ & 235 \\
\hline Camp Navajo & Arizona & Army & NGB & $\mathrm{T}$ & 230 \\
\hline Camp Parks & California & Army & USARC & $\mathrm{T}$ & 255 \\
\hline Camp Perry & Ohio & Army & NGB & $\mathrm{T}$ & 220 \\
\hline Camp Shelby & Mississippi & Army & NGB & $\mathrm{T}$ & 200 \\
\hline Camp Swift & Texas & Army & NGB & $\mathrm{T}$ & 228 \\
\hline Camp Williams & Utah & Army & NGB & $\mathrm{T}$ & 213 \\
\hline Florence Mil Res & Arizona & Army & NGB & $\mathrm{T}$ & 241 \\
\hline Fort AP Hill & Virginia & Army & MDW & $\mathrm{T}$ & 221 \\
\hline Fort Custer & Michigan & Army & NGB & $\mathrm{T}$ & 217 \\
\hline Fort Harrison & Montana & Army & NGB & $\mathrm{T}$ & 190 \\
\hline Fort Nathaniel Greene & Rhode Island & Army & USARC & $\mathrm{T}$ & 229 \\
\hline Fort Pickett & Virginia & Army & NGB & $\mathrm{T}$ & 210 \\
\hline Gowen Field and Orchard Range & Idaho & Army & NGB & $\mathrm{T}$ & 205 \\
\hline
\end{tabular}

Table D3. Installation region vulnerability scores, by mission (Defense Logistics Agency).

\begin{tabular}{|l|l|l|l|l|l|}
\hline Installation Region & State & Branch & MACOM & Mission & Vulnerability Score \\
\hline Columbus DSCC & Ohio & DLA & AMC & I & 253 \\
\hline Richmond DSC & Virginia & DLA & OSD AT\&L & I & 261 \\
\hline Sharpe DDJC & California & DLA & OSD AT\&L & I & 284 \\
\hline Susquehanna DDD & Pennsylvania & DLA & OSD AT\&L & I & 235 \\
\hline Tracy DDJC & California & DLA & OSD AT\&L & I & 283 \\
\hline
\end{tabular}

Table D4. Installation region vulnerability scores, by mission (Marine Corps).

\begin{tabular}{|l|l|l|l|l|l|}
\hline Installation Region & State & Branch & MACOM & Mission & Vulnerability Score \\
\hline Albany MCLB & Georgia & Marine Corps & MCLC & A & 222 \\
\hline Barstow MCLB & California & Marine Corps & MCLC & A & 254 \\
\hline Beaufort MCAS & South Carolina & Marine Corps & TECOM & A & 249 \\
\hline Blount Island Command & Florida & Marine Corps & MCLC & A & 253 \\
\hline Kansas City MCRSC & Missouri & Marine Corps & MOBCOM & A & 238 \\
\hline Quantico MCB & Virginia & Marine Corps & MCCDC MCRC & A & 281 \\
\hline San Diego MCRD & California & Marine Corps & TECOM & A & 289 \\
\hline Twentynine Palms MAGTFTC & California & Marine Corps & TECOM & A & 247 \\
\hline Washington DC MARBKS & Washington DC & Marine Corps & MCCDC & A & 280 \\
\hline Bridgeport MCMWTC & California & Marine Corps & TECOM & E & 390 \\
\hline Camp Lejeune MCB & North Carolina & Marine Corps & TECOM & E & 327 \\
\hline Camp Pendleton MCAS & California & Marine Corps & TECOM & E & 437 \\
\hline Camp Pendleton MCB & California & Marine Corps & TECOM & E & 432 \\
\hline Cherry Point MCAS & North Carolina & Marine Corps & TECOM & E & 337 \\
\hline Miramar MCAS & California & Marine Corps & TECOM & E & 450 \\
\hline New River MCAS & North Carolina & Marine Corps & TECOM & E & 347 \\
\hline Parris Island MCRD & South Carolina & Marine Corps & TECOM & E & 379 \\
\hline Yuma MCAS & Arizona & Marine Corps & TECOM & E & 394 \\
\hline
\end{tabular}


Table D5. Installation region vulnerability scores, by mission (Navy).

\begin{tabular}{|c|c|c|c|c|c|}
\hline Installation Region & State & Branch & MACOM & Mission & Vulnerability Score \\
\hline Annapolis NS & Maryland & Navy & NETC & A & 281 \\
\hline Athens Navy Supply Corps School & Georgia & Navy & NETC & A & 225 \\
\hline Bethesda Naval Medical Center & Maryland & Navy & NMC & A & 265 \\
\hline Cutler NRS & Maine & Navy & NAVFAC & A & 208 \\
\hline Dahlgren NSWC & Virginia & Navy & NAVSEA NAVFAC & A & 247 \\
\hline Midsouth Millington NSA & Tennessee & Navy & NAVFAC & A & 245 \\
\hline Monterey NPS & California & Navy & NETC & A & 270 \\
\hline Naval Research Laboratory & Washington DC & Navy & NAVFAC & A & 278 \\
\hline Norfolk NSA & Virginia & Navy & NAVFAC & A & 277 \\
\hline NS Great Lakes & Illinois & Navy & NETC & A & 262 \\
\hline Portsmouth Naval Medical Center & Virginia & Navy & NMC & A & 265 \\
\hline San Diego Naval Medical Center & California & Navy & NMC & A & 288 \\
\hline Sugar Grove NRS & West Virginia & Navy & NCS & A & 210 \\
\hline US Naval Academy Annapolis & Maryland & Navy & USNA & A & 283 \\
\hline US Naval Observatory & Washington DC & Navy & USNO & A & 279 \\
\hline Washington NSA & Washington DC & Navy & NAVFAC & A & 278 \\
\hline Atlanta NAS & Georgia & Navy & NAVAIR & E & 375 \\
\hline Bangor NSB & Washington & Navy & NAVSEA & E & 333 \\
\hline Bremerton & Washington & Navy & NAVSEA & $\mathrm{E}$ & 405 \\
\hline Brunswick NAS & Maine & Navy & NAVAIR & $\mathrm{E}$ & 357 \\
\hline China Lake NAWC & California & Navy & NAVAIR NAVSEA & E & 405 \\
\hline Coronado NB & California & Navy & NAVAIR NAVSEA & E & 438 \\
\hline Corpus Christi NAS & Texas & Navy & NAVAIR & E & 353 \\
\hline El Centro NAF & California & Navy & NAVAIR & E & 358 \\
\hline Everett NS & Washington & Navy & NAVSEA & E & 322 \\
\hline Fallon NAS & Nevada & Navy & NAVAIR & E & 314 \\
\hline Fentress NALF & Virginia & Navy & NAVAIR & E & 382 \\
\hline Fort Worth NAS JRB & Texas & Navy & NAVAIR NETC & $\mathrm{E}$ & 361 \\
\hline Ingleside NS & Texas & Navy & NAVSEA & E & 345 \\
\hline Jacksonville NAS & Florida & Navy & NAVAIR NAVSEA & E & 388 \\
\hline Key West NAS & Florida & Navy & NAVAIR & E & 389 \\
\hline Keyport NUWC & Washington & Navy & NAVSEA NAVSUP & $E$ & 340 \\
\hline Kings Bay NSB & Georgia & Navy & NAVSEA & E & 319 \\
\hline Kingsville NAS & Texas & Navy & NAVAIR & E & 361 \\
\hline $\begin{array}{l}\text { Little Creek Naval Amphibious } \\
\text { Base }\end{array}$ & Virginia & Navy & NAVFAC NAVSEA & E & 397 \\
\hline Mayport NS & Florida & Navy & NAVSEA & $\mathrm{E}$ & 412 \\
\hline Meridian NAS & Mississippi & Navy & NAVAIR & E & 294 \\
\hline NAS Lakehurst & New Jersey & Navy & NAVAIR & E & 385 \\
\hline Naval Air Station Lemoore & California & Navy & NAVAIR & E & 434 \\
\hline New London NSB & Connecticut & Navy & NAVSEA & E & 360 \\
\hline New Orleans JRB & Louisiana & Navy & $\begin{array}{l}\text { NAVAIR NAVSEA } \\
\text { NETC }\end{array}$ & E & 391 \\
\hline Newport NAVSTA & Rhode Island & Navy & NAVSEA & E & 375 \\
\hline Norfolk NB & Virginia & Navy & NAVSEA & E & 420 \\
\hline Oceana NAS & Virginia & Navy & NAVFAC NAVAIR & E & 395 \\
\hline Panama City CSS & Florida & Navy & NAVSEA & E & 363 \\
\hline Patuxent River NAS & Maryland & Navy & NAVAIR & E & 394 \\
\hline Pensacola NAS & Florida & Navy & NAVAIR & $\mathrm{E}$ & 351 \\
\hline Point Mugu NAS & California & Navy & NAVAIR NAVSEA & E & 436 \\
\hline Pt Loma NB & California & Navy & NAVSEA & E & 447 \\
\hline San Diego NB & California & Navy & NAVSUP NAVSEA & E & 453 \\
\hline Whidbey Island NAS & Washington & Navy & NAVAIR & $\mathrm{E}$ & 336 \\
\hline Whiting Field NAS & Florida & Navy & NAVAIR & $\mathrm{E}$ & 337 \\
\hline Willow Grove NAS and JRB & Pennsylvania & Navy & NAVAIR NETC & E & 385 \\
\hline Carderock NSWC & Maryland & Navy & NAVSEA NAVFAC & 1 & 277 \\
\hline Charleston NWS & South Carolina & Navy & NAVSUP & 1 & 238 \\
\hline Cheatham Annex NSC & Virginia & Navy & NAVSUP & 1 & 251 \\
\hline Crane NWSC & Indiana & Navy & NAVSEA NAVFAC & 1 & 232 \\
\hline Earle NWS & New Jersey & Navy & NAVSUP & 1 & 293 \\
\hline Gulfport CBC & Mississippi & Navy & NAVSUP & 1 & 235 \\
\hline Indian Head NSWC & Maryland & Navy & NAVSEA & I & 286 \\
\hline Indian Island Naval Magazine & Washington & Navy & NAVSUP & 1 & 238 \\
\hline Jacksonville FISC & Florida & Navy & NAVSUP & I & 267 \\
\hline Mechanicsburg NSPC Center & Pennsylvania & Navy & NAVSUP NAVSEA & 1 & 245 \\
\hline Norfolk NSY & Virginia & Navy & NAVSUP & I & 282 \\
\hline
\end{tabular}




\begin{tabular}{l|l|l|l|l|l} 
NSY Portsmouth & Maine & Navy & NAVSUP & I & 256 \\
\hline Puget Sound NSY & Washington & Navy & NAVSUP & I & 215 \\
\hline Seal Beach NWS & California & Navy & NAVSUP & I & 306 \\
\hline Yorktown NWS & Virginia & Navy & NAVFAC NAVSUP & I & 250 \\
\hline San Clemente Island NR & California & Navy & NAVAIR & T & 276 \\
\hline San Nicolas Island NR & California & Navy & NAVSEA & T & 245
\end{tabular}




\section{Appendix E: Interactive Installation Region Vulnerability Scores Spreadsheet}

Electronically attached as "AppendixE.xls."

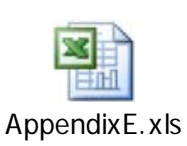




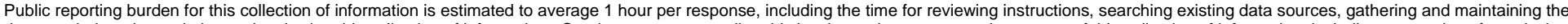

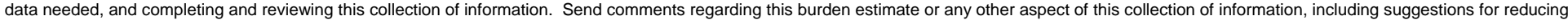

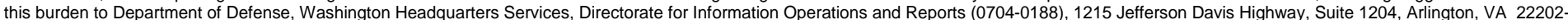

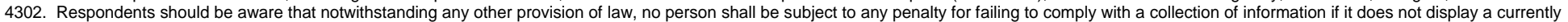
valid OMB control number. PLEASE DO NOT RETURN YOUR FORM TO THE ABOVE ADDRESS.
1. REPORT DATE (DD-MM-YYYY)
2. REPORT TYPE
3. DATES COVERED (From - To)

Final

4. TITLE AND SUBTITLE

$$
\text { 24-09-2006 }
$$

A Comparison of Regional Vulnerability Factors for Department of Defense (DOD) Installations

6. AUTHOR(S)

Elisabeth M. Jenicek, Natalie Downs, Brad Boesdorfer, and Donald F. Fournier

5a. CONTRACT NUMBER

5b. GRANT NUMBER

5c. PROGRAM ELEMENT NUMBER

5d. PROJECT NUMBER

SERDP

5e. TASK NUMBER

5f. WORK UNIT NUMBER

8. PERFORMING ORGANIZATION REPORT NUMBER

7. PERFORMING ORGANIZATION NAME(S) AND ADDRESS(ES)
U.S. Army Engineer Research and Development Center (ERDC)

Construction Engineering Research Laboratory (CERL)

ERDC/CERL TR-06-22

PO Box 9005,

Champaign, IL 61826-9005

9. SPONSORING I MONITORING AGENCY NAME(S) AND ADDRESS(ES)

10. SPONSOR/MONITOR'S ACRONYM(S)

SERDP Conservation Program Manager

SERDP Program Office

901 North Stuart Street, Suite 303

Arlington, VA 22203

11. SPONSOR/MONITOR'S REPORT NUMBER(S)

12. DISTRIBUTION / AVAILABILITY STATEMENT

Approved for public release; distribution is unlimited.

13. SUPPLEMENTARY NOTES

Copies are available from the National Technical Information Service, 5285 Port Royal Road, Springfield, VA 22161.

\section{ABSTRACT}

A key concern for Department of Defense (DoD) installations is their ability to sustain, and sometimes change or expand, their mission activities. Optimal use of installations in the face of changing missions, closures, and realignments requires an understanding of each installation's capabilities. Regional competition for land, transportation, energy, water, and other resources may put an installation's ability to perform essential activities at risk. This research adapted the Sustainable Installation Regional Resource Assessment (SIRRA) methodology to consider primary military mission as a weighting factor in determining vulnerability to a set of sustainability issues, and to identify the most vulnerable installations within each DoD service, and to determine those installations that would benefit from further study and intervention.

\section{SUBJECT TERMS}

encroachment

SERPD

16. SECURITY CLASSIFICATION OF:

a. REPORT

Unclassified b. ABSTRACT

Unclassified c. THIS PAGE

Unclassified sustainabilitymilitary training

SIRRA SERM

17. LIMITATION OF ABSTRACT

SAR
18. NUMBER OF PAGES

172 19a. NAME OF RESPONSIBLE PERSON Elisabeth M. Jenicek

19b. TELEPHONE NUMBER (include area code)

(217) 373-7238 